\title{
On pediatric delirium in critical illness : A clinical multidisciplinary study in child neuropsychiatry at the PICU
}

Citation for published version (APA):

Schieveld, J. N. M. (2008). On pediatric delirium in critical illness : A clinical multidisciplinary study in child neuropsychiatry at the PICU. [Doctoral Thesis, Maastricht University]. Datawyse / Universitaire Pers Maastricht. https://doi.org/10.26481/dis.20080222js

Document status and date:

Published: 01/01/2008

DOI:

$10.26481 /$ dis.20080222js

Document Version:

Publisher's PDF, also known as Version of record

\section{Please check the document version of this publication:}

- A submitted manuscript is the version of the article upon submission and before peer-review. There can be important differences between the submitted version and the official published version of record.

People interested in the research are advised to contact the author for the final version of the publication, or visit the DOI to the publisher's website.

- The final author version and the galley proof are versions of the publication after peer review.

- The final published version features the final layout of the paper including the volume, issue and page numbers.

Link to publication

\footnotetext{
General rights rights.

- You may freely distribute the URL identifying the publication in the public portal. please follow below link for the End User Agreement:

www.umlib.nl/taverne-license

Take down policy

If you believe that this document breaches copyright please contact us at:

repository@maastrichtuniversity.nl

providing details and we will investigate your claim.
}

Copyright and moral rights for the publications made accessible in the public portal are retained by the authors and/or other copyright owners and it is a condition of accessing publications that users recognise and abide by the legal requirements associated with these

- Users may download and print one copy of any publication from the public portal for the purpose of private study or research.

- You may not further distribute the material or use it for any profit-making activity or commercial gain

If the publication is distributed under the terms of Article $25 \mathrm{fa}$ of the Dutch Copyright Act, indicated by the "Taverne" license above, 


\section{On pediatric delirium in critical illness}

A clinical multidisciplinary study in child neuropsychiatry at the PICU

Jan N.M. Schieveld 
ISBN 9789052786957

(c) Copyright JNM Schieveld, Maastricht 2008 


\section{On pediatric delirium in critical illness}

A clinical multidisciplinary study in child neuropsychiatry at the PICU

\section{PROEFSCHRIFT}

ter verkrijging van de graad van doctor aan de Universiteit Maastricht op gezag van Rector Magnificus, Prof. mr. G.P.M.F. Mols

volgens het besluit van het College van Decanen, in het openbaar te verdedigen op 22 februari 2008 om 16.00 uur

door

Johannes Nicolaas Maria Schieveld,

geboren op 27 februari 1952, te Sloten, gemeente Amsterdam

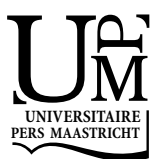


Promotor

Prof. dr. J. van Os

Co-promotores

Dr. A. F. G. Leentjens

Dr. G. J. Vos

Beoordelingscommissie

Prof. dr. L. Zimmermann (voorzitter)

Mevr. Prof. dr. M. Danckaerts, Katholieke Universiteit Leuven, België

Prof. dr. D. M. Dhossche, University of Mississippi Medical Center, U.S.A.

Prof. dr. P. Eikelenboom, Universiteit van Amsterdam

Prof. dr. F. R. J. Verhey

Prof. dr. J. H. Zwaveling 
In memoriam

Eva Ida Ballai - Loya Hoek Schieveld

* 27-11-1923, Budapest (Hungary)

† 16-01-1998, Noordwijkerhout (the Netherlands)

$\&$

Gerard Nicolaas Schieveld

* 23-12-1915, Semarang (Java, Indonesia)

† 28-04-1995, Noordwijkerhout (the Netherlands)

For our children:

Jan-Willem, Eva-Maria (en Daan), Bart, Jasper

and for:

Esmée and Lisa

- "Alter alterius onera portate"- 
The publication of this thesis was financially supported by:

University Hospital Maastricht, De Koraal Groep, De Mutsaersstichting,

De Buitenhofschool, Stichting St. Jozef, Franciscusoord (onderdeel van Stichting

Revalidatie Limburg), ABM AMRO Heerlen, Stichting Steunfonds, DSM Innovation Center, AstraZeneca B.V., Boehringer Ingelheim, Bristol-Myers Squibb B.V., Janssen-Cilag B.V., Lilly Nederland B.V., Lundbeck B.V., Roche Nederland B.V., Servier, Wyeth.

Lay out, editing and concept of front- and back cover: Kirsten Venrooij

English correction chapters 1, 8, 9, 10: DuoVertaalbureau Maastricht.

Photograph: "Young lady with Orca at the PICU", by Gijs Vos, PICU, 2006

Photograph cover "Froukje at the couch in the lounge", Magpie, Lille, France 2004

Inlay design: 'Summer', by Trudy Augustus and children of Wickraderheem, 1996

Cover design and print: Datawyse I Universitaire Pers Maastricht

Contact:

jan.schieveld@spsy.azm.nl

University Hospital Maastricht, the Netherlands

Department of Psychiatry and (Neuro-) psychology/ Divsion Child Psychiatry

ISBN 9789052786957

(C) 2008, J.N.M. Schieveld, Maastricht, The Netherlands

All rights are reserved, whether the whole or part of the material is concerned. No part of this publication may be reproduced, stored in a retrieval system, or transmitted in any form or by any means, electronic mechanical, photocopying, reducing or otherwise, without written permission from the copyright owner 
Preliminary Thoughts

1. .... but it was not until Sebastian, idly turning the pages of Clive Bell's Art, read: 'Does anyone feel the same kind of emotion for a butterfly or a flower that he feels for a cathedral or a picture?' Yes, I do, 'that my eyes were opened.'

Brideshead Revisited, by Evelyn Waugh, 1945,

Chapter I: Et In Arcadia Ego.

2. 'The brain is wider than the sky

For put them side by side

The one the other will include

With ease, and you beside.'

Poem 126, Emily Dickinson, c. 1862

3. 'Mit der Dummheit der Menschen kämpfen die Götter selbst vergebens,'

Friedrich von Schiller, 1759 - 1805, in "Die Jungfrau von Orleans“,1801. 



\section{CONTENTS}

1. Introduction

2. Pets or meds: how to tackle misery in a pediatric intensive care unit. Intensive Care Medicine 2007; 33:1492-1493

3. Delirium in severely ill young children in the pediatric intensive care unit (PICU)

Journal of the American Academy of Child and Adolescent Psychiatry 2005;44(4):392-394

4. Case reports with a child psychiatric exploration of catatonia, autism and delirium.

Catatonia in autism spectrum disorders, International Review of Neurobiology (IRN) 2006; 72:195-206

5. Pediatric delirium in critical illness: phenomenology, clinical correlates and treatment response in 40 cases in the pediatric intensive care unit. Intensive Care Medicine 2007; 33:1033-1040

6. Pediatric illness severity measures predict delirium in a pediatric intensive care unit Revised \& resubmitted 
7. A comparison of the phenomenology of pediatric, adult and geriatric delirium

Accepted for publication by the Journal of Psychosomatic Research

8. General discussion

9. Epilogue

10. Summary

Samenvatting

Acknowledgements

Publications \& Posters

Curriculum Vitae 
CHAPTER 1

Introduction 


\subsection{Rationale}

'Delirium is acute brain failure in man' (Lipowski, 1980)

Pathology affecting the human brain can present itself neuropsychiatrically with primary disorders, such as cerebrovascular accidents or epilepsy in neurology, and with psychosis or affective disorders in psychiatry. In addition, the brain can also become a target organ, in the context of critical illness, giving rise to secondary disorders. Of these, the four most common, once also called reaction types of the brain, are fever, epilepsy, catatonia and delirium (see e.g. Bonhoeffer, 1912; Neumarker, 2007; Young, 1980). Delirium - from the Latin de- plus lira ('out of the furrow' or 'out of the track') - is a neuropsychiatric disorder secondary to a general medical condition, and must be considered a serious complication of the underlying disease and/or its treatment.

In the revised fourth edition of the Diagnostic and Statistical Manual of Mental Disorders (DSM-IV-TR), delirium is defined by four concurrent diagnostic criteria: 1) acute onset and fluctuation of 2) a disturbance of consciousness with a reduced ability to focus, shift or maintain attention and 3) a change of cognition with memory deficit, disorientation, language disturbance, perceptual disturbances or/and hallucinations, 4) caused by the direct physiological consequences of a general medical condition and/or its treatment (American Psychiatric Association, 2000). It is frequently seen in critically ill adult and geriatric patients and is associated with a poor prognosis, reflected by longer hospital stay, worse functional and cognitive outcome, and a higher mortality rate after discharge from hospital. In mechanically ventilated critically ill adults, delirium is an independent predictor of elevated 6month mortality and a longer hospital stay. Its prevalence among adults and the 
elderly is $10-30 \%$ in a general hospital, up to $50 \%$ in ICU settings, and up to $80 \%$ in the terminally ill. In the latter category of patients, it is also the most important predictor of imminent death (American Psychiatric Association, 1999). Therefore, systematic monitoring for delirium and appropriate treatment with haloperidol in critically ill adult patients were included in the clinical practice guidelines of the Society of Critical Care Medicine (Jacobi, Fraser et al., 2002).

Much is known about the four types of secondary disorders of the brain in adults. Several research groups in various parts of the world focus on adult and geriatric delirium, for example those of Paula Trzepacz (USA); Wes Ely and Sharon Inouye (USA); Yonna Skrobik, Nicolas Bergeron, Marc-Jacques Dubois and Sebastien Ouimet (Canada); David Meagher (Ireland); Alisdair McLullich (Scotland), and Piet Eikelenboom, Roos van der Mast, Albert Leentjens and Kees Kalisvaart (Netherlands). And since 2006, there has even been a European Delirium Association (EDA). However, this Ph.D. thesis was inspired by the fact that there is extraordinarily little to guide the clinician with regard to the management of the secondary disorders of the brain in children, particularly regarding the last two types: catatonia and delirium. Why is there such a dearth of knowledge with regard to this age group?

In order to substantiate the purported lack of interest in child delirium, selective PubMed searches were conducted as described below. While not a precise measure, such a search usually yields an approximate indicator of the level of interest and work on a particular topic. We suggest that this qualitative analysis of the existing literature, or rather the lack thereof, lays bare the main reasons why childhood delirium remains an understudied topic, namely first, child psychiatrists have a lack of 
interest (or perhaps even a reciprocally reinforced, 'perverse' lack of interest) in children with critical illness and second, pediatric intensive care medicine and child neurology have a lack of interest in the possible added values of child psychiatry on the other. Furthermore, there is a formidable methodological and psychometric problem that can be best summarized by the following questions: what is pediatric delirium (PD)? Where does withdrawal end and PD start? How can one diagnose PD in a critically ill $<2$ year old child in a PICU? There is certainly a lack of knowledge among child psychiatrists. Consequently, administrators, civil servants and insurers also display a lack of awareness regarding the potential beneficial effects of pediatric psychiatry and a pediatric consultation-liaison service. There is also a simple reason to do with resources: in many countries there was, and still is, a severe shortage of child psychiatrists. Finally, there are hardly any scientific publications on the issue of pediatric child psychiatry, a fact that completes and perpetuates the vicious circle.

This state of affairs gives rise to two genuine concerns. First, there are, at least in the Western world, adult and geriatric consultation-liaison services and MedPsych units, which have gathered a growing body of knowledge regarding, for example, adult catatonia and adult delirium. However, that knowledge cannot be generalized automatically to pediatric services, which means that there is a growing, relative gap in the knowledge and relative underperformance of pediatric services in this regard. Second, according to data from the seminal Isle of Wight study conducted by Sir Michael Rutter (Rutter, Tizard et al., 1976), the cumulative incidence of child psychiatric disorders in somatic environments and contexts is very high: $7 \%$ in a somatically healthy Western population, $15 \%$ in those with pediatric disorders, $30 \%$ in children with epilepsy and up to $45 \%$ in child populations with structural brain pathology. Therefore, a priori there is a need for extensive child psychiatric services 
to assess, treat and study children with pediatric disorders - a sharp contrast with the existing generalized poverty of services for these children.

Therefore, the aim of this thesis is to robustly and quantitatively draw attention to pediatric child psychiatry by exploring, essentially for the first time, the field of pediatric delirium at the pediatric intensive care unit (PICU). In order to meet these goals, a multidisciplinary study group - 'Pediatric delirium azM' study group ('azM' = academisch ziekenhuis Maastricht/University Hospital Maastricht) - was established. Its motto is: 'one in multitude'.

The following persons have participated in the study group throughout the years:

- Piet Leroy, M.D., and Gijs Vos, M.D., Ph.D. (pediatric intensivists)

- Albert Leentjens, M.D., Ph.D. (adult neuropsychiatrist)

- Jim van Os, M.D., Ph.D. (professor of psychiatric epidemiology)

- Joost Nicolai, M.D. (child neurologist)

- Richel Lousberg, Ph.D., and Helen Vossen M.Sc. (psychologists-statisticians)

- Femke Dings, M.Sc., and Jos Hendriksen, Ph.D. (child neuropsychologists)

- Karin Smeets (medical social worker)

- Joke Joossens, M.D., Kim Daniels, M.D., Karen Gillaerts, M.D., Eva Van den

Broeck, M.D., Liesbet Devalkeneer, M.D., and Tine Jaspers, M.D. (all six are from the Catholic University Hospital in Louvain, Belgium), and Paul Reijnen, M.D. (all are former or current senior registrars in child psychiatry at the azM).

- Ellen van Vliet, M.D., Bas Pos, M.D., Marasha de Jong, M.D., Noortje de Bont, M.D., Emmily Bueno de Mesquita, M.D., Inge Smeets, M.Sc., Eline Berghmans, M.D., Eva Tan, M.Sc. (all eight are former or current medical research students)

- Kirsten Venrooij (research assistant)

- Jan Schieveld (child neuropsychiatrist) 


\subsection{Some key notes on adult delirium}

The written history of delirium is more than 2400 years old (Kenneth Davis quoting Hippocrates' Books of Epidemics 400 BC (Samuels \& Neugroschl, 2005)). Shakespeare, for example, describes pre-terminal delirium preceding Falstaff's death $^{1}$ (Kolb, 1977). In 1944, Romano and Engel wrote a seminal paper in which they related the severity of delirium with corresponding EEG changes (Romano \& Engel, 1944). Fifteen years later (1959), these authors wrote another landmark paper, entitled 'Delirium, a syndrome of cerebral insufficiency', in which they hypothesized that delirium was due to metabolic disarrangements leading to characteristic cognitive disturbances and EEG changes (Engel \& Romano, 1959). 1980 saw the publication of Delirium: Acute brain failure in man (Lipowski, 1980), which set the standard for a long time after. In his Organic psychiatry, Lishman treated the subject beautifully and at length in Chapter 1 ('Cardinal features of cerebral disorder'), under the names 'acute brain syndrome', 'acute confusional state', 'acute organic psychosis', 'acute psycho-organic syndromes', and 'delirium' (Lishman, 1998). Roberts dedicated a separate chapter to the issue in his Differential diagnosis in neuropsychiatry (Roberts, 1984). Wise contributed a lucid chapter entitled 'Delirium' to the Textbook of neuropsychiatry; in it, he introduced the now widely used 'I WATCH DEATH' acronym for the somatic differential diagnosis of delirium (Wise, 1987). The DSM-IV, 2000 (American Psychiatric Association, 2000), the New Oxford textbook of psychiatry (Gelder, Lopez-lbor et al., 2000) and Kaplan \& Sadock's Comprehensive textbook of psychiatry (Sadock \& Sadock, 2005) have chapters on

\footnotetext{
${ }^{1}$ The clinical picture of delirium is well depicted in Shakespeare's description of Fallstaff's death: 'For after I saw him fumble with the sheets, and play with the flowers, and smile upon his finger's ends, I knew there was but one way; for his nose was sharp as a pen, and 'a babbled of green fields.' Henry V, Act II, Scene iii Shakespeare, W.H. (1600). Henry V. The Chronicle History of Henry the Fifth. London, Thomas Creede.
} 
delirium, as well as a multitude of entries on delirium in the index. Currently, probably the most authoritative text is the chapter 'Delirium' by Paula Trzepacz and David Meagher in Levenson's Textbook of psychosomatic medicine (Trzepacz \& Meagher, 2005).

Searching in PubMed (23 May 2007) with the MESH heading 'delirium' resulted in 14,842 hits, the earliest (1902) from the USA - on delirium tremens after a cataract extraction by T. R. Pooley. The combination 'delirium and adult' resulted in 8996 hits ('confusion and adults' yielded 9962), the earliest (1964) from France. The combination 'delirium and geriatric' yielded 681 hits, the earliest from Switzerland (1964), and the combination 'delirium and elderly' yielded 4306 hits ('confusion and and tremens' yielded 1862 hits, and 'delirium and alcohol' 1941 hits, the earliest again from Pooley. 'Delirium and anaesthesiology' yielded only 11 hits, the earliest (1975) from the USA, and the combination 'delirium and anaesthesia' yielded 238 hits, the earliest from 1963. Finally, I searched for the combinations 'delirium and ICU' (127 hits, the earliest from 1973), 'delirium and critical illness' (67 hits, the earliest from 1993), 'delirium and CCU' (5 hits - 2001 -> 1984), and 'delirium and coronary' (194 hits, the earliest from 1964).

Table 1. PubMed search, May 2007: main findings on delirium +

\begin{tabular}{|l|l|l|l|}
\hline MESH heading & Hits & Earliest year & Origin \\
\hline Delirium & & & \\
\hline+ adult & 14842 & 1902 & USA \\
\hline+ elderly & 8996 & 1964 & France \\
\hline+ tremens & 4306 & 1963 & USA \\
\hline
\end{tabular}




\begin{tabular}{|l|l|l|l|}
\hline & & & \\
\hline+ ICU & 127 & 1973 & English language \\
\hline+ critical illness & 67 & 1993 & USA \\
\hline+ coronary & 194 & 1964 & UK \\
\hline
\end{tabular}

However, to put things in their right perspective, three further observations must be made:

1) Although the search term 'delirium' yielded 14,842 hits, in relation to other major somatic MESH headings this is not a very high figure. For example, 'cancer' yielded 1,940,616 hits (the earliest from 1881); 'coronary' 567,164 hits (the earliest from 1869); 'HIV' 210,979 hits (the earliest from 1970); 'stroke' 111,139 hits; 'pneumonia' 81,794 hits; 'encephalopathy' 26,595 hits (dating back to 1949 from Scandinavia); and 'chronic encephalopathy' 24,499 hits (dating back to 1951 from Czechoslovakia).

Table 2. PubMed search, May, 2007 relative to other major somatic disorders

\begin{tabular}{|l|l|l|l|}
\hline MESH heading & Hits & Earliest year & Origin \\
\hline & & & \\
\hline Cancer & $1,940,616$ & 1881 & UK \\
\hline Coronary & 567,164 & 1869 & UK \\
\hline HIV & 210,979 & 1970 & USA \\
\hline Stroke & 111,139 & 1928 & USA \\
\hline Pneumonia & 81,794 & 1881 & UK \\
\hline Encephalopathy & 26,595 & 1949 & Scandinavia \\
\cline { 2 - 4 }+ chronic & 24,499 & 1951 & Czechoslovakia \\
\hline
\end{tabular}


2) In PubMed, the combinations 'delirium' and 'confusion / adults / children / anaesthesia' yielded: 19,496, 9958, 1741 and 344 hits, respectively.

3) What DSM-IV refers to as 'delirium' is probably called 'encephalopathy' (EP) by most neurologists, and then frequently combined with the prefix 'metabolic' (which constitutes $40 \%$ of all the cases of EP) or 'drugs' (20\% of these cases). The National Institute of Neurological Disorders and Stroke (NINDS, 2007) stated in February 2007 that: 'Encephalopathy is a term for any diffuse disease of the brain that alters brain function or structure' and 'The EP may cause permanent structural changes and irreversible damage to the brain, and some EPs can be fatal'. Finally: in PubMed, the combination 'EP and delirium' yielded 320 hits, the earliest (1955) from France, and the combination 'EP and critical illness' yielded 55 hits (the earliest from 1987).

\section{Discussion}

At first glance, the 14,842 hits on delirium, as well as the date of its recognized first scientific publication (1902), are impressive. However, a comparison with the data for other major disorders suggests a more modest conclusion. Confusion is a synonym for delirium, but because it is also used, for example, in relation to equivocal medical and/or laboratory test findings, a PubMed search results in findings that are difficult to interpret. The NINDS definition shows that EP is a container concept and much broader than delirium; thus, delirium is a special case of it, namely confusion due to EP. Confusion, defined as a psychiatric disturbance, is associated primarily with thought disorder, with or without psychotic features such as delusions, delusional thinking, and/or visual or other hallucinations, with or without motor disturbances. 
There are also other psychiatric disorders arising in the context of EP, for example, catatonia, mania and mood disorders. These clinical facts justify the role of the psychiatrist in these cases. EP is mostly described with the assumed causative prefix, and there are many of these, for example hepatic, renal, metabolic, vascular, drugs, infectious, perinatal, acute, chronic, etc. These prefixes reflect the I WATCH DEATH terms of the acronym indicating the causes of EP. In conclusion, delirium, acute brain failure and confusion due to EP can be treated as synonymous, but in practice can cause confusion.

\subsection{Some key notes on pediatric delirium}

The history of child psychiatry starts in the middle of the late eighteenth century, with anecdotal case reports from England in the period of the Enlightenment (Neve \& Turner, 2002). Ever since, all the nestors of psychiatry have described child psychiatric cases, but the scientific dawn - as well as the next step in the emancipation of the child - starts with Leo Kanner's textbook Child psychiatry (Kanner, 1935). In my copy ( $3^{\text {rd }}$ edition, 1966), there is a chapter entitled 'Transient cerebral affections' with eloquent paragraphs on, for example, delirium and catalepsy. I quote the beginning of the paragraph on delirium: 'Despite the great frequency of delirium in children's infections, little attention has been paid to it in the literature.' This neglect is perhaps accounted for by the belief, expressed by Bleuler, that 'children react quite easily with delirium so that in them the psychic disturbances do not have great significance' (see Lehrbuch der Psychiatrie, Bleuler, 1955).

A few lines later, Kanner writes: 'It is difficult to state at what earliest age delirious reactions occur.' Again a few lines later, he writes: 'Typical delirious pictures have been observed in infants as young as 16 months; they were especially outspoken in 
cases of atropine poisoning.' The youngest child described in the literature was 6 months old (Turkel \& Tavare, 2003), and my colleague Gerlant van Berlaer, M.D. (pediatric intensivist in Brussels) discussed with us a typical patient who was 3 months old. Of course, a modern observation in very young children is the withdrawal syndromes observed in babies born to mothers with drug dependence syndromes. In 1980, Prugh and colleagues described a case series of 33 children and adolescents with delirium and compared these with a matched hospitalized control group without central nervous involvement (Prugh, Wagonfeld et al., 1980). After complete recovery, however, they reported the persistence of mild perceptual-motor abnormalities for some weeks. 1995 saw the publication of Psychiatric aspects of general hospital pediatrics (Jellinek \& Herzog, eds.), for which Stoddard and Wilens had written a short but clinically important chapter on delirium (Stoddard \& Wilens, 1995). The DSM-IV section on child psychiatry (American Psychiatric Association, 2000), does not mention delirium, and Rutter and Taylor's Child and adolescent psychiatry does so only in the index (Rutter \& Taylor, 2002). There is a helpful chapter on delirium in Clinical manual of pediatric psychosomatic medicine (Shaw \& DeMaso, 2006), and there is a very thoughtful chapter from D. T. Williams entitled 'Neuropsychiatric signs, symptoms and syndromes' in which he discusses delirium, along with stupor and catatonia, in Lewis's Child and adolescence psychiatry (Williams, 2002). All the other major textbooks, whether on child psychiatry/neuropsychiatry, child neurology, pediatrics or pediatric intensive care medicine, either do not mention delirium or devote to it only a line or two (or, at best, a short but never very elucidating paragraph). There is one exception: Handbook of pediatric emergencies (Baldwin, 2001) has a cogent and clinically important subsection, three pages long, on delirium. 
The year 2003, however, was a turning point due to two important publications by Susan Turkel and C. Jane Tavare (Turkel \& Tavare, 2003). One was a descriptive study of a retrospective case series from 1998, regarding 84 cases of pediatric delirium, in the age range of 6 months - 18 years, of whom $20 \%$ died, out of 1027 consultations in 4 years. These authors, together with Kenneth Braslow and Paula Trzepacz, published another article on the same case series (Turkel, Braslow et al., 2003), in which they analyse the retrospective usefulness of the DRS (Delirium Rating Scale) in children and adolescents (but in neither paper do they explicitly mention 'critical illness' or 'PICU'). In 2004, a publication by Nancy Sikich and Jerrold Lerman (Sikich \& Lerman, 2004) presented an important treatise of the Pediatric Anaesthesia Emergence Delirium (PAED) scale, which in my opinion constitutes a milestone in clinical pediatric delirium research.

A PubMed search with the MESH headings 'delirium and child / children' resulted in 1438 and 1428 hits, respectively, the earliest (1955) from France. 'Pediatric delirium' yielded 101 hits, the earliest (1968) from Germany; 'delirium and anaesthesia / anaesthesiology' yielded 238/11 hits, the earliest from 1963 (unknown origin) and 1975 (USA), respectively; 'delirium and anaesthesia and child' yielded 50 hits, the earliest from 1966 from oral surgery, of unknown origin. 'Surgery and child and delirium' yielded 134 hits (1964), 'delirium and pediatrics / pediatric critical illness / PICU' yielded 14 / 6 / 3 hits, respectively, from 1968 (Spain), 1996 (Brown's remarkable paper from the USA) and 2005 (Netherlands). 
Table 3. PubMed search, May 2007: Main findings on 'pediatric' delirium

\begin{tabular}{|l|l|l|l|}
\hline MESH heading & Hits & Earliest year & Origin \\
\hline Delirium: & & & \\
\hline+ child & 1,438 & 1955 & France \\
\hline+ pediatric & 101 & 1968 & Germany \\
\hline+ anaesthesia & 238 & 1963 & $?$ \\
+ child & 50 & 1966 & $?$ \\
\hline+ child \& surgery & 134 & 1964 & USA \\
\hline+ pediatrics & 14 & 1968 & Spain \\
\hline+ pediatric critical illness & 6 & 1996 & USA \\
\hline+ PICU & 3 & 2005 & Netherlands \\
\hline
\end{tabular}

The combinations 'EP and children' yielded 4,263 hits, the earliest (1950) from Brazil; 'chronic EP and children' yielded 484 hits, the earliest (1951) in an unknown language; 'EP and delirium and children' yielded 41 hits, the earliest (1968) from Germany; and 'EP and critical and illness and children' yielded 6 hits, the earliest (1992) from Canada, on three children who died from Wernicke's EP.

Finally, 'EP and haloperidol' yielded 18 hits (1978); 'EP and risperidone' 8 hits (1995); 'EP and haloperidol and children' 1 hit (1994), and 'EP and risperidone and children' 2 hits (2006, 2000).

Table 4. PubMed search, May 2007: main findings on encephalopathy (EP) +

\begin{tabular}{|l|l|l|l|}
\hline MESH heading & Hits & Earliest year & Origin \\
\hline EP: & 26.595 & 1949 & Scandinavia \\
\hline + children & & & \\
\hline chronic & 4.263 & 1950 & Brazil \\
\hline + delirium + children & 41 & 1951 & $?$ \\
\hline
\end{tabular}


In a final summary search, we used the search terms '(delirium[ti] OR (confusional[ti] and state[ti])) and (child OR children OR pediatric OR pediatric)'. This yielded only 66 hits, confirming the view that pediatric delirium is an understudied topic.

\section{Discussion}

The number of publications of delirium in children (1438) is roughly $10 \%$ of that seen in adults, and this may reflect, for example, the fact that children have a much lower use of medical services, delirium in children is assumed to be of low clinical importance or of low prevalence, or may be detected only infrequently. Unexpected findings were: 1) the low number (approximately 14\%) of the 1438 publications with the combination 'post-anaesthesia/surgery' and 'delirium in children', given the fact that withdrawal seems a major factor in pediatric delirium; and 2) the mere six papers in relation to pediatric critical illness. Inspection of the much larger number (4263) on 'EP and children' revealed that this was largely related to the many publications on perinatal asphyxia and cerebral palsy. The low number (6) on 'EP and critical illness' was also something of a surprise, as was the even lower number (4) on EP and antipsychotics.

In conclusion, very little is known about PD in critical illness or, to put it another way, the field of PD has hardly been explored. To our knowledge, there are perhaps four groups studying pediatric delirium more or less regularly: Susan Turkel, C. Jane Tavare, Kenneth Braslow and Paula Trzepacz in the USA; Nancy Sikich and Jerrold Lerman in Canada; Sean Hatherill in South Africa; and our Pediatric Delirium study group in the Netherlands. 


\subsection{Some remarks on the Dutch context and history}

The scientific history of delirium research in the Netherlands that culminated in a thesis starts in 1994 with the thesis by Roos van der Mast, M.D., psychiatrist (Van der Mast, 1994), entitled: 'Delirium after cardiac surgery - a prospective study'. This was followed by the theses 'Early recognition of delirium' by Marieke J. Schuurmans, R.N. (Schuurmans, 2001); 'Primary prevention of delirium in the elderly' by Kees Kalisvaart, M.D., geriatrician (Kalisvaart, 2005); and 'Aspects of acute hospital admission in the elderly' by Sophia E. J. A. de Rooij, M.D., geriatrician (Rooij de, 2006). The first work deals mainly with delirium in adults, and the last with delirium in the elderly. Another landmark in the Dutch tradition in delirium research is the 'Richtlijn delirium' ('Guideline on delirium') (NVvP, 2004), which was initiated by the Nederlandse Vereniging voor Psychiatrie (NVvP; Dutch Psychiatric Association) and formulated by a multidisciplinary task force chaired by Roos van der Mast.

The Dutch child psychiatric literature on childhood delirium is scarce. In 'Hoofdlijnen van de kinderpsychiatrie' ('Essentials of Child Psychiatry’) (Hart de Ruyter \& Kamp, 1972), there is one sentence devoted to the subject: 'Bij infectieziekten, die met koorts gepaard gaan, komen delirante toestanden voor, het ijlen' ('In infectious diseases, accompanied by fever, acute confusional states occur, the delirium'). In Amsterdam in 1992, a poster was presented by Yvonne Colijn (then a medical student) and Jeanne van Weel, M.D. (child psychiatrist, at that time at the Academic Medical Centre, Amsterdam) about 11 children with delirium who were referred to the consultation-liaison service. In 1995, Jeanne van Weel gave a presentation at ESCAP (Utrecht) on a case series of approximately 15 children. In 2000, Professor Boudewijn Gunning, M.D., Ph.D. (child psychiatrist) contributed a chapter to Kinder- 
en jeugdpsychiatrie, onderzoek en diagnostiek ('Child and adolescent psychiatry, assessment and diagnosis') (F. C. Verhulst \& F. Verheij, eds.), entitled 'Organisch psychiatrische stoornissen' ('Organic psychiatric disturbances'), that included a threepage section on delirium (Gunning, 2003).

In 1999, Nico Bouman, M.D., Ph.D. (child psychiatrist, at that time at Sophia University Hospital for Children, Rotterdam) gave an oral presentation entitled: 'Psychotic states at the pediatric intensive care unit: delirium or IC syndrome?' In 2003 he contributed a chapter to Kinder- en jeugdpsychiatrie: Psychopathologie ('Child and adolescent psychiatry: Psychopathology') (Verhulst, Verheij \& Ferdinand, eds.) entitled 'Delier' ('Delirium'), in which he underlines the importance of the differential diagnosis of reactive anxiety and agitation on the one hand, and those states due to the direct consequences of the somatic disorder on the other, describing their treatments (Bouman, 2003).

In 2001, I started work as a consultant child neuropsychiatrist at University Hospital Maastricht, both on the pediatric ward and in the PICU. There I frequently saw children with delirium, and to my surprise there was little to guide the clinician in these cases. This greatly stimulated me to collect data and discuss the possibility of doing research with friends and colleagues. In 2003, I gave a poster presentation in Paris for ESCAP describing my first findings. In 2004, Jeanne van Weel and I gave a double presentation on delirium at one of the symposia for the IACAPAP congress in Berlin.

I stand in two other traditions as well. The first is that of the European tradition of writing a doctoral thesis, see for example the family chronicles by Emmanuel Le Roy 
Ladurie: 'Le siècle des Platters' ('The age of the Platters'), Paris, Fayard, 1997 (Le Roy Ladurie, 1995). In it, he describes three generations of the Platter family in Switzerland during the $16^{\text {th }}$ century (1499-1628). The book provides a rich description of the history of European Ph.D. traditions and the rituals that Felix Platter (15361614) experienced during his medical studies in Montpellier, France. Although all this was a long time ago, I strongly identify with the non-linear progression of academic development in the European tradition. The other tradition is my long-standing career interest in attempting to describe patterns in the way in which the brain reacts to the environment. This tradition started in 1982 with my internal publication and oral presentation at the end of my specialty training at the Psychiatric Hospital Bloemendaal (now part of the Parnassia group), in Monster, The Hague, called: 'Temperatuurstoornissen in de psychiatrie' ('Temperature disturbances in psychiatry') (Schieveld, 1982). In it, I discussed the concept of 'pernicious psychosis' (or Stauder's lethal catatonia), the malignant neuroleptic syndrome, and possible continuity with heat intoxication, the porcine stress syndrome and the hyperthermia in anaesthesiology. And now, 25 years later, I have the honour of submitting a manuscript regarding another brain reactive typology in children with critical illness: delirium.

\subsection{Thesis aims and research questions}

Given the fact that PD remains largely unexplored, our primary research questions were clinically orientated 1) Does PD occur in critical illness, and how does it manifest itself; what are the clinical presentations in patients admitted to the PICU? 2) How can one solve the psychometric and conceptual difficulties associated with this area of research? Can we analyse routine epidemiological data and apply basic 
rules from knowledge and decision making theory that may be used profitably in guiding us to improve measurement and prediction; 3) Given the likely considerable morbidity force associated with delirium in clinical practice - as evidenced by the impressive figures in adults and the elderly - : what is the rate of PD? Relevant other questions in daily clinical care were: 4) are there identifiable risk factors and can these be used to predict PD?, 5) what is the pharmacological treatment response?, and 6) what are the similarities and differences across the age span including children, adults and elderly?

Ever since Gelenberg's remarkable paper in The Lancet (Gelenberg, 1976) entitled 'The catatonic syndrome', there has been a growing awareness among neuropsychiatrists and consultation-liaison psychiatrists about the important association (at least in adults and the elderly) between many internal medicine and/or neurological disorders on the one hand, and catatonic features/presentations - and their similarities and differences of the latter with delirium as well - on the other (see also Masand's chapter in Levinson's Textbook of psychosomatic medicine (Masand, Christopher et al., 2005). Therefore, it was also necessary to review and update knowledge about the same possible association in children to answer the final question 7) 'Is there a relation between PD and catatonia?'. To this end, we performed a textbook and PubMed search.

Chapter 2 continues with an illustrative case report as an introduction to pediatric child psychiatry at the PICU, and to demonstrate that common sense can guide management to a degree. In Chapter 3, I present two small children with pediatric delirium at the PICU, and discuss several important clinical issues related to diagnosis and treatment. In Chapter 4, I detour to make a nosological observation, 
reviewing and discussing the associations between autism and catatonia, and between catatonia and delirium. In Chapter 5, the focus is redirected to our multidisciplinary experiences with PD during a four-year period (2002-2005) at the PICU, examining the phenomenology, clinical correlates and treatment responses in 40 cases. In Chapter 6, I present a way of predicting delirium by exploring possible associations between mortality risk assessment scores on the one hand and the occurrence of PD on the other, making use of the PIM and PRISM II scores. In Chapter 7, I present a comparison between the phenomenology of delirium presentations in children, adults and the elderly. In Chapter 8, I provide the main results and the answers to the research questions, which represents a synthesis at new levels of knowledge and understanding. In chapter 9 I present some final thoughts and future directions for research - after all, new levels of knowledge and understanding often create new and intensifying questions as well. Chapter 10 rounds off this thesis with the summary, samenvatting, acknowledgements and curriculum vitae. 
References

American Psychiatric Association (1999). "Practice guidelines for the treatment of patients with delirium." American Journal of Psychiatry 5(156 (suppl. 5)): 1-20.

American Psychiatric Association (2000). Diagnostic and statistical manual of mental disorders. 4th edition text, revision (DSM-IV-TR). Washington DC, American Psychiatric Association.

Baldwin, G.A. (2001). Handbook of pediatric emergencies, Lippincott Williams \& Wilkens.

Bleuler, E. (1955). Lehrbuch der Psychiatrie. Berlin, Springer Verlag.

Bonhoeffer, K. (1912). Die Psychosen im Gefolge von akuten Infektionen, allgemeinen Krankheiten und inneren Erkrankungen. Handbuch der Psychiatrie, BD III. Aschaffenburg, G. Leipzig, Wien, Deuticke.

Bouman, N.H. (2003). Delier. Kinder- en Jeugdpsychiatrie. Psychopathologie. Verhulst, F.C., Verheij, F. and Ferdinand, R.F. Assen, Van Gorcum: 237-242.

Engel, G.L. and Romano, J. (1959). "Delirium, a syndrome of cerebral insufficiency." J Chronic Dis 9(3): 260-77.

Gelder, M.G., Lopez-lbor, J.J. and Andreasen, N. (2000). New Oxford Textbook of Psychiatry. Oxford, Oxford University Press.

Gelenberg, A.J. (1976). "The catatonic syndrome." Lancet 1: 1339-1341.

Gunning, W.B. (2003). Organisch psychiatrische stoornissen. Kinder- en Jeugdpsychiatrie. Onderzoek en Diagnostiek. Verhulst, F.C. and Verheij, F. Assen, Van Gorcum \& Comp. B.V.: 266-277.

Hart de Ruyter, T. and Kamp, L.N.J. (1972). Hoofdlijnen van de kinderpsychiatrie. Deventer, Van Loghum Slaterus.

Jacobi, J., Fraser, G.L., Coursin, D.B., Riker, R.R., Fontaine, D., Wittbrodt, E.T., Chalfin, D.B., Masica, M.F., Bjerke, H.S., Coplin, W.M., Crippen, D.W., Fuchs, B.D., Kelleher, R.M., Marik, P.E., Nasraway Jr, S.A., Murray, M.J., Peruzzi, W.T. and Lumb, P.D. (2002). "Clinical practise guidelines for the sustained use of sedatives and analgesics in the critically ill adult." Critical Care Medicine: 119-141.

Kalisvaart, C.J. (2005). Primary prevention of delirium in the elderly. Amsterdam, PhD Thesis, Universiteit van Amsterdam, The Netherlands: 160.

Kanner, L. (1935). Child Psychiatry. Springfield, Chas. C. Thomas.

Kolb, L.C. (1977). Modern Clinical Psychiatry. Philadelphia, W.B. Saunders Company. 
Le Roy Ladurie, E. (1995). Le Siecle des Platter, 1499-1628. Paris, Fayard.

Lipowski, Z.J. (1980). Delirium: Acute brain failure in man. Springfield (Illinois), Charles C. Thomas, Publisher.

Lishman, W.A. (1998). Organic Psychiatry: the psychological consequences of cerebral disorder. Oxford, Blackwell Science.

Masand, P.S., Christopher, E.J., Clary, G.L., Mago, R., Levenson, J.L. and Patkar, A.A. (2005). Mania, Catatonia, and Psychosis. Textbook of Psychosomatic Medicine. Levenson, J.L. Washington, DC, American Psychiatric Publishing Inc: 235-250.

Neumarker, K. (2007). "Karl Bonhoeffer (31.3.1868 - 4.12.1948). Annotations to his life and science." Psychosom Konsiliarpsychiatr 1: 179-183.

Neve, M. and Turner, T. (2002). History of Child and Adolescent Psychiatry. Child and Adolescent Psychiatry. Rutter, M. and Taylor, E. Oxford, Blackwell Science Ltd: 382-395.

NINDS (2007). "http://www.ninds.nih.gov/." The National Institute of Neurological Disorders and Stroke.

NVvP (2004). Richtlijn Delirium. Amsterdam, Uitgeverij Boom.

Prugh, D.G., Wagonfeld, S., Metcalf, D. and Jordan, K. (1980). "A clinical study of delirium in children and adolescents." Psychosomatic Medicine 41((1 Suppl)): 177-95.

Roberts, J.K.A. (1984). Delirium. Differential diagnosis in neuropsychiatry. Roberts, J.K.A. Chichester, John Wiley: 158-168.

Romano, J. and Engel, G.L. (1944). "Delirium, I: electroencephalographic data." Archives of Neurology and Psychiatry 51: 356-377.

Rooij de, S.E.J.A. (2006). Aspects of acute hospital admission in the elderly. Amsterdam, PhD thesis, Universiteit van Amsterdam, The Netherlands.

Rutter, M. and Taylor, E.e. (2002). Child and Adolescent Psychiatry. Oxford, Blackwell Science.

Rutter, M., Tizard, J., Yule, W., Graham, P. and Whitmore, K. (1976). "Research report: Isle of Whight Studies. 1964-1974." Psychological Medicine 6: 313-332.

Sadock, B.J. and Sadock, V.A. (2005). Kaplan \& Sadock's Comprehensive Textbook of Psychiatry. Philadelphia, Lippincott Williams \& Wilkens.

Samuels, S.C. and Neugroschl, J.A. (2005). Delirium. Kaplan \& Sadock's Comprehensive Textbook of Psychiatry. Sadock, B.J. and Sadock, V.A. Philadelphia, Lippincott Williams \& Wilkens: 10541068. 
Schieveld, J.N.M. (1982). Temperatuurstoornissen in de psychiatrie. Monster, Internal Publication, Psychiatric Hospital Bloemendaal.

Schuurmans, M.J. (2001). Early recognition of delirium, PhD thesis, Universiteit Utrecht, The Netherlands.

Shakespeare, W.H. (1600). Henry V. The Chronicle History of Henry the fifth. London, Thomas Creede.

Shaw, R.J. and DeMaso, D.R. (2006). Clinical Manual of Pediatric Psychosomatic Medicine. Washington, DC, American Psychiatric Publishing Inc.

Sikich, N. and Lerman, J. (2004). "Development and psychometric evaluation of the pediatric anesthesia emergence delirium scale." Anesthesiology(100): 1138-45.

Stoddard, F.J. and Wilens, T.E. (1995). Delirium. Psychiatric Aspects of General Hospital Pediatrics. Jellinek, M.S. and Herzog, D.B. Chicago, Yearbook Medical Publishers: 254-259.

Trzepacz, P.T. and Meagher, D.J. (2005). Delirium. Textbook of Psychosomatic Medicine. Levinson, J.L. Washington DC, The American Psychiatric Publishing: 92-130.

Turkel, S.B., Braslow, K., Tavare, C.J. and Trzepacz, P.T. (2003). "The Delirium Rating Scale in children and adolescents." Psychosomatics 44: 126-129.

Turkel, S.B. and Tavare, C.J. (2003). "Delirium in children and adolescents." The Journal of Neuropsychiatry and Clinical Neurosciences 15: 431-435.

Van der Mast, R.C. (1994). Delirium after cardiac surgery: a prospective study. PhD thesis, Erasmus Universiteit Rotterdam, The Netherlands.

Williams, D.T. (2002). Neuropsychiatric Signs, Symptoms, and Syndromes. Child and Adolescent Psychiatry, a Comprehensive Textbook. Lewis, M. Philadelphia, Lippincott Williams \& Wilkins: $399-404$

Wise, M.G. (1987). Delirium. Textbook of Neuropsychiatry. Hales, R.E. and Yudofsky, S.C. Washington, The American Psychiatric Press: 89-106.

Young, D. (1980). "The relationship between etiology and symptomatology in psychiatry." Cult Med Psychiatry 4(1): 17-23. 



\section{CHAPTER 2}

Pets or meds: how to tackle misery in a pediatric intensive care unit

Intensive Care Medicine 2007; 33:1492-1493 
Gijs D. Vos

Jim van Os

Piet L. J. M. Leroy

Jan N. M. Schieveld

\section{Pets or meds: how to tackle misery in a paediatric intensive care unit}

Accepted: 17 May 2007

Published online: 19 June 2007

(C) Springer-Verlag 2007

Sir: Rates of mood disorder and delirium in patients admitted to an intensive care unit are high and associated with a poor prognosis, as evidenced by longer hospital stay, poorer functional and cognitive outcomes and higher mortality rates after discharge from hospital. Among the adult population, the incidence is particularly high in geriatric patients [1]. In paediatric patients, similarly high rates of psychiatric disorder, mainly mood disorder and delirium, are observed, with reported rates of $5-40 \%[2,3]$. Targeted pharmacological interventions may be used for primary and secondary prevention, but a common-sense population approach towards prevention in the form of extensive psychosocial interventions may be more productive, particularly in high-risk paediatric intensive care unit (PICU) settings [3-5]. Thus, parents' presence and comfort throughout the day (and night), familiar music, favourite toys, pictures, lighting schedules and sometimes even fragrances may be used productively in all admitted patients.

One of our patients, a 12-year-old girl, became less talkative, displayed a sad facial expression, and lost interest in the surrounding environment. She was known with spina bifida,
Arnold Chiari type II malformation, and central hypoventilation during sleep. She was hospitalized because she required non-invasive ventilation during the night, and for a plastic surgery procedure. As she clearly developed an adjustment disorder with depressed mood, an intensification of the routine psychosocial protocol was attempted - guided by the words of colleague David Mrazek: "During the prolonged hospitalization of young children, the single most important aspect of treatment is to ensure that the primary attachment figures are available..." [6] - by allowing her friend Orka to visit her daily (Fig. 1). Orka was the patient's assistance dog, permanently placed in her home to provide therapeutic benefits. After the change in the psychosocial protocol allowing for the canine company, the patient did very well during her stay on the PICU, became cheerful and started talking and making jokes again to the nurses and doctors, and did not need any further treatment. There were no complications due to Orka's visits; in particular, no infections arose.

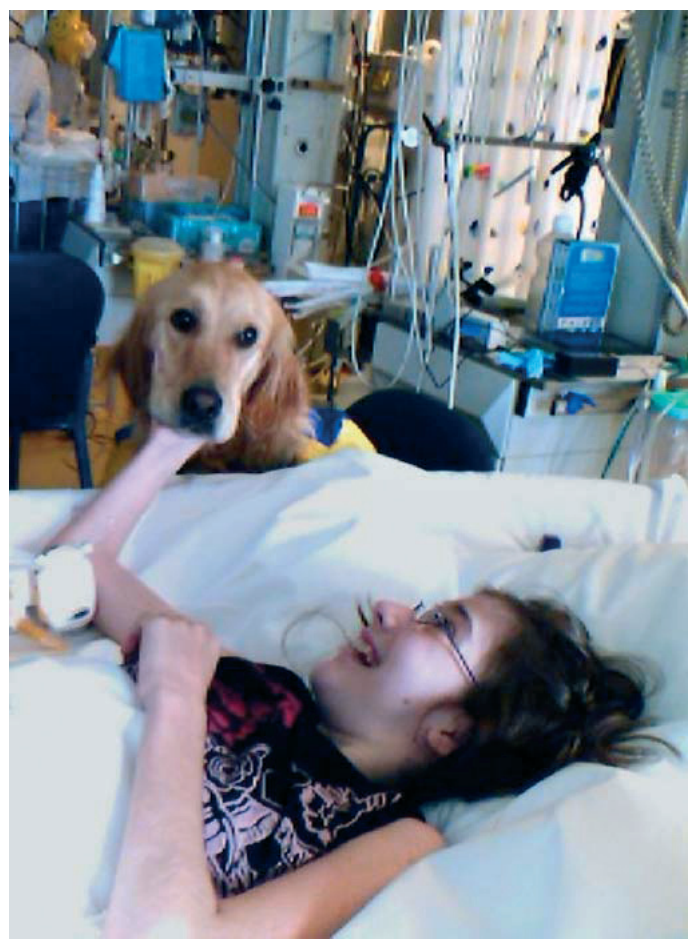

Fig. 1 Published with written permission of the patient and her parents. The patient gave written permission on behalf of Orka, who agreed with 


\section{References}

1. Ely EW, Shintani A, Truman B, Speroff T, Gordon SM, Harrell FE Jr, Inouye SK, Bernard GR, Dittus RS (2004) Delirium as a predictor of mortality in mechanically ventilated patients in the intensive care unit. J Am Med Assoc 291:1753-1762

2. Mrazek DA (2002) Psychiatric aspects of somatic disease and disorders. In: Rutter M, Taylor E (eds) Child and adolescent psychiatry, 4th edn. Blackwell, Oxford, pp 810-827

3. Schieveld JNM, Leroy PLJM, van Os JJ, Nicolai J, Vos GD, Leentjens AFG (2007) Pediatric delirium in critical illness: phenomenology, clinical correlates and treatment response in 40 cases at the pediatric intensive care unit. Intensive Care Med DOI 10.1007/s00134-007-0637-8
4. Schieveld JNM, Leentjens AFG (2005) Delirium in severely ill young children in the pediatric intensive care unit (PICU). J Am Acad Child Adolesc Psychiatry 44:392-394

5. Inouye SK, Bogardus ST, Williams CS, Leo-Summers L, Agostinin JV (2003) The role of adherence on the effectiveness of non-pharmacologic interventions. Arch Intern Med 163:958-964

6. Mrazek DA (2002) Chronic pediatric illness and multiple hospitalizations. In: Lewis M (ed) Child and adolescent psychiatry, 3rd edition. Lippincott Williams \& Wilkins, Philadelphia, pp 1230-1238
G. D. Vos (『) · P. L. J. M. Leroy

University Hospital Maastricht, Division of Paediatric Intensive Care, Department of Paediatrics,

P.O. Box 5800, 6202 AZ Maastricht,

The Netherlands

e-mail: gvo@paed.azm.nl

J. van Os · J. N. M. Schieveld

University Hospital Maastricht, Division of

Child and Adolescent Psychiatry,

Department of Psychiatry,

P.O. Box 5800, 6202 AZ Maastricht, The Netherlands

J. van Os

Institute of Psychiatry, Division of Psychological Medicine,

SE5 8AF London, UK 


\section{CHAPTER 3}

Delirium in severely ill young children in the pediatric intensive care unit (PICU)

Journal of the American Academy of Child and Adolescent Psychiatry 2005;44(4):392-394 


\title{
Delirium in Severely Ill Young Children in the Pediatric Intensive Care Unit (PICU)
}

\author{
JAN N. M. SCHIEVELD, M.D., AND ALBERT F. G. LEENTJENS, M.D., Ph.D.
}

Delirium is a serious neuropsychiatric disorder frequently seen in severely ill adult and geriatric patients. The clinical picture in adults is well known, as are the negative prognostic implications of delirium on length of hospital stay, morbidity, and mortality (American Psychiatric Association, 1999); however, it is less appreciated that delirium frequently occurs in severely ill children. Even if the condition is recognized, its seriousness is often underestimated and the condition is not treated. Bleuler (1955) stated that "children react with delirium easily and therefore this disturbance is of no great importance." We consider delirium in children to be a serious complication of illness that requires adequate diagnosis and treatment. Unfortunately, there are few reports in the literature on delirium in children.

We, a consultation liaison child psychiatrist and an adult neuropsychiatrist working in a university hospital, are frequently asked to examine severely ill young children with acute behavioral changes in a pediatric intensive care unit (PICU). We report our clinical experience of delirium in two children younger than 4 years.

\section{CASE 1}

A 28-month-old girl was admitted to the PICU because of a meningococcal meningitis and septic shock. She required intubation and ventilation because of respiratory insufficiency. She was treated with antibiotics

\footnotetext{
Accepted September 30, 2004.

Drs. Schieveld and Leentjens are with the Department of Psychiatry of Maastricht University Hospital, Maastricht, the Netherlands.

The authors gratefully acknowledge the support of the pediatric intensivists and the help of Kirsten Venrooij, medical secretary.

Correspondence to Dr. Jan N. M. Schieveld, Department of Psychiatry, Maastricht University Hospital, P.O. Box 5800, 6202 AZ Maastricht, the Netherlands; e-mail: jan.schieveld@spsy.azm.nl.

0890-8567/05/4404-0392@2005 by the American Academy of Child and Adolescent Psychiatry.

DOI: 10.1097/01.chi.0000153231.64968.1a
}

(intravenous), opioids, and benzodiazepines. She recovered quickly on this intensive treatment and was extubated the next day. Two hours after extubation, she started crawling around in her bed restlessly, yelling, and crying. Neither the pediatric intensivist nor the pediatric neurologist could find an explanation for this sudden behavioral change, and a psychiatric consultation was requested. We saw a small girl in a nightgown, continuously crawling around in her bed, yelling, and moaning, with a narrowed consciousness. It was impossible to establish contact with her. Further formal psychiatric examination was impossible. The score on the Delirium Rating Scale (DRS), rated in retrospect, was 15 (the DRS consists of 10 items and has a maximum score of 32; a score higher than 10 is indicative of delirium) (Turkel et al., 2003). Her mother was upset and said that she did not recognize her child. Our working diagnosis was delirium. She received a single dose of $0.25 \mathrm{mg}$ haloperidol administered slowly intravenously and made a complete recovery within 30 minutes.

\section{CASE 2}

A 42-month-old girl who had cystic fibrosis was admitted to the PICU for pneumonia. She was treated with intravenous antibiotics and required intubation and ventilation because of respiratory insufficiency and low oxygen saturation. She also received opioids and benzodiazepines. She responded rapidly to treatment and was extubated the same day. Over the next hours, she became progressively anxious, and because there was neither a pediatric nor a neurological explanation, a psychiatric consultation was requested because of suspected "anxiety disorder." We saw a small toddler with orthopnea and a clear but narrowed consciousness. She gazed around her with a frightened and helpless look, was inattentive, and cried inconsolably. Her speech was incomprehensible and she could no longer 
use her spoon. The DRS, scored in retrospect, was 16 . Her mother said that her child had lost her skills and talked nonsense. Further formal psychiatric examination was impossible. Again, our working diagnosis was delirium. She received a single dose of $0.15 \mathrm{mg}$ haloperidol, administered slowly intravenously, and fell asleep. The next morning she had recovered completely.

\section{DISCUSSION}

\section{Symptomatology, Prevalence, and Pathophysiology}

Delirium is primarily a disturbance of consciousness. It is characterized by a reduced awareness of the environment with a reduced ability to focus, sustain, and shift attention. Changes in cognition, such as memory deficits, disorientation, and language disturbance, and hallucinations and delusions may also be present (American Psychiatric Association, 2000). In addition to the DSM-IV$T R$ criteria, Lipowski (1980) considers abnormalities of psychomotor behavior to be a core symptom of delirium.

The clinical signs of delirium show considerable variation in children and adults (Stoddard and Wilens, 1995). Although the presentation in older children may be the same as that seen in adults, in young children, the child's age and developmental stage may influence the clinical picture. Formal psychiatric assessment, including the assessment of orientation in time and place, memory deficits, and language difficulties, may not be possible in young children, and for this reason, observed behavior and caretaker information are important (Stoddard and Wilens, 1995). Psychomotor retardation or agitation, anxiety, difficulty getting the child's attention, and regression with loss of previously acquired skills may be evidence of delirium, as illustrated by the second case (Turkel and Tavare, 2003). An acute onset of symptoms and the fact that the child may be inconsolable support the diagnosis of delirium. The caretakers' opinion is important because caretakers may more readily recognize abnormal behavior in the child.

There are no reliable estimates of the incidence of delirium in children, but the lifetime prevalence is probably high. The pathophysiology of delirium is also not clear, but it is assumed that alterations in different neurotransmitter systems, among which dopaminergic, serotonergic, cholinergic, and other pathways, account for the symptomatology.

\section{Etiology and Differential Diagnosis}

Delirium as a syndrome may have many etiologies that are summarized by the I WATCH DEATH acronym (Wise et al., 2002). In children, infections and medication use are the most frequent causes (American Psychiatric Association, 1999; Turkel and Tavare, 2003). It is wise, however, to realize that often not one single factor but multiple factors contribute to the etiology, such as somatic disorder(s), prescribed medication, and/or medication withdrawal effects. The differential diagnosis of delirium includes regressive states and oppositional behavior due to acute stress, adjustment disorder, dissociative and/or conversion disorder with or without regression, and childhood psychosis.

In our experience, the diagnosis of delirium in severely ill children, especially in a PICU setting, is usually obvious, although it may be difficult to differentiate delirium from a primary psychiatric diagnosis. Generally, an acute serious general medical condition takes precedence over a primary psychiatric condition. Moreover, one explanation for multiple simultaneous disorders is more likely than simultaneous multiple explanations (Occam's razor). Thus, in young children, delirium is more likely to be a consequence of somatic disease than due to the simultaneous occurrence of an unrelated primary psychiatric disorder. More specifically, it has been suggested that the presence of subtle higher cortical disturbances occurring during regression, such as dyspraxia or dysphasia, is more likely to be due to organic disease than due to acute emotional distress. Also, the acute onset of incoherent speech is usually organic in origin (Roberts, 1984). Disorders of consciousness are always suggestive of an organic origin, especially when there are simultaneous higher cortical dysfunctions or other neurological signs and symptoms (Lishman, 1998).

\section{Treatment}

We consider that delirium in children should be treated actively and not conservatively for several reasons. First, it is important to control psychomotor agitation to prevent the child from harming him-or herself, for example, by extubating him- or herself, disconnecting lines, and falling out of bed. Moreover, reducing the stress associated with delirium improves recovery from the somatic disorder. The prognostic impact of delirium in children is not known, but one study suggests that delirium is related to a longer hospital stay and a higher 
mortality (Turkel and Tavare, 2003). Last, because delirium is a disturbing and frightening experience for both the child and his or her caretakers, treating delirium restores quality of life and may reduce the incidence of posttraumatic stress.

Treatment of delirium in young children consists of both psychosocial and pharmacological interventions. Psychosocial interventions are directed at restoring orientation and comfort. For example, psychoeducation for the family, the presence of a family member, bringing in favorite toys and pictures of the home and family, and restoration of the usual day and night rhythm. We prefer haloperidol for pharmacological treatment (Brown et al., 1996; Harrison et al., 2002), although risperidone has been suggested for use in children older than 4 years (Posey et al., 1999). There is wide clinical experience with haloperidol also in children, and the possibility of intravenous administration is an advantage. Although haloperidol is not registered for intravenous use and this possibility is not mentioned in the APA "Practice Guideline for the Treatment of Patients With Delirium," it is nevertheless widely used in this way (American Psychiatric Association, 1999; Skrobik et al., 2004). In 1975, Ayd already called intravenous haloperidol "safe and efficient" (Lipowski, 1980). Suggested dosages for children younger than 4 years of age are $0.25 \mathrm{mg}$ slowly intravenously over 30 to 45 minutes as a loading dose and 0.05 to $0.5 \mathrm{mg} / \mathrm{kg} / 24 \mathrm{~h}$ intravenously as a continuing dose (Brown et al., 1996; Schieveld, 2003). In our experience, young children generally respond quickly to a low dose of haloperidol without experiencing extrapyramidal or other side effects. Because of the impact of delirium on the child and caretaker, we think that pharmacological treatment should be part of the routine care of delirious young children.

\section{CONCLUSION}

The occurrence of acute psychiatric symptoms and behavioral disturbances in severely ill young children should be considered due to delirium until proven otherwise. The diagnosis in children is essentially consistent with the DSM-IV criteria, but the child's age and developmental stage may make the clinical picture more complex and harder to recognize, especially in very young children. Delirium should be considered if there is regression to earlier stages of development, chaotic behavior, anxiety, and moaning in severely ill young children. Because of the serious impact of delirium on prognosis as well as the disruptive nature of the delirium, it should be considered a child psychiatric emergency and treated accordingly. We fear that this child psychiatric emergency often goes unrecognized and is undertreated; the complex combination of a serious illness and polypharmacy in a young child often results in reluctance and a delayed decision to add yet another medication to treat the delirium. We hope that this clinical perspective will allay this reluctance and lead to a more active therapeutic approach to treating delirium, including the use of pharmacotherapy.

Disclosure: The authors have no financial relationships to disclose.

\section{REFERENCES}

American Psychiatric Association (1999), Practice guidelines for the treatment of patients with delirium. Am J Psychiatry 5:1-20

American Psychiatric Association (2000), Diagnostic and Statistical Manual of Mental Disorders, 4th edition, text revision (DSM-IV-TR). Washington, DC: American Psychiatric Association

Bleuler E (1955), Lehrbuch der Psychiatrie, IXth ed. Berlin: Springer-Verlag

Brown RL, Henke A, Greenhalgh DG, Warden GD (1996), The use of haloperidol in the agitated, critically ill pediatric patient with burns. J Burn Care Rehabil 17:34-38

Harrison AM, Lugo RA, Lee WE et al. (2002), The use of haloperidol in agitated, critically ill children. Clin Pediatr (Phila) 41:51-54

Lipowski ZJ (1980), Delirium: Acute Brain Failure in Man. Springfield, IL: Charles C Thomas

Lishman WA (1998), Differential diagnosis. In: Organic Psychiatry: The Psychological Consequences of Cerebral Disorder, 3rd ed, Lishman WA, ed. Oxford: Blackwell Science, pp 149-157

Posey DJ, Walsh KH, Wilson GA, McDougle CJ (1999), Risperidone in the treatment of two very young children with autism. J Child Adolesc Psychopharmacol 9:273-276

Roberts JKA (1984), Delirium. In: Differential Diagnosis in Neuropsychiatry, Roberts JK, ed. Chichester: John Wiley, pp 158-168

Schieveld JNM (2003), Delirium and pre-delirious state at the PICU (pediatric intensive care unit) and at the pediatric ward. A preliminary report. Presented at the Congress of the European Society for Child and Adolescent Psychiatry, Paris

Skrobik YK, Bergeron N, Dumont M, Gottfried SB (2004), Olanzapine versus haloperidol: treating delirium in a clinical care setting. Intensive Care Med 30:444-449

Stoddard FJ, Wilens TE (1995), Delirium. In: Psychiatric Aspects of General Hospital Pediatrics, Jellinek MS, Herzog DB, eds. Chicago: Year Book Medical Publishers, pp 254-259

Turkel SB, Braslow K, Tavare CJ, Trzepacz PT (2003), The Delirium Rating Scale in children and adolescents. Psychosomatics 44:126-129

Turkel SB, Tavare CJ (2003), Delirium in children and adolescents. J Neuropsychiatry Clin Neurosci 15:431-435

Wise MG, Hilty DM, Cerda GM, Trzepacz PT (2002), Delirium (confusional states). In: Textbook of Consultation-Liaison Psychiatry in the Medically Ill, 2nd ed, Wise MG, Rundell JR, eds. Washington, DC: American Psychiatric Publishing, pp 257-272 



\section{CHAPTER 4}

Case reports with a child psychiatric exploration of catatonia, autism and delirium

Catatonia in autism spectrum disorders, International Review of Neurobiology (IRN) 2006; 72:195-206 


\title{
CASE REPORTS WITH A CHILD PSYCHIATRIC EXPLORATION OF CATATONIA, AUTISM, AND DELIRIUM
}

\author{
Jan N. M. Schieveld \\ Department of Psychiatry and Neuropsychology, University Hospital Maastricht \\ The Netherlands
}

\author{
I. Introduction \\ II. Case Histories
A. Case History 1 \\ B. Case History 2 \\ III. Methods \\ IV. Results \\ V. Discussion \\ VI. Conclusions \\ VII. Epicrisis \\ References \\ "... I have not a body, I am one." \\ Rudolph Nurejev
}

This chapter starts with some remarks on the conceptual history of catatonia, which begins with Kahlbaum and continues with Kraeplin, Bleuler, and Leonhard. The Diagnostic and Statistical Manual, 4th ed., Text Revision, criteria for catatonia and the multicausal origin of the disorder are discussed. So, not only schizophrenia and mood disorders associated with catatonia, which is the primary form, are introduced but also an extensive list of somatic disorders - resulting in secondary catatonia - along with the work of Gelenberg and Wing. Next, two very difficult cases, of boys with autism, catatonia, and one of them with mental retardation as well, are presented. Major textbooks, PubMed, and Medline were used for a select literature search. The results show the main and really relevant but scarce data concerning primary and secondary catatonia. In the discussion the topics are this dearth in knowledge, the concept of catatonia and its similarities with delirium, and the relation catatonia-autism, and where to find the data. The conclusions summarize the main points and end with a gentle reminder, or is it an appeal?

\section{Introduction}

The noun catatonia is a Greek neologism derived from, cata (down, overall) + teinein (tense), meaning pervasive (motor) tension, and was coined in 1874 by 
Kahlbaum, when he published his monograph Die Katatonie oder das Spannungsirresein (Catatonia or the tension madness). Here he described for the first time, in a clear fashion, the combination of alternating motor abnormalities, psychiatric symptoms, and different outcomes. He compared catatonia with the "general paralysis of the insane" (i.e., dementia paralytica), and reported on his findings at autopsy. Then there were always neuropathological changes, and he noticed a close comorbid correlation with tuberculosis. Kraepelin (1899), as well as Bleuler (1911) recognized the clinical description and adopted the name in their textbooks in relation with the schizophrenic psychosis. Leonhard (1979) published in the second half of the last century extensively on the "psychomotor psychosis," distinguishing three types: motility psychosis, periodic catatonia, and catatonic schizophrenia. He was also the first who published extensively on catatonia in childhood (Leonhard, 1960). The Diagnostic and Statistical Manual, 4th ed., Text Revision (DSM-TR-IV) (APA, 2000) defines the essential feature of catatonia as a marked psychomotor disturbance in which the clinical picture is dominated by at least two of the following five psychopathological signs: (1) motor immobility, (2) excess motor activity, (3) extreme negativism or mutism, (4) peculiarities of voluntary movement, and (5) echolalia or echopraxia.

Major textbooks invariably claim that catatonia in adults is uncommon (Sadock and Sadock, 2005). The DSM states that catatonia occurs in at least $5 \%$ of adult inpatient samples. However, higher rates have been reported in recent studies. For example, van der Heijden (2004) and van der Heijden et al. (2005) studied a large sample $(\mathcal{N}=19,309)$ of schizophrenics. Although the diagnosis of catatonic schizophrenia dropped from $7.8 \%$ in $1980-1989$ to $1.3 \%$ in 1990-2001, a possible underdiagnosis of catatonic schizophrenia was found in an independent sample. In a consecutive sample of patients admitted with psychosis, their application of a systematic catatonia rating scale showed that $18 \%$ fulfilled criteria for catatonia.

About $25-50 \%$ of catatonia cases occur in association with mood disorders, $10 \%$ in association with schizophrenia, and the rest in association with other mental disorders, these are the primary forms. However, catatonia can also occur in a general medical condition, especially in various metabolic, neurological, or infectious diseases (Gelenberg, 1976), and these are the secondary forms. Catatonic symptoms can also be a side effect of medication (Gelenberg, 1977; Wing and Shah, 2000b). Besides that, it is notorious in neuroleptic malignant syndrome and in Stauder's lethal catatonia. Children can also suffer from catatonia, especially in a comorbid fashion with autism (Wing and Atwood, 1987). Dhossche and Bouman (1997a) reviewed the literature between 1966 and 1996 and found just 30 published cases of catatonia: 11 with atypical psychosis (also in combination with infantile autism and mental retardation), 10 with general medical condition, 6 with a mood disorder, and 3 with schizophrenia. 
Next, two challenging cases of autistic boys with catatonia are presented, after all: one picture tells more than a thousand words. This is followed by a summary of the state of affairs in child psychiatry anno 2005 on catatonia, especially in relation to autism.

\section{Case Histories}

\section{A. Case History 1}

A was diagnosed with autism and severe mental retardation at the age of 2.4 year, and later on he proved to have complete aphasia as well. An extensive pediatric-metabolic-neurological-genetic assessment was completely normal. He has an older brother, now 17-year old, who has been diagnosed with pervasive developmental disorder not otherwise specified (PDD-NOS) and mild mental retardation. His intensive medical assessment was also completely normal. The family history is uneventful, except for coronary heart disease. Both parents are well-informed health professionals.

A always had extensive rituals, but around the age of 8 he became increasingly passive. His development came to a complete standstill, to the exasperation of his parents. That was the reason why he was transferred to an outpatient clinic for an intensive multidisciplinary daily treatment program, from 8.30 a.m. to 4 p.m., based on the learning principles of behavioral therapy. His parents, and sometimes his brother as well, received support, counseling, and mediation therapy. Then a long-term period of waxing and waning of problematic behaviors started.

When he was 9-year old, A developed periods of startled gazing, with anxiety, self-injurious, and extreme varieties of stereotypical behavior (e.g., clinging upside down on a couch when left alone, self-fixating in his coat, etc.). His overall level of functioning deteriorated. After ruling out epilepsy, a working diagnosis of psychosis was made and we started with haloperidol $1.2 \mathrm{mg}$ administered 2 times a day, with some effect - but he never fully returned to his previous level of functioning. Later on, he developed mild extrapyramidal side effects and was switched to risperidone $1 \mathrm{mg} /$ day, with the same success but without these side effects. A was admitted to an inpatient unit for further evaluation and treatment. During the next few years, we tapered off his medication twice, but he quickly became chaotic, very obsessed, and anxious with startled gazing. We never succeeded in stopping this medication. Almost 2 years later, in the fall of 2003, 13-year old and with a weight of $45 \mathrm{~kg}$, he developed full-blown catatonia with immobility/stupor and posturing/catalepsy over the course of a few weeks, without any psychiatric, somatic, or psychosocial cause or precipitant. His score 
on a catatonia rating scale (Bush et al., 1996a) was 40 and we added lorazepam, slowly increasing to $8 \mathrm{mg}$ /day, 3-3-2, which proved the best dosage schedule. His catatonia scores decreased from 40 to 32 to 24 in July 2004. At that time, he started to speak words for the first time in his life, "mama, papa"! In May 2004, he weighted $60 \mathrm{~kg}$ with a length of $1.58 \mathrm{~m}$. Recently there has been a recurrence of catatonic behavior, especially, posturing/catalepsy and walking just as a very stiff shadow at a distance of just $2 \mathrm{~cm}$ away from his personal nurse. The dose of lorazepam has been increased to $14 \mathrm{mg}$ /day, decreasing catatonia scores from 35 to 29 . His treatment is ongoing. He seems to learn nothing anymore. His quality of life is enhanced, but for how long?

\section{B. Case History 2}

B was born a terme and at the end of an uneventful pregnancy. His birth however was complicated by cord strangulation and hypoxia. He was described as a peaceful baby. At age 2, B did not speak any words and was overly quiet and passive. Hearing deficits were suspected by his mother. Audiological testing indicated normal hearing.

At age 3, he was evaluated by a child neurologist and child psychiatrist because of problems with speech development and poor social interactions. Psychiatric observation showed avoidant gaze, limited interest in social interactions, limited emphatic contact, inappropriate smiling, and bizarre postures. His vocabulary was limited to a few words. He also used many jargons and was echolalic. B was greatly fascinated by flickering lights and twirling objects. Neurological investigations were normal, including urinary amino acids, CSF, and a pneumo encephalography! The EEG was slightly abnormal, with mild general slowing. A diagnosis of autistic disorder (AD) was made and he was placed in special education. His adjustment at school and home improved over time. Social functioning remained poor. Insistence on routines and obsessive preoccupations were constantly present throughout this period. Developmental progress was somewhat jerky. At age 5 , his speech greatly improved unexpectedly in a short period. He also showed more interests. Cognitive testing was done at age 11 and showed a total IQ(WISG-R) of 103.

When $\mathrm{B}$ was 15, he started to complain about command auditory hallucinations. There was also marked a worsening of obsessive-compulsive behaviors, including obsessive slowness. He became literally in slow motion and sometimes even in a complete standstill. His psychomotor retardation alternated with outbursts of aggression and agitation. School performance deteriorated gradually. He was admitted to a child psychiatric hospital for further evaluation and treatment (with Jan Schieveld). 
Initial psychiatric assessment showed a disheveled, leptosomic, adolescent with long fingernails. There were alternating episodes of agitation and severe psychomotor retardation, staring in space, waxy flexibility, posturing, and decreased verbal output mainly in dialect. There were no other formal thought disorders. He reported command hallucinations. Obsessions were elaborate and had a delusional quality. There were very extensive wars going on inside his head between different countries (with good and bad ones). He suffered gravely during those battles, and experienced these especially inside his head. He described some of these wars afterwards in his so-called "history books." His mood was constricted. No focal neurological abnormalities were found. The CT of brain and routine laboratory tests were normal. Chromosomal analysis showed $46 \mathrm{XY}$ karyotype without fragile X. Schizophrenia with catatonia and paranoid features, superimposed on $\mathrm{AD}$, was diagnosed.

He was treated with several antipsychotic medications but his condition did not improve. B continued to complain about hearing voices. He was aggressive and difficult to manage in the ward. He ran away from the ward twice, trying to rescue an-indeed-kidnapped boy with whom he had fallen in love. Episodes of catatonic behavior were among the most prominent features throughout the first year of admission. At that point, clozapine was prescribed in monotherapy (400 mg/day). Improvement was seen after a few weeks. B became less aggressive and more social. Catatonic recurrences continued. The frequency of stuporous episodes decreased after lorazepam (2.5 $\mathrm{mg}$ three times a day) was added to this medication regimen. A few months later, B was discharged from the hospital. Follow-up shows a young man in his early twenties with autistic symptoms but without catatonic-psychotic recurrences. He attends a day treatment center and lives with his parents. He continues to take clozapine and a small dose of lorazepam (2.5 mg/day) (Dhossche, 1998).

\section{Methods}

We performed a PubMed and Medline search with the terms: catatonia, catatonia and children, catatonia and autism, catatonia and autism spectrum disorder (ASD), and autism and motor signs. Next, we studied the index entries, catatonia/children/autism, in the most important standard textbooks on: adult (neuro-) psychiatry, child (neuro-) psychiatry, mental retardation, and on autism. And we studied the following books: Differential Diagnosis in Neuropsychiatry by Roberts (1984), Movement Disorders in Neurology and in Neuropsychiatry by Joseph and Young (1999), Textbook of Psychosomatic Medicine by Levenson (2005), and Catatonia by Fink and Taylor (2003). 


\section{Results}

In PubMed and in Medline, there were the following hits, respectively, catatonia 1754 and 1742, catatonia in children 105 and 36 (both dating from 2005 back to 1960), catatonia and autism 33 and 14 (from 2005 back to 1964), catatonia and ASD 52 and 0, autism and motor signs 260 and 2. The publication of Leonhard in 1960 Über kindliche Katatonien (On catatonia in children) is very beautifully written (with four pictures of a catatonic child and with an abstract in Cyrillian as well). He gives an overview on catatonia, up until 1960, and the relation with childhood schizophrenia: "Ich habe bisher unter den kindlichen Schizophrenien nur Katatonien gesehen" (I have - up until now-only seen the catatonic forms of childhood schizophrenia). And he presents very lucid and extensive clinical descriptions of four children (with their full names, and their relevant family anamnesis), with the catatonic form of childhood schizophrenia, who had been examined by him. Their genders and age were: 3 boys of 5, 6, and 13 years, and 1 girl of 13 years. And he discusses the differential diagnosis from catatonia with chorea minor, chorea major, and tic disorder; and from the marked impairment of social interaction with schizophrenia and autism. And in 1971, in one of the most famous children's book in the Dutch language, Pluk van de Petteflet, a clear description of catatonia was already given: "De directeur deed de kooi open. De arme krullevaar keek angstig en bleef stokstijf staan. Hij moest naar buiten worden gedragen." (The director opened the cage. The poor krullevaar looked anxious and stood like a statue. He had to be carried away.) (Schmidt, 1971).

Epidemiological findings vary greatly, for example, Dhossche and Bouman (1997a) reviewed the world literature and found 29 cases (2 with autism), with gender ratio: 18 males and 11 females, age range was 8-18, with a mean age of 14 years. And they even described, also in 1997, a 17-year-old male adolescent with: Prader-Willi syndrome, mild mental retardation, psychosis, and catatonia. The catatonia was successfully treated with lorazepam $4 \mathrm{mg}$, and the psychosis with risperidone $6 \mathrm{mg}$. They tapered off the medication 2 months after discharge uneventfully, and there was no relapse in the 5-year follow-up period (Dhossche and Bouman, 1997b). Cohen et al. (1999) reported on a consecutive case series of inpatients: 9 cases (2 with PDD-NOS) with gender ratio: 6 males and 3 females, age range was $13-17$ years. They estimated the incidence of catatonia in an inpatient adolescent population as $0.6 \%$. Wing and Shah (2000a) assessed catatonia in a large sample of referred adolescents and young adults (age 15-19 years) with autism and found that 17\% met criteria for catatonia. Details can be found in the chapter by Wing. Slooter et al. (2005) estimated the incidence of malignant pediatric catatonia, defined as occurring below 18 years, at 0.16 per million. 
There was one recent and very lucid conceptual review article named, Catatonia in psychiatric classification: A home of its own (Taylor and Fink, 2003). The standard textbooks, whether on adult (neuro-) psychiatry, child (neuro-) psychiatry, mental retardation or autism, deal scarcely on the subject of catatonia (and autism), with the exception of a nice chapter by Williams in the textbook of Lewis (Williams, 2002). Four contributions stand out: Roberts (1984) with a chapter named Catatonia and stupor in his Differential Diagnosis in Neuropsychiatry; Joseph and Young (1999) with a chapter on Catatonia (by Joseph himself) in their Movement Disorders in Neurology and Neuropsychiatry; and Masand et al. (2005) with their chapter Mania, catatonia and psychosis in James L. Levenson's Textbook of Psychosomatic Medicine (2005). They are all instructive in their own right: Roberts from a neuropsychiatric point of view, Joseph with more the neurological vision; and Masand deals nicely with the aspects in relation to general hospital medicine. Fink and Taylor (2003) with Catatonia is the overall nec plus ultra.

\section{Discussion}

There are no clear data on the epidemiology of childhood catatonia, and those that exist vary greatly. That is very worrisome given its great clinical importance in child neuropsychiatry, vide supra, as well as in understanding psychiatry at all. One explanation is the relatively rarity of its occurrence, another one is the lack of knowledge about the issue in us, child psychiatrists. Moreover, there is the lack of a clear concept of catatonia and of reliable rating scales. Again, child psychiatry falls way behind the rest of the flock of psychiatry. Many adult psychiatric disorders have its prodromal phase in child or adolescent psychiatry, and we child psychiatrists are obliged to realize this fact and to act accordingly.

What is catatonia: a symptom, a syndrome, a disease entity, a category, or a dimension in psychopathology? (van der Heijden, 2004). There are great conceptual similarities indeed between catatonia and delirium: both have multiple etiologies, a wide range of clinical manifestations, variable courses, and both have a hyperactive and a hypoactive form (Taylor and Fink, 2003). Delirium is the neuropsychiatric expression of a destabilizing underlying other neuropsychiatric - or internal medicine related - disorder and it is driven by the I WATCH DEATH causes (Wise, 1987), and so is secondary (76\% [sic] according to Masand quoting Carroll et al. 1994) catatonia as well (Gelenberg, 1976, 1977; Wing and Shah, 2000b). Delirium has a considerable variation in clinical signs in adults and in children (Schieveld and Leentjens, 2005); it has many faces and a kaleidoscopic, fluctuating course; it is a spectrum disorder, and so is catatonia. (A spectrum disorder is a phenomenological set of different signs and symptoms, 
which are internal coherent, and can fluctuate in the course of time. This can be seen partially or completely in one patient but mostly only in a set of different patients. Other examples of spectrum disorders are, autism and epilepsy.) Both are neuropsychiatric spectrum disorders that overlap to some degree. For example, there are also similarities in the treatment modalities such as with a benzodiazepine (but not in the dosages), or with an antipsychotic, or even with electroconvulsive therapy (ECT) in lethal (delirious?) catatonia. Catatonia and delirium are perhaps both (and sometimes even similar) final common pathways for many complex (child-) neuropsychiatric disorders; they seem to be "reaction types of the brain." There are more famous examples in medicine of this kind (e.g., fever or anemia), which are more often than not a sign of an underlying disease, rather than a separate disease entity in itself. Catatonia is in my opinion a set of different, but coherent, syndromes consisting of subsets of maximal 5 of the core symptoms as recognized by the DSM-IV-TR and again this conceptualization probably holds with delirium as well. (And perhaps there exist no primary forms of catatonia at all, only secondary ones, when one regards affective disorders, schizophrenia, and autism as true medical conditions - brain diseases.)

There are differences as well, delirium is always secondary to a medical condition and catatonia only most of the time. And the brain structures and neural circuitries that are affected in catatonia and delirium may be different; in delirium, it is assumed that there are, especially, at the level of the neurotransmitter systems, general metabolic disturbances; and in catatonia, the disturbances may be more specifically located at the level of the basal ganglia. After all the brain is not one single organ, but a set of different organ systems, with different vulnerabilities (Gualtieri, 1990).

It was Piet Eikelenboom, M.D., Ph.D, professor of adult neuropsychiatry in Amsterdam who concluded, "when psychiatry and neurology were divorced, neurology became mindless, and psychiatry brainless" (Njiokiktjien, 2004). This may explain why there are more publications on autism and motor signs, than autism and catatonia, and why those writings on motor signs are mostly not from the hands of child psychiatrists. Diagnostic criteria of autism show many similarities with items of catatonia rating scales. It seems therefore incomprehensible that so little is known about the relation between these two major conditions (see the low number of hits in medical databases). Previous studies have supported a positive correlation between the severity of autism and the severity of mental retardation. If further studies confirm that catatonia is a common syndrome in autism, it logically follows that the relation between autism and catatonia should be studied intensely in severe mentally retarded people, a long neglected research population. After all: there almost everybody, or nearly no one, suffers from autism (Gualtieri, pg. 147, 1990), so, "ad fontes." 


\section{Conclusions}

Childhood catatonia, both the primary as well as secondary form, exists in all the combinations known in adult psychiatry: with mood disorders, psychosis, schizophrenia, a general medical condition, as a side effect of medication, with autism, with mental retardation, and even with the lethal variety. It deserves a place in nearly any major child psychiatric differential diagnosis, but that is seldom done. There are many similarities between catatonia and delirium, both seem to be, at least partially, final common pathways (i.e., "reaction types" of the brain), but there are differences as well. The epidemiology is unclear owing to lack of studies. Childhood catatonia, especially the primary form, is perhaps not so rare if one would systematically look for it. So child psychiatrists: remember your medical roots and the human body. Or in other words, take good care of our opening phrase from that great ballet dancer, for more than one reason.

\section{Epicrisis}

How can we evaluate the medical histories of these boys?

Boy B, Case History 2, is typical for AD until the onset of psychosis. Hallucinations and delusions in $\mathrm{AD}$ are considered rare but have been reported, mostly in high-functioning patients (Kurita, 1999; Petty et al., 1984). Obsessions are always difficult to differentiate from delusions, also in this boy. Auditory hallucinations were prominent and the catatonic symptoms were equally disabling. But most of all impressed me from then (1991) until this day, the very frightening visual and haptic hallucinations inside his head (cf. the Pensieve in Rowling, 2000). The whole clinical presentation, its longevity, and nearly complete unresponsiveness to pharmacological treatment are characteristic of schizophrenia. The progression of stereotypical movements, compulsions, withdrawal into full catatonia is remarkable but not uncommon in adult psychiatry, and has been observed by others (Wing and Shah, 2000a; Zaw et al., 1999). In that respect, autistic symptomatology appears indeed as a forme fruste of full catatonia, or is it the other way around!

During the protracted inpatient course the catatonic syndrome seemed refractory to treatment with various typical antipsychotics. It is possible that catatonia was sustained or exacerbated by this medication regimen.

The marked response to clozapine may indicate superior effect in childhood schizophrenia and/or in catatonia (Frazier et al., 1994 quoted by Marriage, 2002) and there is anecdotal evidence that clozapine improves behavioral problems in autistic children as well (Zuddas et al., 1996). The positive response to lorazepam suggests specificity of benzodiazepine treatment in catatonic stupor, in accord 
with controlled studies in general psychiatric patients (Bush et al., 1996b; Ungvari et al., 1994).

Boy A, Case History 1, lives indeed in a home for severe mentally retarded children. The psychiatric findings, clinical course, and response to medications, documented over several years, force me to conclude - at last - that there are several important comorbid diagnoses to make: autism with almost complete expressive language disorder, mental retardation, schizophrenia, and catatonia. And indeed, regarding both case histories there are some diagnostic and academic questions left to ask: after all, where does autism stop and catatonia begin or, for that matter, catatonic schizophrenia?

\section{Acknowledgments}

I thank Kirsten Venrooij, medical secretary, Eric Dumont, M.Sc., educational psychologist, Diana Kroes and her staff for their support and cooperation; Dirk Dhossche, M.D., Ph.D., child psychiatrist for his inspirational e-mails, thoughts, and support; and Karen Gillaerts, M.D., child and adolescent psychiatry resident for her critical reading of the last draft.

\section{References}

American Psychiatric Association (APA) (2000). "Diagnostic and Statistical Manual of Mental Disorders," 4th ed. Text Revision (DSM-IV-TR). APA Press, Washington, DC.

Bleuler, E. (1911). "Dementia Praecox Oder Gruppe Der Schizophrenien.” Leipzig und Wien, Franz Deuticke.

Bush, G., Fink, M., Petrides, G., Dowling, F., and Francis, A. (1996a). Catatonia: I: Rating scale and standardized examination. Acta Psychiatr. Scand. 93, 129-136.

Bush, G., Fink, M., Petrides, G., Dowling, F., and Francis, A. (1996b). Catatonia: II: Treatment with lorazepam and electroconvulsive therapy. Acta Psychiatr. Scand. 93, 137-143.

Carroll, B. T., Anfinson, T. J., Kennedy, J. C., Yendrek, R., Boutros, M., and Bilon, A. (1994). Catatonic disorder due to general medical conditions. F. Neuropsychiatry 6, 122-133.

Cohen, D., Flament, M., Dubos, P. F., and Basquin, M. (1999). Case series: Catatonic syndrome in young people. F. Am. Acad. Child Adolesc. Psychiatry 38(8), 1040-4046.

Dhossche, D., and Bouman, N. (1997a). Catatonia in children and adolescents. F. Am. Acad. Child Adolesc. Psychiatry 36(7), 870-871.

Dhossche, D., and Bouman, N. (1997b). Catatonia in an adolescent with Prader-Willi Syndrome. Ann. Clin. Psychiatry 4, 247-253.

Dhossche, D. (1998). Catatonia in autistic disorders (brief report). F. Autism Dev. Disord. 28, 329-331.

Fink, M., and Taylor, M. A. (2003). "Catatonia: A Clinician's Guide to Diagnosis and Treatment." Cambridge University Press, Cambridge.

Frazier, J., Gordon, C. T., McKenna, K., Lenane, M. C., Jih, D., and Rapoport, J. L. (1994). An open trial of clozapine with 11 adolescents with childhood onset schizophrenia. F. Am. Acad. Child Adolesc. Psychiatry 33, 658-663. 
Gelenberg, A. J. (1976). The catatonic syndrome. Lancet 1, 1339-1341.

Gelenberg, A. J. (1977). Catatonic reactions to high-potency neuroleptic drugs. Arch. Gen. Psychiatry 43, 947-950.

Gualtieri, C. T. (1990). "Neuropsychiatry and Behavioral Pharmacology." Springer-Verlag, New York. Joseph, A. B., and Young, R. R. (1999). "Movement Disorders in Neurology and Neuropsychiatry," 2nd ed. Blackwell Science, Malden.

Kahlbaum, K. (1874). "Die Katatonie oder das Spannungsirresein, Eine klinische Form psychischer Krankheit." Verlag Von August Hirschwald, Berlin.

Kraepelin, E. (1899). "Psychiatrie. Ein Lehrbuch für Studirende und Aerzte. 6," vollständig umgearbeitete Auflage. Leipzig, Barth.

Kurita, H. (1999). Delusional disorder in a male adolescent with high-functioning PDDNOS. 7. Autism Dev. Disord. 29, 419-423.

Leonhard, K. (1960). “On catatonia in children. Psychiatric Neurologic Medical Psychology.” Über kindliche Katatonien. Psychiatrie, Neurologie und medizinische Psychologie. Zeitschrift für Forschung und Praxis. Mitteilungsorgan der Gesellschaft für Psychiatrie und Neurolgie der Deutsche Demokratische Republik. Jahrgang 12, Januar 1960, Heft I, Seite 1-12.

Leonhard, K. L. (1979). "The Classification of Endogenous Psychoses” (E. Robins, Ed. and R. Berman, trans.), 5th ed. Irvington Publishers, New York.

Levenson, J. L. (2005). "Textbook of Psychosomatic Medicine." American Psychiatric Publishing, Inc., Arlington, VA.

Marriage, K. (2002). Schizophrenia and related psychoses. In "Practical Child and Adolescent Psychopharmacology" (S. Kutcher, Ed.), Cambridge University Press, Cambridge.

Masand, P. S., Christopher, E. J., Clary, G. L., Mago, R., Levenson, J. L., and Patkar, A. A. (2005). Mania, catatonia, and psychosis. In "Textbook of Psychosomatic Medicine" (J. L. Levenson, Ed.), American Psychiatric Publishing, Inc., Washington, DC.

Njiokiktjien, C. (2004). "Gedragsneurologie van het kind.” Suyi Publicaties, Amsterdam.

Petty, L., Ornitz, E., Michelman, J., and Zimmerman, E. (1984). Autistic children who become schizophrenic. Arch. Gen. Psychiatry 41, 129-135.

Roberts, J. K. (1984). Catatonia and Stupor. In "Differential diagnosis in Neuropsychiatry." John Wiley and Sons, Chichester.

Rowling, J. K. (2000). "Harry Potter and the Goblet of Fire." Bloomsbury Publishing, London.

Sadock, B. J., and Sadock, V. A. (2005). "Kaplan \& Sadock's Comprehensive Textbook of Psychiatry." Lippincott Williams and Wilkins, Philadelphia.

Schieveld, J. N. M., and Leentjens, A. F. G. (2005). Delirium in severely ill young children in the pediatric intensive care unit (PICU). F. Am. Acad. Child Adolesc. Psychiatry 44(4), 392-394.

Schmidt, A. M. G. (1971). "Pluk van de Petteflet," p. 145. Em. Querido's Uitgeverij B.V., Amsterdam.

Slooter, A., Braun, K., Balk, F., van Nieuwenhuizen, O., and van der Hoeven, J. (2005). Electroconvulsive therapy for malignant catatonia in childhood. Pediatr. Neurol. 32(3), 190-192.

Taylor, M. A., and Fink, M. (2003). Catatonia in psychiatric classification: A home of its own. Am. $\mathcal{J}$. Psychiatry 160(7), 1233-1244.

Ungvari, G., Leung, C., Wong, M., and Lau, J. (1994). Benzodiazepines in the treatment of the catatonic syndrome. Acta Psychiatr. Scand. 89, 285-288.

van der Heijden, F. (2004). "Atypicality: Clinical Studies Concerning Atypical Psychosis.” Academic Thesis, University of Utrecht, The Netherlands.

van der Heijden, F., Tuinier, S., Arts, N., Hoogendoorn, M., Kahn, R., and Verhoeven, W. (2005). Catatonia: Disappeared or under-diagnosed? Psychopathology 15, 3-8.

Williams, D. T. (2002). Neuropsychiatric signs, symptoms, and syndromes. In "Child and Adolescent Psychiatry, A Comprehensive Textbook" (M. Lewis, Ed.), 3rd ed. Lippincott Williams and Wilkins, Philadelphia. 
Wing, L., and Atwood, A. (1987). Syndromes of autism and atypical development. In "Handbook of Autism and Pervasive Developmental Disorders" (D. L. Cohen and A. M. Donellan, Eds.), pp. 3-19. Silver Spring, VH Winston \& Sons, MD.

Wing, L., and Shah, A. (2000a). Catatonia in autistic spectrum disorder. Br. f. Psychiatry 176, 357-362.

Wing, L., and Shah, A. (2000b). Possible causes of catatonia in autistic spectrum disorder. (Reply to Chaplin). Br. F. Psychiatry 177, 180-181.

Wise, M. G. (1987). Delirium. In "Textbook of Neuropsychiatry" (R. E. Hales and S. C. Yudofsky, Eds.), The American Psychiatric Press, Washington, DC.

Zaw, F., Bates, G., Murali, V., and Bentham, P. (1999). Catatonia, autism, and ECT. Dev. Med. Child Neurol. 41, 843-845.

Zuddas, A., Ledda, M., Fratta, A., Muglia, P., and Cianchetti, C. (1996). Clinical effects of clozapine on autistic disorder. Am. F. Psychiatry 153, 738 (letter). 


\title{
CHAPTER 5
}

\author{
Pediatric delirium in critical illness: phenomenology, \\ clinical correlates and treatment response in 40 cases \\ in the pediatric intensive care unit
}

Intensive Care Medicine 2007; 33:1033-1040 
Jan N. M. Schieveld

Piet L. J. M. Leroy

Jim van Os

Joost Nicolai

Gijs D. Vos

Albert F. G. Leentjens

\section{Pediatric delirium in critical illness: phenomenology, clinical correlates and treatment response in $\mathbf{4 0}$ cases in the pediatric intensive care unit}

Received: 22 June 2006

Accepted: 26 March 2007

Published online: 25 April 2007

(C) Springer-Verlag 2007

J. N. M. Schieveld and P. L. J. M. Leroy contributed equally to this paper.

J. N. M. Schieveld ( $)$ J. van Os

A. F. G. Leentjens

University Hospital Maastricht, Division of

Child and Adolescent Psychiatry,

Department of Psychiatry,

5800, 6202 AZ Maastricht, The Netherlands

e-mail: jan.schieveld@spsy.azm.nl

Tel.: +31-43-3877499

Fax: +31-43-3875444

P. L. J. M. Leroy · G. D. Vos

University Hospital Maastricht, Division of

Pediatric Intensive Care, Department of

Pediatrics,

5800, 6202 AZ Maastricht, The Netherlands

\section{J. Nicolai}

University Hospital Maastricht, Department of Neurology,

5800, 6202 AZ Maastricht, The Netherlands

J. van Os

Institute of Psychiatry, Division of

Psychological Medicine,

SE5 8AF London, UK
Abstract Objective: To study the phenomenology, clinical correlates, and response to treatment of delirium in critically ill children in the pediatric intensive care unit (PICU). Design, setting and patients: Descriptive study of a cohort of child psychiatric consultations from a tertiary PICU between January 2002 and December 2005. Demographic data, clinical presentation, and response to treatment of children subsequently diagnosed with delirium were analyzed. $R e$ sults: Out of 877 admissions (age distribution $0-18$ years) arose 61 requests for psychiatric assessment. Of the 61 children, 40 (15 girls and 25 boys) were diagnosed with delirium (cumulative incidence 5\%; mean age 7.6 years). Age-specific incidence rates varied from $3 \%$ ( $0-3$ years) to $19 \%$ (16-18 years). In addition to the classical hypoactive and hyperactive presentations, a third presentation was apparent, characterized mainly by anxiety, with a higher prevalence in boys. All but 2 of the 40 children received antipsychotic medication:
$27(68 \%)$ haloperidol, $10(25 \%)$ risperidone, and 1 both in succession. Two children treated with haloperidol experienced an acute torticollis as side effect. All children made a complete recovery from the delirium; five, however, died of their underlying disease. Conclusion: The rate of delirium in critically ill children on a PICU is not negligible, yet prospective studies of the phenomenology, risk factors and treatment of childhood delirium are very rare. Once pediatric delirium has been recognized, it generally responds well to treatment.

Keywords Delirium · Critically ill children - Pediatric intensive care unit (PICU) · Consensus meetings . Haloperidol $\cdot$ Risperidone

\section{Introduction}

Delirium is a neuropsychiatric disorder secondary to a general medical condition, and must be considered a serious complication of the underlying disease or its treatment. In the revised fourth edition of the Diagnostic and Statistical Manual of Mental Disorders (DSM-IV$\mathrm{TR}^{\circledR}$ ), delirium is defined by four concurrent diagnostic criteria: (1) acute onset and fluctuation of (2) a disturbance of consciousness with reduced ability to focus, shift or maintain attention and (3) a change of cognition with memory deficit, disorientation, language disturbance, perceptual disturbances or hallucinations, (4) caused by the direct physiological consequences of a general medical condition [1]. It is frequently seen in critically ill adult and geriatric patients [2-5] and is associated with a poor prognosis, reflected by longer hospital stay, worse functional and cognitive outcome, and a higher mortality 
rate after discharge from hospital [3]. In mechanically ventilated critically ill adults, delirium is an independent predictor of elevated 6-month mortality and a longer hospital stay [6]. If appropriate diagnostic tools validated for bedside use by non-psychiatrists [e.g. Delirium Rating Scale (DRS), Confusion Assessment Instrument for the Intensive Care Unit (CAM-ICU)] are used, delirium is diagnosed in over $80 \%$ of critically ill adult patients [7]. Thus, systematic monitoring for delirium and appropriate treatment with haloperidol in critically ill adult patients were included in the recently published clinical practice guidelines for sedatives and analgesia of the Society of Critical Care Medicine [8]. However, the optimal management of patients with delirium and the effects of the pharmacological treatment on the outcome are still key concerns for today [9]. Given lack of age-appropriate diagnostic criteria and assessment tools in children, even less is known about the incidence, clinical presentation, response to treatment and consequences of childhood delirium in general, and in critically ill children in particular [10-12]. The few available published data on childhood delirium suggest that morbidity and mortality are higher in children with than in children without delirium [13]. Therefore, delirium in children should be considered a serious complication and be treated accordingly. Unfortunately, while there are comprehensive guidelines on the diagnosis and treatment of delirium in adults, clinical guidelines for delirium in children are nonexistent.

The aim of this study was to investigate the incidence, patient and population characteristics, clinical presentation and response to treatment of delirium in a cohort of critically ill children admitted to a tertiary pediatric intensive care unit (PICU). Given the necessarily multidisciplinary approach to assessment and treatment of these children, the input of four disciplines - child psychiatry, pediatric intensive care medicine, child neurology and adult neuropsychiatry - was used.

\section{Methods}

Design, setting and patients

A descriptive study was carried out over a 4-year period (January 2002 to December 2005) in an eight-bed tertiary PICU. This PICU is a tertiary referral center for both general and surgically critically ill children in the southeastern region of the Netherlands (population 1.4 million, 350 annual admissions). Critically ill children, acutely, nonelectively and consecutively admitted, were prospectively sampled. Both mechanically ventilated and non-ventilated patients were included.

\section{Diagnostic approach}

All children with (1) confusion, agitation, anxiety, moaning, discomfort, or behavioral disturbances with no acceptable medical explanation or (2) failure of standard analgosedative treatment were systematically assessed for the presence of delirium in a two-step diagnostic approach. The standard analgosedative treatment can be summarized as follows: children who required analgosedation because of obvious or expected pain or because of stress related to their underlying disease or treatment received adequate doses of opioids and/or benzodiazepines according to internationally published guidelines for analgesia and sedation in critically ill children [14]. Drug doses were individually tailored to achieve optimal patient comfort and were slowly reduced in order to avoid a withdrawal syndrome. In the event that a withdrawal syndrome was suspected, based on clinical observation or the revised Finnegan score, specific treatment with long-acting benzodiazepines (e.g. lorazepam) or opioids (e.g. methadone) was started according to internationally published guidelines $[15,16]$.

At the time the assessment for delirium was initiated, none of the patients had signs of imminent life-threatening respiratory, circulatory or neurological failure, while ongoing asphyxia, respiratory acidosis, metabolic disturbances, fighting the ventilator due to inappropriate ventilator settings and withdrawal syndrome all had been excluded systematically as an explanation for the observed behavior.

The first step of the diagnostic approach was a systematic assessment by a child neuropsychiatrist (J.S.) using DSM-IV criteria for delirium. Criteria were evaluated on the basis of (1) hetero-anamnestic information from parents, nurses, intensivists, and child neurologists about behavior and behavioral changes and (2) child psychiatric examination. Based on the findings, patients were categorized as having a (probable) delirium or not. In a second step, the provisional diagnosis of delirium was further tested in a daily multidisciplinary consensus meeting. The team consisted of the child neuropsychiatrist, the attending pediatric intensivist, and occasionally a geriatric neuropsychiatrist specialized in delirium in geriatric patients and/or a child neurologist. If this team agreed that alternative explanations for a child's behavior were unlikely, the consensus diagnosis was delirium.

Based on the dominant clinical presentation, cases of delirium were classified as "hyperactive" when psychomotor agitation was present, and as "hypoactive" when retardation and/or inhibition was present. A number of children presented with cognitive and/or attentional disturbances in the context of severe anxiety states, often accompanied with moaning and restlessness, but 
without clear agitation or retardation. This latter group was classified as "emerging" or "veiled" delirium [17], in reference to the way delirious syndromes have been described as "partial delirium" in adult ICU patients or as "subsyndromal delirium" in elderly medical patients [7, $18,19]$. The different presentation forms were not always clear-cut, and some fluctuated dramatically over time. The severity of illness was scored according to the Pediatric Index of Mortality (PIM) and Pediatric Risk of Mortality (PRISM) [20].

\section{Therapeutic approach}

Whenever delirium was identified or suspected, a twotrack treatment approach consisting of both psychosocial and pharmacological interventions was implemented. Psychosocial interventions - the parents' presence and comforting throughout the day (and night), familiar music, favorite toys, pictures of home and pets, friends, school, lighting schedules, sometimes even fragrances - are standard in the PICU. The parents also received an information leaflet on childhood delirium [21]. All patients were also treated with antipsychotic medication after the referring pediatric intensivist had agreed and the parents, because of the off-label use, had given informed consent, which was never refused. In children with psychomotor agitation that was acutely threatening to their health status, haloperidol at a loading dosage of $0.15-0.25 \mathrm{mg}$ i.v. was used, given slowly over a period of 30-45 $\mathrm{min}$, followed by a maintenance dose of $0.05-0.5 \mathrm{mg} / \mathrm{kg} / 24 \mathrm{~h}$ i.v. [11, 22, 23]. In less acute situations, and when oral medication was possible, risperidone at a loading dose of $0.1-0.2 \mathrm{mg}$ p.o. was used, followed by a maintenance dose of $0.2-2.0 \mathrm{mg} / 24 \mathrm{~h}$ p.o. as the treatment of choice. Clinical response and side effects were recorded by the child neuropsychiatrist and the pediatric intensivists. In order to tailor the treatment for delirium, daily discussions were held with the multidisciplinary team. Adjustment of treatment was based on the clinical observations and judgements of the parents, nurses, intensivists and child psychiatrist.

Children were followed up for 6 weeks after discharge from the hospital either at the outpatient clinic or by contacting the parents by telephone.

As the study solely involved the structured recording of routine clinical practice, under Dutch law no institutional review board approval was required.

Table 1 Number and incidence of delirium in the total sample* by age and gender

\begin{tabular}{lllc}
\hline Age & $\begin{array}{l}\text { Total } \\
\text { sample* }\end{array}$ & $\begin{array}{l}\text { Patients } \\
\text { with delirium }\end{array}$ & $\begin{array}{l}\text { Incidence } \\
(\%)\end{array}$ \\
\hline 0-2.99 years & 513 & 14 & 2.7 \\
Male & 310 & 9 & 2.9 \\
Female & 203 & 5 & 2.5 \\
3-5.99 years & 106 & 4 & 3.8 \\
Male & 56 & 3 & 5.4 \\
Female & 50 & 1 & 2.0 \\
6-8.99 years & 80 & 6 & 7.5 \\
Male & 46 & 1 & 2.2 \\
Female & 34 & 5 & 14.7 \\
9-11.99 years & 77 & 3 & 3.9 \\
Male & 61 & 3 & 4.9 \\
Female & 16 & 0 & 0 \\
12-14.99 years & 70 & 7 & 10 \\
Male & 35 & 5 & 14.3 \\
Female & 35 & 2 & 5.7 \\
15-18 years & 31 & 6 & 19.4 \\
Male & 13 & 4 & 30.8 \\
Female & 18 & 2 & 11.1 \\
Total & 877 & 40 & 4.6 \\
Male & 521 & 25 & 4.8 \\
Female & 356 & 15 & 4.2 \\
\hline
\end{tabular}

${ }^{*}$ Critically ill children, acutely, non-electively and consecutively admitted during a 4-year period
Fig. 1 Incidence of delirium in the sub-groups by age and gender

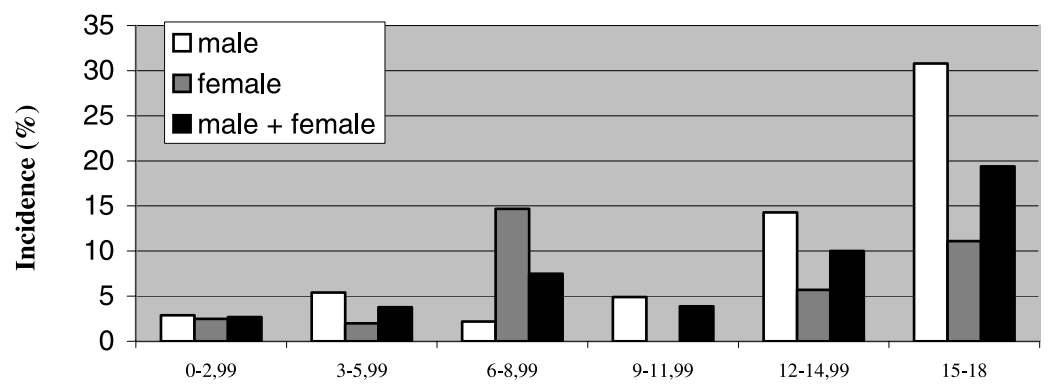

Age cohort (yr) 
Table 2 Child psychiatric diagnosis at the first consultation $(n=61)$

\begin{aligned} & \hline$n$ Diagnosis \\ & \hline 40 delirium \\ & 5 $\begin{array}{l}\text { adjustment disorders with anxiety and } \\ \text { depressed mood, post operative }\end{array} \\ & 4 \begin{array}{l}\text { psychological-psychiatric factors } \\ \text { affecting the medical condition }\end{array} \\ & 3 \begin{array}{l}\text { anxiety disorder } \\ 3\end{array} \\ & 2 \begin{array}{l}\text { emotional and behavioral problems } \\ \text { during chronic ventilation }\end{array} \\ & 1$ adjustment disorders with depressed mood \\ & 1 mood disorder \\ & 1 adjustment disorder with anxiety \\ & 1 sleeping problem \\ & \hline\end{aligned}

Table 3 Population characteristics of the 40 PICU cases with delirium, 2002-2005

\begin{tabular}{lc}
\hline Characteristics & $\begin{array}{l}\text { Frequency } \\
\text { (total } n=40)\end{array}$ \\
\hline Age (mean \pm SD) & $7.6 \pm 5.9$ \\
Male & 25 \\
$\quad n$ & $7.6 \pm 6.1$ \\
age (mean \pm SD) & 15 \\
Female & $7.6 \pm 5.8$ \\
$\quad n$ & \\
age (mean \pm SD) & $36(90 \%)$ \\
Ethnicity & $3(7.5 \%)$ \\
White & $1(2.5 \%)$ \\
African & $34(85 \%)$ \\
Asian & $9.96 \pm 16.20$ \\
Mechanical ventilation & $23.54 \pm 24.94$ \\
PIM score (mean \pm SD) & \\
PRISM score (mean \pm SD) & \\
Major somatic pharmacological & \\
features & \\
Recent increase or decrease of & $22(55 \%)$ \\
analgosedative medication & $21(52 \%)$ \\
$\quad$ Neurological disorders & $20(50 \%)$ \\
Infectious disorders & $12(30 \%)$ \\
Respiratory disorders & \\
\hline
\end{tabular}

PIM, Pediatric Index of Mortality; PRISM, Pediatric Risk of Mortality

\section{Results}

From January 2002 to December 2005, there were 877 acute, non-elective admissions to the PICU. Distribution of age and gender are shown in Table 1. In 61 cases (7\%), a systematic assessment by a child neuropsychiatrist was requested, usually for agitation, anxiety, moaning, discomfort, behavioral disturbance or problematic analgosedation.

Of these 61 patients, $40(61 \%)$ were diagnosed with delirium, yielding a cumulative incidence of $5 \%$ (boys $5 \%$; girls $4 \%$ ). Age-specific incidences increased from $3 \%$ in the $0-3$ years age group (boys $3 \%$; girls $3 \%$ ), to $19 \%$ in the $16-18$ years age group (boys $31 \%$; girls $11 \%$ ) (Table 1 , Fig. 1).

The child psychiatric disorders diagnosed in the 61 referrals are summarized in Table 2 .

Table 3 summarizes the population characteristics of the sample diagnosed with delirium, while Table 4 lists the underlying somatic disease or causative pharmacological treatment.

The underlying features were: recent increase or decrease in analgosedative medication $(n=22)$, neurological disorders $(n=21)$, infections $(n=20)$ and respiratory disorders $(n=12)$. Usually, a combination of these existed.

All but two patients were treated with an antipsychotic drug. Twenty-seven children were given haloperidol, 10 risperidone, and 1 child received both drugs in succession. In most cases, the beneficial results were observed rapidly, especially in the hyperactive forms, sometimes even after a single dose [11]. Sometimes it took a few hours or days. Two patients experienced acute dystonia as a likely side effect of the haloperidol, responding well to biperidene. Two children received no medication: one because of lack of consensus in our expert team, and one because of an endotracheal intubation at the time that medication was indicated. In most cases, the medication was stopped or tapered off successfully during hospitalization or afterwards in an outpatient setting. Five children (12.5\%) with delirium died of their underlying disease; the mean PIM was $10 \%$ and the mean PRISM 24\% (Table 3 ).

\section{Discussion}

This is the first systematic multidisciplinary study of the phenomenology and treatment of delirium in 40 critically ill children in a PICU context. The low cumulative incidence of 5\% is mainly the result of the low incidence in the younger age groups ( $<9$ years old), this segment constituting the majority of the total sample $(80 \%)$. A clearly higher incidence is seen in the older age groups. However, in critically ill adult patients substantially higher incidences have been reported, ranging from $10-30 \%$ in general hospital settings to $50 \%$ in postoperative patients and up to $80 \%$ in the terminally ill [2].

There are several possible explanations for this difference. First, the incidence of delirium in young critically ill children may be truly low: differences in age-related resilience and underlying conditions may contribute to true differences in the incidence between the very young and the very old. However this explanation seems unlikely, given the tendency in the very young to develop delirium under even much less severe circumstances [1, 11, 24]. A second explanation may relate to the fact that extensive psychosocial interventions are provided as a routine in Dutch PICU settings, with a possibly preventive effect on delirium in much the same way as observed in geriatric patients [25]. A third factor may be an anti-delirium 
Table 4 Patient characteristics of the 40 PICU cases with delirium 2002-2005

\begin{tabular}{|c|c|c|c|c|c|c|}
\hline No. & Sex & Age & Primary diagnosis on admission PICU & $\begin{array}{l}\text { Mechanical } \\
\text { ventilation }\end{array}$ & $\begin{array}{l}\text { Delirium } \\
\text { type }\end{array}$ & Treatment \\
\hline 1 & M & 3 months & Multiple congenital malformations & + & Emerging & Haloperidol \\
\hline 2 & $\mathrm{~F}$ & 4 months & Meningococcal septic shock & + & Emerging & Risperidone \\
\hline 3 & M & 4.5 months & Severe CLD & + & Emerging & Risperidone \\
\hline 4 & $\mathrm{~F}$ & 10 months & Near drowning & + & Emerging & Haloperidol \\
\hline 5 & $\mathrm{~F}$ & 1 year & Pneumonia & + & Emerging & Haloperidol \\
\hline 6 & M & 1 year & Sepsis due to perforated appendicitis & + & Emerging & Haloperidol \\
\hline 7 & M & 1 year & Subarachnoid bleeding & + & Emerging & Haloperidol \\
\hline 8 & M & 1 year & Pericardial effusion with pretamponade & + & Hyperactive & Haloperidol \\
\hline 9 & M & 1 year & Multiple dysmorphia, upper airway obstruction & - & Emerging & Haloperidol \\
\hline 10 & $\mathrm{~F}$ & 2 years & Meningococcal septic shock & + & Hyperactive & Haloperidol \\
\hline 11 & M & 2 years & ADEM & + & Hyperactive & Risperidone \\
\hline 12 & M & 2 years & Cervical mass, upper airway obstruction & + & Emerging & Haloperidol \\
\hline 13 & M & 2 years & Aspiration and pneumothorax & + & Hypoactive & - \\
\hline 14 & $\mathrm{~F}$ & 2 years & Meningococcal meningitis with sepsis and DIC & + & Hyperactive & Haloperidol \\
\hline 15 & $\mathrm{~F}$ & 3 years & Cystic fibrosis and pneumonia & + & Hypoactive & Haloperidol \\
\hline 16 & M & 4 years & Intracerebral hemorrhage, Marfan syndrome & + & Hypoactive & Haloperidol \\
\hline 17 & M & 5 years & Medulloblastoma post surgery & + & Emerging & Risperidone \\
\hline 18 & M & 5 years & Upper respiratory tract infection & + & Hyperactive & Haloperidol \\
\hline 19 & M & 6 years & Multiple trauma & + & Emerging & Risperidone \\
\hline 20 & $\mathrm{~F}$ & 8 years & Meningo-encephalitis & + & Hyperactive & Risperidone \\
\hline 21 & $\mathrm{~F}$ & 8 years & Viral encephalitis & + & Hyperactive & - \\
\hline 22 & $\mathrm{~F}$ & 9 years & Status asthmaticus & + & Hyperactive & Risperidone \\
\hline 23 & $\mathrm{~F}$ & 9 years & TBI, gunshot wound & + & Hypoactive & Risperidone \\
\hline 24 & M & 9 years & Status asthmaticus & + & Hyperactive & Haloperidol \\
\hline 25 & M & 9 years & Neural tube defect and drain dysfunction & - & Emerging & $\begin{array}{l}\text { first Haloperidol, } \\
\text { then Risperidone }\end{array}$ \\
\hline 26 & M & 11 years & Hypovolemic shock, typhus abdominalis & - & Hyperactive & Haloperidol \\
\hline 27 & $\mathrm{~F}$ & 12 years & TBI & + & Hypoactive & Haloperidol \\
\hline 28 & M & 12 years & TBI and fracture of lower leg & + & Emerging & Haloperidol \\
\hline 29 & M & 13 years & Sepsis, paronychia & - & Hyperactive & Haloperidol \\
\hline 30 & M & 13 years & Status epilepticus & + & Emerging & Haloperidol \\
\hline 31 & $\mathrm{~F}$ & 14 years & TBI & + & Hyperactive & Haloperidol \\
\hline 32 & $\mathrm{~F}$ & 15 years & Post TBI & + & Hypoactive & Haloperidol \\
\hline 33 & M & 15 years & Postoperative state & + & Hypoactive & Risperidone \\
\hline 34 & M & 15 years & Acute lymphoblastic leukemia & - & Hypoactive & Haloperidol \\
\hline 35 & M & 15 years & TBI & + & Emerging & Haloperidol \\
\hline 36 & $\mathrm{~F}$ & 15 years & Status asthmaticus & + & Hyperactive & Haloperidol \\
\hline 37 & M & 16 years & Multiple trauma & - & Hypoactive & Haloperidol \\
\hline 38 & $\mathrm{~F}$ & 16 years & Bacterial meningitis & + & Hyperactive & Risperidone \\
\hline 39 & M & 16 years & Respiratory failure, Duchenne disease & + & Emerging & Haloperidol \\
\hline 40 & M & 17 years & Septic shock & + & Emerging & Haloperidol \\
\hline
\end{tabular}

$C L D$, chronic lung disease; $A D E M$, acute disseminated encephalomyelitis; $D I C$, diffuse intravascular coagulation; $T B I$, traumatic brain injury

effect of the routinely used analgosedative medication, although especially benzodiazepines may have excitatory side effects in children. A fourth factor may relate to reluctance on the part of the intensivists and/or child neurologists to request psychiatric evaluation in the case of behavioral changes for fear of adding stigmatization to an already burdened system. Perhaps the fifth, most likely and important explanation is that parents, nurses, pediatric intensivists and child neurologists do not easily recognize delirium, because the medical condition of these critically ill PICU children is so complex and changeable. It is possible that a psychiatric consultation was readily requested only in cases of anxiety and/or hyperactive delirium, not in the hypoactive and or veiled ones.
The differential diagnosis of pediatric delirium consists of acute stress reactions, acute anxiety states, adjustment disorders with mixed emotions, dissociative and/or regressive states and childhood-onset psychosis (see also Table 2). However, differentiating delirium from extreme stress and agitation due to acute and life-threatening conditions is not only impossible, it is also unwanted, because it is usually irrelevant at that point of time in the process of medical care. Causative treatment, if possible, is always the first step to be taken. Furthermore, the diagnosis of delirium in children is complicated by the fact that the criteria for adult delirium are not always easily applicable to children because of important differences in age and developmental levels. The DSM-IV criteria for delirium are 
not always useful in the case of pediatric delirium, especially in a PICU context. This is a source of concern. Moreover, delirium is not mentioned in the DSM-IV section on child psychiatry. DSM-IV describes as an essential feature of delirium the "disturbance of consciousness" leading to "impairment of the ability to focus, shift and sustain attention". This, however, is of little relevance in the critically ill in a PICU context, where disturbance of attention is routinely present due to the disorder(s) itself. In fact, attention is often the first "to go" $[17,26]$. In addition, patients almost always require treatment with opioids and benzodiazepines, which also have a strong impact on attention. Furthermore, it has been hypothesized that a disturbance of consciousness is not a discriminating characteristic of delirium in an ICU setting [27].

Our case series suggests that in addition to the hyperand hypoactive forms of delirium, a third form may be characterized by anxiety, moaning, and/or restlessness. This was referred to as an "emerging" or veiled delirium, as described previously [17]. In the PICU population this state did not develop into a frank hyper- or hypoactive form, but appeared to exist in its own right, accompanied by disturbances of consciousness and cognition.

Although atypical presentations of disorders are often not captured in classification systems, the high prevalence of "emerging" delirium in our sample (17/40) stresses the importance of further phenomenological study. Adhering too strongly to DSM-IV criteria for adult delirium, for clinical use in a PICU context, may result in persistent underdiagnosis. On the other hand, the incidence of delirium may be overestimated by using the CAM-ICU, so most important is the issue of what constitutes delirium in critical illness [28].

There are accumulating indications that pediatric delirium can be subtle and accompanied or even dominated by other neuropsychiatric signs such as: reduction of awareness of the caregiver and/or the surrounding environment, purposeless actions, restlessness, inconsolability, signs of autonomic dysregulation and other subtle higher cortical dysfunctions [29-32]. Parents and nurses have a way of discriminating patterns in their children that may be diagnostically important. Thus, parents sometimes state: "This is not my child anymore." Pediatric delirium therefore may have various subtle presentations and can be considered a spectrum disorder, which makes it sometimes difficult to diagnose [33]. Neither haloperidol nor risperidone is registered for the treatment of childhood delirium, although both are mentioned as the treatment of choice for adults [1]. Moreover, haloperidol is not registered for i.v. administration, even though it is used in this way in many places. We prefer risperidone in non-acute situations because of the theoretically lower risk of extrapyramidal side effects. Haloperidol and risperidone have been used for other indications in young children as well, such as childhood psychosis [34] or aggression in autism [35]. There are two limitations regarding our observations of treatment response. First, no severity scale for pediatric delirium was used, because none exists for this PICU population. Second, because no studies on the natural course of childhood delirium exist that have established the rate of spontaneous remission, spontaneous remissions may have been misclassified as response to treatment. In our opinion, however, the time frame of response points towards a medication effect.

Most medications employed in pediatrics and child psychiatry are used off-label [36], which means that special attention should be paid to information and informed consent procedures. Given the relatively high incidence of extrapyramidal symptoms with haloperidol, the "off-label" use needs further study [37].

This study has several limitations. First, it was a study of routine clinical practice. Observations were based on referrals emerging from care as usual. Although the focus on delirium may have altered referral paths and rates, we did not actively advocate any change, nor did we screen all admissions for delirium. In the absence of a hard clinical indication, no routine blood level measurements were performed to rule out persistent high levels of sedatives as a possible explanation for any neuropsychiatric symptom. Next, the lack of DSM-IV criteria for pediatric delirium and the disputed relevance of its main criterion in a (P)ICU setting make a standardized diagnosis difficult. Finally, treatment was provided in an open setting and based on consensus, especially among child psychiatrist, pediatric intensivist and child neurologist.

In conclusion, critically ill children in a PICU can develop delirium, with a hyperactive, hypoactive or veiled presentation, despite adequate analgosedation and intensive psychosocial interventions. The approach using an algorithmic structuring and an intensifying of daily clinical care, including the use of multidisciplinary daily consensus meetings, appeared effective in assessing, diagnosing and treating childhood delirium at the PICU. The findings suggest that the incidence is much lower than in adults, but a likely explanation is that delirious states requiring child psychiatric referral are still frequently under-diagnosed. There is also still a great need for developing delirium criteria in critically ill patients, children and adults alike, in a (P)ICU setting. Treatment with haloperidol or risperidone was successful in all patients. Future research is necessary to identify the risk factors for pediatric delirium in a multivariate prospective approach, to develop "easy to use" bedside tools for non-psychiatric trained team members for the early detection of delirium in all pediatric PICU patients, and to study the effects of interventions in a double-blind and ideally placebo-controlled fashion. 


\section{References}

1. American Psychiatric Association (2000) Diagnostic and statistical manual of mental disorders, 4th edition text, revision (DSM-IV-TR). American Psychiatric Association, Washington DC

2. American Psychiatric Association (1999) Practice guidelines for the treatment of patients with delirium. Am J Psychiatry 5:1-20

3. Leentjens AFG, Van der Mast RC (2005) Delirium in the elderly: an update. Curr Opin Psychiatry 18:325-330

4. Trzepacz PT, Van der Mast RC (2002) Pathophysiology of delirium. In: Lindesay J, Rockwood K, MacDonald A (eds) Delirium in old age. Oxford University Press, Oxford, pp 51-90

5. Wise MG, Hilty DM, Cerda GM, Trzepacz PT (2002) Delirium (confusional states). In: Wise MG, Rundell JR (eds) Textbook of consultationliaison psychiatry in the medically ill. American Psychiatric Publishing, Washington, DC, pp 257-272

6. Ely EW, Shintani A, Truman B, Speroff T, Gordon SM, Harrell Jr FE, Inouye SK, Bernard GR, Dittus RS (2004) Delirium as a predictor of mortality in mechanically ventilated patients in the intensive care unit. J Am Med Assoc 291:1753-1762

7. Ely E, Inouye SK, Bernard GR, Gordon S, Francis J, May L, Truman B, Speroff T, Gautam S, Margolin R, Hart RP, Dittus R (2001) Delirium in mechanically ventilated patients: validity and reliability of the confusion assessment method for the intensive care unit (CAM-ICU). J Am Med Assoc 286:2703-2710

8. Jacobi J, Fraser GL, Coursin DB, Riker RR, Fontaine D, Wittbrodt ET, Chalfin DB, Masica MF, Bjerke HS, Coplin WM, Crippen DW, Fuchs BD, Kelleher RM, Marik PE, Nasraway Jr SA, Murray MJ, Peruzzi WT, Lumb PD (2002) Clinical practise guidelines for the sustained use of sedatives and analgesics in the critically ill adult. Crit Care Med 30:119-141

9. Andrews P, Azoulay E, Antonelli M, Brochard L, Brun-Buisson C, Dobb G, Fagon J, Gerlach H, Groeneveld J, Mancebo J, Metnitz P, Nava S, Pugin J, Pinsky M, Radermacher P, Richard C, Tasker R, Vallet B (2005) Year in review in intensive care medicine, 2004. III. Outcome, ICU organisation, scoring, quality of life, ethics, psychological problems and communication in the ICU, immunity and hemodynamics during sepsis, pediatric and neonatal critical care, experimental studies. Intensive Care Med 31:356-372
10. Martini RC (2005) Commentary: The diagnosis of delirium in pediatric patients. J Am Acad Child Adolesc Psychiatry 44:395-398

11. Schieveld JNM, Leentjens AFG (2005) Delirium in severely ill young children in the pediatric intensive care unit. J Am Acad Child Adolesc Psychiatry 44:392-394

12. Turkel SB, Trzepacz PT, Tavare CJ (2006) Comparing symptoms of delirium in adults and children. Psychosomatics 47:320-324

13. Turkel SB, Tavare CJ (2003) Delirium in children and adolescents. J Neuropsychiatry Clin Neurosci 15:431-435

14. Tobias JD (1999) Sedation and analgesia in pediatric intensive care units: a guide to drug selection and use. Pediatr Drugs 1:109-126

15. Tobias JD (2000) Tolerance, withdrawal, and physical dependency after long-term sedation and analgesia of children in the pediatric intensive care unit. Crit Care Med 28:2122-2132

16. Anand KJ, Arnold JH (1996) Opioid tolerance and dependence in infants and children. Crit Care Med 22:334-342

17. Lishman WA (1998) Cardinal psychological features of cerebral disorder. In: Lishman WA (ed) Organic psychiatry: the psychological consequences of cerebral disorder, 3rd edn. Blackwell Science, Oxford, vol 8, pp 3-20

18. Cole M, McCusker J, Dendukuri N, Han L (2003) The prognostic significance of subsyndromal delirium in elderly medical inpatients. J Am Geriatr Soc 51:754-760

19. Lipowski ZV (1990) Delirium. Acute confusional state. Oxford University Press, New York

20. Gemke RJ, van Vught J (2002) Scoring systems in pediatric intensive care: PRISM III versus PIM. Intensive Care Med 28:204-207

21. Nederlandse Vereniging voor Psychiatrie (2004) Richtlijn Delirium. Uitgeverij Boom, Amsterdam

22. Brown RL, Henke A, Greenhalgh DG, Warden GD (1996) The use of haloperidol in the agitated, critically ill pediatric patient with burns. J Burn Care Rehabil 17:34-38

23. Harrison AM, Lugo RA, Lee WE, Appachi E, Bourdakos D, Davis SJ, McHugh MJ, Weise KL (2002) The use of haloperidol in agitated, critically ill children. Clin Pediatr 41:51-54
24. Williams DT (2002) Neuropsychiatric signs, symptoms, and syndromes. In: Lewis M (ed) Child and adolescent psychiatry, a comprehensive textbook. Lippincott Williams \& Wilkins, Philadelphia, pp 399-404

25. Inouye SK, Bogardus ST, Williams CS, Leo-Summers L, Agostini JV (2003) The role of adherence on the effectiveness of non-pharmacologic interventions. Arch Intern Med 163:958-964

26. Weiss M, Weiss G (2002) Attention deficit hyperactivity disorder. In: Lewis M (ed) Child and adolescent psychiatry, a comprehensive textbook. Lippincott Williams \& Wilkins, Philadelphia, pp 645-670

27. Bergeron N, Skrobik YK, Dubois MJ (2005) Is disturbance of consciousness an important feature of ICU delirium? Intensive Care Med 31:887

28. Quimet S, Kavanagh BP, Gottfried SB, Skrobik Y (2007) Incidence, risk factor and consequences of ICU delirium. Intensive Care Med 33:66-73

29. Stoddard FJ, Wilens TE (1995) Delirium. In: Jellinek MS, Herzog DB (eds) Psychiatric aspects of general hospital pediatrics. Yearbook, Chicago, pp 254-259

30. Sikich N, Lerman J (2004) Development and psychometric evaluation of the pediatric anesthesia emergence delirium scale. Anesthesiology 100:1138-1145

31. Wise MG (1987) Delirium. In: Hales RE, Yudofsky SC (eds) Textbook of neuropsychiatry. The American Psychiatric Press, Washington, DC pp 89-105

32. Trzepacz PT, Meagher DJ (2005) Delirium. In: Levinson JL (ed) Textbook of psychosomatic medicine. American Psychiatric Publishing, Washington, DC, pp 92-130

33. Schieveld JNM (2005) Case reports with a child psychiatric exploration of catatonia, autism, and delirium. In: Dhossche DM, Wing L, Ohta M, Neumarker K (eds) Catatonia in autism spectrum disorders. International review of neurobiology, vol 72. Elsevier Academic Press, Amsterdam, pp 195-206

34. Carlson GA (2002) Clinical aspects of child and adolescent psychopharmacology. In: Kutcher S (ed) Practical child and adolescent psychopharmacology. Cambridge University Press, Cambridge, pp 70-90 
35. Lynn D, King BH (2002) Aggressive behavior. In: Kutcher S (ed) Practical child and adolescent psychopharmacology. Cambridge University Press Cambridge, pp 305-327
36. Hill P (2005) Off licence and off label prescribing in children: litigation fears for physicians. Arch Dis Child 90 [Suppl 1]:i17-i18
37. Ratcliff SL, Meyer WJ, Cuervo LJ, Villarreal C, Thomas CR, Herndon DN (2004) The use of Haloperidol and associated complications in the agitated, acutely ill pediatric burn patient. J Burn Care Rehabil 25:472-478 


\section{CHAPTER 6}

Pediatric illness severity measures predict delirium in a pediatric intensive care unit

By: Jan Schieveld, Richel Lousberg, Eline Berghmans, Inge Smeets,

Piet Leroy, Gijs Vos, Joost Nicolai, Albert Leentjens and Jim van Os.

Revised and resubmitted 
Abstract

Context: Delirium in children is a serious but understudied neuropsychiatric disorder. As a consequence, there is little to guide the clinician in terms of identifying those at risk.

Objective: To study, in a pediatric intensive care unit (PICU), the predictive power of widely used generic pediatric mortality scoring systems in relation to the occurrence of pediatric delirium (PD).

Design and methods: Four-year prospective observational study, 2002 - 2005. Predictors used were the Pediatric Index of Mortality (PIM) and Pediatric Risk of Mortality (PRISM II).

Setting: A tertiary 8-bed PICU in the Netherlands.

Patients: 877 critically ill children who were, acutely, non-electively and consecutively admitted.

Main outcome measure: Pediatric delirium.

Main results: Out of 877 children with mean age 4.4 years, 40 were diagnosed with PD (Cumulative incidence: $4.5 \%$ ), $85 \%$ of whom (versus $40 \%$ in the non-delirium group) were mechanically ventilated. The area under the curve of the receiver operator characteristic curve of the PIM was 0.70 , and of the PRISM II 0.73 , with optimal cut-off points around the median value. A PIM or PRISM II score above the median was strongly associated with later $P D$ in terms of relative risk (PIM: OR=9.1; 95\% Cl: 3.2 - 26.0; PRISM II: OR=19.7; 95\% Cl: 4.7 - 82.2), with lower values for positive predictive value (PIM: $7.8 \%$; PRISM II: $8.2 \%$, rising to respectively $10.2 \%$ and $10.7 \%$ in mechanically ventilated patients) but high values for negative predictive value (PIM: 99.1\%; PRISM II: 99.6\%). 
Limitations: Given the relatively low incidence of delirium, a low detection rate biased towards the most severe cases cannot be excluded.

Conclusions: Given the fact that PIM and PRISM II are widely used generic pediatric mortality scoring instruments in PICU settings, prospective associations with PD, particularly in mechanically ventilated children, suggest additional value for ruling in, or out, patients at risk of PD.

Introduction

Delirium is a serious neuropsychiatric disorder caused by a general medical condition or its treatment and characterized by an acute onset, fluctuating disturbances of consciousness and cognitive disturbances (American Psychiatric Association, 2000). It is frequently seen in critically ill adult patients, associated with a poorer prognosis of the primary disorder, longer hospital stay, higher mortality rate and a worse functional outcome, especially in patients who are also mechanically ventilated (Ely, Shintani et al., 2004; Leentjens \& Van der Mast, 2005). In critically ill adult patients, incidences have been reported ranging from $10-30 \%$ in a general hospital setting, to $50 \%$ in postoperative patients and up to $80 \%$ in the terminally ill. The systematic screening for delirium and its appropriate treatment in critical illness were recently included in the clinical practice guidelines for sedatives and analgesia of the Society of Critical Care Medicine (Jacobi, Fraser et al., 2002). The search for risk factors is therefore a key concern. Known risk factors in adult and elderly patients are: severe illness, any medical procedure, exposure to medication, notably polypharmacy, malnutrition and dehydration (Kalisvaart, 2005; Trzepacz \& Meagher, 2005).

There is an emerging literature on pediatric delirium (PD), as evidenced by, for example, the papers from Sikich and Lerhman (2004) regarding the PAED 
(Paediatric Anesthesia Emerging Delirium) scale and of Kain, Caldwell - Andrews et al. (2007) regarding treatment of peri-operative discomfort in children. These last authors reported a reduction of post-operative emerging delirium in children from $24 \%$ in the control group to just $10 \%$ in the intervention group. However, PD in critical illness in a PICU (Pediatric Intensive Care Unit) context is an understudied area. Two papers reported PD incidences of at least 4\% (Larsen, Donaldson et al., 2007) and $4.5 \%$ (Schieveld, Leroy et al., 2007). However, little is known about risk factors for this condition. Given the fact that many routine illness severity measures are used in pediatrics, an efficient way to expand the possibilities to make a quantitative judgment about the risk of pediatric delirium (PD) is to focus on such existing measures in the first instance. The aim of the current study, therefore, was to assess whether two routinely used illness severity indicators, the Pediatric Index of Mortality (PIM) and the Pediatric Risk of Mortality (PRISM II), are of value in the risk assessment and diagnosis of pediatric delirium (Gemke \& van Vught, 2002; Vos, 2004), hypothesizing that higher PIM and PRISM II values would be associated with greater risk for PD. The rationale for this was that delirium is strongly associated with critical illness, and critical illness, in turn, is strongly associated with death (American Psychiatric Association, 1999; Ely, Shintani et al., 2004). Therefore, in critically ill children, mortality risk assessment can logically be hypothesized to contribute to the prediction of delirium as well. Similarly, given the strong association between critical illness, the need for mechanical ventilation and the onset of delirium in adults, the predictive power of PIM and PRISM II were examined in relation to mechanical ventilation as well (Ely, Shintani et al., 2004; Ouimet, Kavanagh et al., 2007).

Methods 
Design, setting and patients

An observational study was carried out over a 4-year period (January 2002 to December 2005) in an eight-bed PICU. This PICU is a tertiary referral center for both general and surgically critically ill children in the South-East of the Netherlands (population: 1.4 million inhabitants, 350 annual admissions). Critically ill children, acutely, non-electively and consecutively admitted, were enrolled. Both mechanically ventilated and non-ventilated patients were included. The PIM and PRISM II were scored by the attending pediatric intensivist. Both PIM and PRISM II are widely used in assessing the severity of illness and the associated risk of mortality in critically ill children (Vos, 2004) and generally accepted for use in mortality risk prediction models for critically ill pediatric patients. The PRISM is based on 14 routinely measured clinical and laboratory parameters, with for each parameter an abnormal range. The most abnormal value in the first 24 hours following admission on the PICU contributes to this score. Every parameter, scored in the range of abnormal values, has a weighted contribution to the PRISM score leading to a predicted mortality. The PIM is also based on clinical and laboratory parameters assessed in the first hour after admission on the intensive care. Both scores are obtained from data pertaining to vital signs and laboratory results that are stored in the hospital information system, the bedside monitors and the intensive care nursing lists. The items making up the scores of PIM and PRISM II are assessed in real time and so the question of blinding is not an issue given the delay in onset of delirium (vide infra). PIM and PRISM II scores in the Netherlands are scored for all children at the PICU and checked by a paediatric intensivist before being sent to a national data base.

Several studies have shown useful predictive characteristics for morbidity and mortality as evidenced by receiver operator characteristic areas under the curve for 
mortality from 0.82 to 0.95 , with one study showing a positive predictive value of the PRISM II of 51\% (Choi, Wong et al., 2005; Kennedy \& Aoki, 2002; Kim \& Boo, 2005; Leteurtre, Leclerc et al., 2007; Martha, Garcia et al., 2005; Ozer, Kizilgunesler et al., 2004).

\section{Diagnostic approach}

Children who required analgosedation because of obvious or expected pain or stress related to their underlying disease or treatment, were treated in accordance with internationally published guidelines for analgesia and sedation in critically ill children. First choice of drug combination was midazolam and morphine. In some patients, ketamine or propofol was used (Tobias, 1999). Drug doses were individually tailored to achieve optimal patient comfort and were slowly reduced in order to avoid withdrawal syndromes. In case a withdrawal syndrome was suspected, specific treatment with long acting benzodiazepines (e.g. lorazepam) or opioids (e.g. methadone) was started, following internationally published guidelines (Anand \& Arnold, 1996; Tobias, 2000). At the time of the assessment for delirium, none of the children had signs of imminent life threatening respiratory, circulatory or neurological failure, while ongoing asphyxia, respiratory acidosis, metabolic disturbances and "fighting the ventilator" all had been excluded systematically as an explanation for the observed behavior.

Thus all children with unexplained i) confusion, agitation, anxiety, moaning, discomfort, or behavioral disturbance or ii) failure of standard analgosedative treatment are routinely referred by the pediatric intensivists for systematic assessment of delirium by the child neuropsychiatrist. In case of suspicion and/or recognition of delirium and referral to a child psychiatrist, a two-step approach towards diagnosis was used. The first step was a systematic assessment by a child 
neuropsychiatrist using DSM-IV criteria for delirium. Criteria were assessed on the basis of (1) hetero-anamnestic information from parents, nurses, intensivists and child neurologists about behavior and behavioral changes and (2) child psychiatric examination. On the basis of these assessments, patients were categorized as having a (probable) delirium or not. In a second step, the provisional diagnosis was further tested in the multidisciplinary team which held a daily diagnostic consensus meeting. The team consisted of the child neuropsychiatrist, the attending pediatric intensivist and occasionally a neuropsychiatrist and/or a child neurologist. If this team agreed that alternative explanations for a child's behavior were unlikely, the child's consensus diagnosis was delirium (Schieveld, Leroy et al., 2007). As the study solely involved the structured recording of routine clinical practice, under Dutch law no institutional review board approval was required.

\section{Statistical approach}

The data were analyzed using STATA, version 9.2. Children with and without delirium were compared on demographic and clinical characteristics. As the population of patients with delirium $(n=40)$ was much smaller than the population of patients without delirium $(n=837)$, a comparison of these two groups would be overpowered statistically. Therefore, a random sample of 160 patients from the group of patients without delirium was selected and compared with the patients with a delirium.

As both PIM and PRISM II are expressed as continuous scores of clinical and laboratory data, many cut-offs can be chosen to determine its predictive power in relation to PD. For ease of interpretation, PIM and PRISM II scores were divided by their quartiles in order to create continuous quartile scores for each, followed by construction of receiver operating characteristic (ROC) curves for quartile scores. 
ROC curves allows for exploration of the relationship between the sensitivity and specificity of a continuous predictor and a dichotomous outcome (in this case delirium) (Murphy, Berwick et al., 1987). Cut-off scores for optimal sensitivity or specificity, or for optimal discrimination (highest sum of sensitivity and specificity) can be inferred from the curve. In addition, the positive predictive value (PPV) and negative predictive value (NPV) for the later development of delirium were calculated, as well as the likelihood ratio for a positive test result (the ratio of the probabilities of the true positives to false positives of a diagnostic test). Finally, odds ratios were calculated for the development of delirium, comparing patients with PIM and PRISM II scores above the median, with those with scores below the median.

Results

\section{Sample and PD group characteristics}

Out of 877 cases (mean age: 4.4 years, SD=4.9; boys: $60 \%$; see Table 1 for population characteristics) 61 were referred to the child psychiatrist, and in 55 cases this was because of emotional and/or anxiety and/or behavioral problems. 40 developed PD, yielding a cumulative incidence of $4.5 \%$. Based on the dominant clinical presentation there were: 14 hyperactive types, 9 hypoactive types and 17 emerging - subsyndromal types (Schieveld, Leroy et al., 2007). Delirium was diagnosed after a median time of 5 days after admission (inter quartile range: 3 - 17 days). 
Table 1. Population characteristics of the 877 acute, non-elective admitted cases to the PICU from January 2002 to December 2005

\begin{tabular}{|c|c|c|c|c|c|}
\hline Characteristics & $\begin{array}{l}\text { Patients } \\
\text { with delirium } \\
n=40\end{array}$ & $\begin{array}{l}\text { Patients } \\
\text { without } \\
\text { delirium } \\
n=837\end{array}$ & $\begin{array}{l}\text { Significance } \\
\text { level }\end{array}$ & $\begin{array}{l}\text { Mean } \\
\text { difference }\end{array}$ & $\begin{array}{l}95 \% \mathrm{Cl} \\
\text { of the } \\
\text { difference }\end{array}$ \\
\hline $\begin{array}{l}\text { Age in years (mean } \\
\pm \text { SD) } \\
\text { Male (n) } \\
\text { Female (n) } \\
\text { Mechanical } \\
\text { ventilation (n) } \\
\text { PIM score (mean } \pm \\
\text { SD) score } \\
\text { PRISM PICU } \\
\text { (mean } \pm \text { SD) } \\
\text { Mortality (n) } \\
\text { Primary } \\
\text { indication }{ }^{\text {b }} \\
\text { Neurological } \\
\text { disorder } \\
\text { Respiratory } \\
\text { disorder } \\
\text { Circulatory } \\
\text { disorder } \\
\text { Multiple } \\
\text { trauma } \\
\text { Post } \\
\text { surgical } \\
\text { Combined } \\
\text { Metabolic } \\
\text { disorder }\end{array}$ & \begin{tabular}{|l|}
$7.7 \pm 5.8$ \\
$25(62,5 \%)$ \\
$15(27,5 \%)$ \\
$34(85 \%)$ \\
$9.96 \pm 16.21$ \\
23.54 \\
24.94 \\
$5(12,5 \%)$
\end{tabular} & $\begin{array}{l}4.2 \pm 4.7 \\
496 \\
(59,3 \%) \\
340 \\
(40,6 \%) \\
333 \\
(39,8 \%) \\
6.99 \quad \pm \\
14.24 \\
13.37 \\
23.24 \\
36(4.3 \%) \\
\\
159(19.0 \%) \\
434 \\
(51.9 \%) \\
138 \\
(16.5 \%) \\
17(2.0 \%) \\
55(6.6 \%) \\
\\
22(2.6 \%) \\
12(1.4 \%)\end{array}$ & $\begin{array}{l}P<0.0005 \\
P=0.211 \\
P=0.009 \\
P=0.016^{a}\end{array}$ & $\begin{array}{l}2.98 \\
10.16\end{array}$ & $\begin{array}{l}-1.69 \\
7.64 \\
2.58 \\
17.75\end{array}$ \\
\hline $\begin{array}{l}\text { Mean length of } \\
\text { PICU stay }\end{array}$ & $\begin{array}{ll}17.66 & \pm \\
21.41 & \\
\end{array}$ & $\begin{array}{ll}10.63 & \pm \\
54.67 & \\
\end{array}$ & $P=0.430$ & 7.02 & $\begin{array}{l}-10.45 \\
24.50 \\
\end{array}$ \\
\hline
\end{tabular}

PIM, Pediatric Index of Mortality; PRISM, Pediatric Risk of Mortality; PICU, Pediatric Intensive Care Unit; Combined, a combination of different types of disorders

a $25 \%$ of the cells have an expected count less than 5

${ }^{\mathrm{b}}$ Due to small numbers a significance - test is not possible

Respiratory disorders: upper-/lower airway obstruction, pneumonia, ARDS (Acute Respiratory Distress Syndrome)

Neurological disorders: TBI (Traumatic Brain Injury), meningo-encepahalitis, status epilepticus, ADEM (Acute Disseminated Encephalo-Myelitis)

Circulatory disorders: septic shock, hypovolaemic shock, cardiomyopathy / myocarditis Metabolic disorders: diabetic acidosis, inborn errors.

Multiple trauma:

a combination of bone fracture(s)/intra abdominal-/intra thoracic trauma/TBI.

Combined: a combination of different other types of primary disorders. 
Patients with delirium, compared to those without (Table 2) were older, of similar sex distribution and much more likely to have received mechanical ventilation. Both PIM and PRISM II scores were higher in the delirium group and the delirium group had a much longer stay than patients without a delirium episode (Table 2).

Table 2. Comparison of patients with a delirium episode and patients without a delirium episode

\begin{tabular}{|c|c|c|c|c|c|}
\hline Characteristics & $\begin{array}{l}\text { Patients } \\
\text { with } \\
\text { delirium } \\
n=40\end{array}$ & $\begin{array}{l}\text { Patients } \\
\text { without } \\
\text { delirium } \\
\mathrm{n}=160\end{array}$ & $\begin{array}{l}\text { Significance } \\
\text { level }\end{array}$ & $\begin{array}{l}\text { Mean } \\
\text { difference }\end{array}$ & $\begin{array}{l}95 \% \mathrm{Cl} \\
\text { of the } \\
\text { difference }\end{array}$ \\
\hline $\begin{array}{l}\text { Age in years (mean } \pm \\
\text { SD) } \\
\text { Male (n) } \\
\text { Female (n) } \\
\text { Mechanical ventilation } \\
\text { (n) } \\
\text { PIM score (mean } \pm \\
\text { SD) } \\
\text { PRISM score (mean } \pm \\
\text { SD) PICU } \\
\text { Mortality (n) } \\
\text { Primary } \\
\text { indication }{ }^{b} \\
\quad \text { Neurological } \\
\text { disorder } \\
\text { Respiratory } \\
\text { disorder } \\
\text { Circulatory } \\
\text { disorder } \\
\text { Multiple } \\
\text { trauma } \\
\text { Post surgical } \\
\text { Combined } \\
\text { Metabolic } \\
\text { disorder }\end{array}$ & $\begin{array}{ll}7.68 & \pm \\
5.78 \\
25 \\
(62.5 \%) \\
15 \\
(27.5 \%) \\
34(85 \%) \\
\\
9.96 \\
16.21 \\
23.54 \\
24.94 \\
5(12,5 \%) \\
\end{array}$ & $\begin{array}{|lr|}4.04 & \pm \\
4.78 & \\
91 & \\
(56.9 \%) & \\
69 & \\
(43.1 \%) & \\
59 & \\
(36.9 \%) & \\
5.26 & \pm \\
9.87 & \\
11.89 & \pm \\
21.85 & \\
7(4.4 \%) & \end{array}$ & $\begin{array}{l}P<0.0005 \\
P=0.023 \\
P=0.005 \\
P=0.163^{a}\end{array}$ & $\begin{array}{l}4.70 \\
11.65\end{array}$ & $\begin{array}{l}0.64-8.76 \\
3.63 \\
19.67\end{array}$ \\
\hline $\begin{array}{l}\text { Mean length of PICU } \\
\text { stay }\end{array}$ & $\begin{array}{l}17.66 \quad \pm \\
21.41\end{array}$ & $\begin{array}{|ll|}6.48 & \pm \\
10.43 & \end{array}$ & $P=0.003$ & 11.18 & $\begin{array}{l}3.98 \\
18.39\end{array}$ \\
\hline
\end{tabular}

PIM, Pediatric Index of Mortality; PRISM, Pediatric Risk of Mortality; PICU, Pediatric Intensive Care Unit; Combined, a combination of different types of disorders

a $25 \%$ of the cells have an expected count less than 5

${ }^{\mathrm{b}}$ Due to small numbers a significance - test is not possible. 
Respiratory disorders: upper-/lower airway obstruction, pneumonia, ARDS (Acute Respiratory Distress Syndrome )

Neurological disorders: TBI (Traumatic Brain Injury), meningo-encepahalitis, status epilepticus, ADEM (Acute Disseminated Encephalo-Myelitis)

Circulatory disorders: septic shock, hypovolaemic shock, cardiomyopathy/myocarditis metabolic disorders: diabetic acidosis, inborn errors.

Multiple trauma:

a combination of bone fracture(s)/intra abdominal- /intra thoracic trauma/TBI.

Combined: $\quad$ a combination of different other types of primary disorders.

PIM and PRISM II in relation to PD

Median scores on the PIM and PRISM II were 1.8 and 2.9 respectively. The PIM and

PRISM II scores were moderately correlated (Pearson $r=0.64$ ), suggesting a moderate amount of overlap between the two scales. For both PIM and PRISM II, the ROC curve suggested an optimal discrimination between patients at risk of subsequent PD and those not at risk at scores around the median (Fig. 1 and 2), with likelihood ratio values of 1.9 and 2.0 respectively.

Fig. 1 ROC curve PIM, using PIM quartile groups

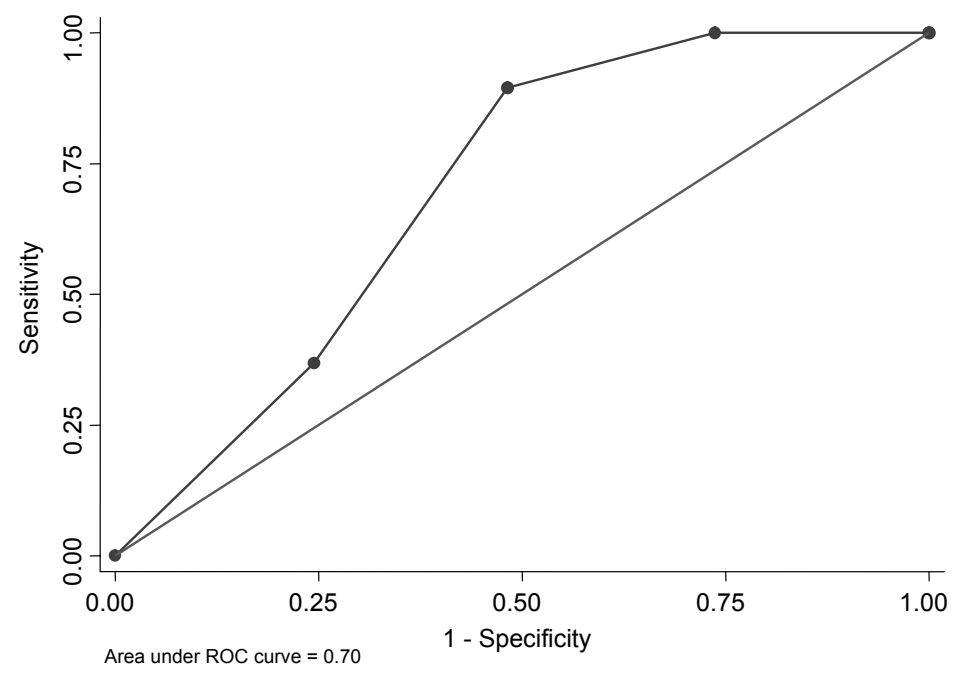


Fig. 2 Roc curve PRISM II, using PRISM II quartile groups

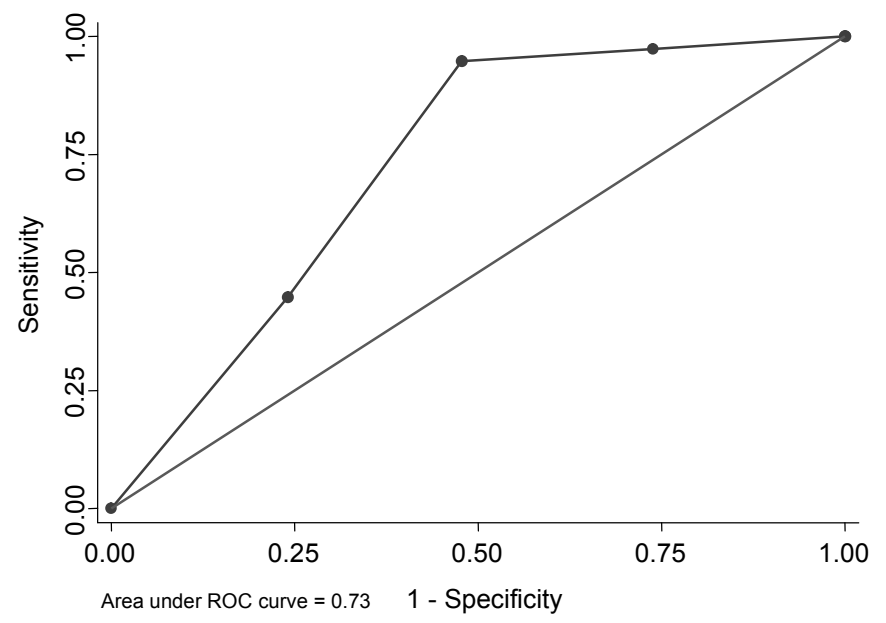

Dichotomizing PIM and PRISM II scores around the median value revealed strong associations in terms of relative risk for PD (PIM: OR= 9.1; 95\% $\mathrm{Cl}=3.2-26.0$; PRISM II: OR $=19.7,95 \% \mathrm{Cl}=4.7-82.2$ ) with a low positive predictive value (PPV; PIM: 7.8\%; PRISM II: 8.2\%) and a high negative predictive value (NPV; PIM: 99.1\%; PRISM II: 99.6\%). In the mechanically ventilated patients, the PPVs for PIM and PRISM II were slightly higher at $10.2 \%$ and $10.7 \%$ respectively.

\section{Discussion}

This is the first systematic study of disease severity as a risk factor for PD, using PIM and PRISM II, two frequently used generic disease severity scales for children, as an indicator. ROC curves showed AUCs of 0.70 and of 0.73 respectively, which can be characterized as "fair" in terms of diagnostic prediction. The NPVs for the median PIM and PRISM II scores, at 99\%, were very high, indicating that PIM and PRISM II can be used to predict non-occurrence of, or rule out risk of, delirium. The PPV, 
however, was low (PIM: 7.8\%; PRISM II: 8.2\%), indicating that in terms of positive prediction the value of PIM and PRISM II is limited, although still useful as general risk indicators. This is confirmed by the relative low likelihood ratio's that did not exceed 2.0: as a test for predicting future cases, PIM and PRISM II were only twice as likely to yield a true positive case relative to a false positive result. The optimal cut-off points for PIM and PRISM II cut the patient population in half. The results therefore, indicate that about 1 in 2 PICU patients is not at risk for developing delirium, based only on PIM/PRISM II scores. We conclude that although in terms of absolute prediction the PPVs were low, the high ORs, the seriousness of PD and the frequent difficulties in making the right clinical decision suggest that it certainly is worthwhile to employ PIM and PRISM II scores in the risk assessment of PD, particularly in the presence of mechanical ventilation. We hypothesize that ROC curves using APACHE scores (Acute Physiology and Chronic Health Evaluation the adult equivalent for PIM/PRISM II scores) could similarly be of value in predicting delirium in adult and elderly patients (Cho \& Wang, 1997; Knaus, Draper et al., 1985). Thus, Ouimet and colleagues recently stated: '...the higher APACHE II scores may account for the higher incidence of delirium' (Ouimet, Riker et al., 2007).

\section{Limitations}

This study has some limitations. First, it was an observational study, uncontrolled and making use of routine assessments rather than dedicated research appraisals. This, however, was also an advantage as the values reported in this paper reflect those that would be found with the use of PIM and PRISM II in routine clinical practice. A second limitation is that the incidence of delirium in our study was very low. Detection depended on routine referrals to the child psychiatrist and not on systematic 
prospective assessment of all admissions. The low incidence may have been the result of under detection of delirium. If this is the case, there may be a bias towards better recognition of more severe PD. Also, the DSM (Diagnostic and Statistical Manual) criteria for delirium, which were used in this study next to other ones, are in some ways not suitable for a pediatric population, and this is especially so in a PICU (Pediatric Intensive Care Unit) context (Schieveld, Leroy et al., 2007). The DRS (Delirium Rating Scale) and, once published in 2004, and the PAED (Pediatric Anesthesia Emergence Delirium) scale have both been used in the PICU. Both can be of help, but the DRS sometimes was of limited use given the specific PICU context and the very young age of the children. Hence, diagnosis was as much as possible based on DSM criteria, but also involved consensus on aspects that cannot always be easily interpreted or categorized (Schieveld, Leroy et al., 2007). 


\section{References}

American Psychiatric Association (1999). "Practice guidelines for the treatment of patients with delirium." American Journal of Psychiatry 5(156 (suppl. 5)): 1-20.

American Psychiatric Association (2000). Diagnostic and statistical manual of mental disorders. 4th edition text, revision (DSM-IV-TR). Washington DC, American Psychiatric Association.

Anand, K.J., Arnold, J.H. (1996). Opioid tolerance and dependence in infants and children. Critical Care Medicine 22(2):334-42

Cho, D.Y. and Wang, Y.C. (1997). "Comparison of the APACHE III, APACHE II and Glasgow Coma Scale in acute head injury for prediction of mortality and functional outcome." Intensive Care Medicine 23(1): 77-84.

Choi, K.M., Ng, D.K., Wong, S.F., Kwok, K.L., Chow, P.Y., Chan, C.H. and Ho, J.C. (2005).

"Assessment of the Pediatric Index of Mortality (PIM) and the Pediatric Risk of Mortality (PRISM) III score for prediction of mortality in a pediatric intensive care unit in Hong Kong." Hong Kong Med J 11(2): 97-103.

Ely, E.W., Shintani, A., Truman, B., Speroff, T., Gordon, S.M., Harrell Jr, F.E., Inouye, S.K., Bernard, G.R. and Dittus, R.S. (2004). "Delirium as a predictor of mortality in mechanically ventilated patients in the intensive care unit." J Am Med Assoc(291): 1753-1762.

Gemke, R.J. and van Vught, J. (2002). "Scoring systems in pediatric intensive care: PRISM III versus PIM." Intensive Care Medicine 28(2): 204-7.

Jacobi, J., Fraser, G.L., Coursin, D.B., Riker, R.R., Fontaine, D., Wittbrodt, E.T., Chalfin, D.B., Masica, M.F., Bjerke, H.S., Coplin, W.M., Crippen, D.W., Fuchs, B.D., Kelleher, R.M., Marik, P.E., Nasraway Jr, S.A., Murray, M.J., Peruzzi, W.T. and Lumb, P.D. (2002). "Clinical practise guidelines for the sustained use of sedatives and analgesics in the critically ill adult." Critical Care Medicine: 119-141.

Kain, Z.N., Caldwell-Andrews, A.A., Mayes, L.C., Weinberg, M.E., Wang, S.M., MacLaren, J.E., Blount, R.L. (2007). Family-centered preparation for surgery improves perioperative outcomes in children. Anesthesiology 106(1):65-74

Kalisvaart, C.J. (2005). Primary prevention of delirium in the elderly. Amsterdam, PhD Thesis, Universiteit van Amsterdam, The Netherlands: 160. 
Kennedy, C.E. and Aoki, N. (2002). "Generating a mortality model from a pediatric ICU (PICU) database utilizing knowledge discovery." Proc AMIA Symp: 375-9.

Kim, J.S. and Boo, S.J. (2005). "Evaluating the validity of the Pediatric Index of Mortality II in the intensive care units." Taehan Kanho Haktoe Chi 35(1): 47-55.

Knaus, W.A., Draper, E.A., Wagner, D.P. and Zimmerman, J.E. (1985). "APACHE II: a severity of disease classification system." Critical Care Medicine 13(10): 818-829.

Larsen, G.Y., Donaldson, A.E., Parker, H.B., Grant, M.J.C. (2007) Preventable harm occuring to critically ill children. Pediatric Critical Care Medicine 8(4):331-336.

Leentjens, A.F.G. and Van der Mast, R.C. (2005). "Delirium in the elderly; an update." Current Opinion in Psychiatry 18: 325-330.

Leteurtre, S., Leclerc, F., Wirth, J., Noizet, O., Magnenant, E., Sadik, A., Fourier, C. and Cremer, R. (2004). "Can generic pediatric mortality scores calculated 4 hours after admission be used as inclusion criteria for clinical trials?" Critical Care Medicine 8(4): R185-93.

Martha, V.F., Garcia, P.C., Piva, J.P., Einloft, P.R., Bruno, F. and Rampon, V. (2005). "Comparison of two prognostic scores (PRISM and PIM) at a pediatric intensive care unit." J Pediatric (RIO J) 81(3): 259-64.

Murphy, J.M., Berwick, D.M., Weinstein, M.C., Borus, J.F., Budman, S.H. and Klerman, G.L. (1987). "Performance of screening and diagnostic tests; application of receiver operator characteristics analysis." Arch Gen Psychiat 44: 550-555.

Ouimet, S., Kavanagh, B.P., Gottfried, S.B. and Skrobik, Y.K. (2007). "Incidence, risk factors and consequences of ICU delirium." Intensive Care Medicine 33(1): 66-73.

Ouimet, S., Riker, R.R., Bergeron, N., Cossette, M., Kavanagh, B.P., Skrobik, Y.K. (2007) Subsyndromal delirium in the ICU: evidence for a disease spectrum. Intensive Care Medicine 33:1007-1013.

Ozer, E.A., Kizilgunesler, A., Sarioglu, B., Halicioglu, O., Sutcuoglu, S. and Yaprak, I. (2004). "The comparison of PRISM and PIM scoring systems for mortality risk in infantile intensive care." J Trop Pediatr 50(6): 334-8.

Schieveld, J.N.M., Leroy, P.L.J.M., van Os, J.J., Nicolai, J., Vos, G.D. and Leentjens, A.F.G. (2007). "Pediatric delirium in critical illness: phenomenology, clinical correlates and treatment response in 40 cases at the pediatric intensive care unit." Intensive Care Medicine 33: 10331040. 
Sikich, N., Lerman, J. (2004). Development and psychometric evaluation of the pediatric anesthesia emergence delirium scale. Anesthesiology (100):1138-45.

Tobias, J.D. (1999). Sedation and analgesia in pediatric intensive care units: a guide to drug selection and use. Pediatric Drugs 1(2):109-126.

Tobias, J.D. (2000). Tolerance, withdrawal, and physical dependency after long-term sedation and analgesia of children in the pediatric intensive care unit. Critical Care Medicine 28(6):2122-32.

Trzepacz, P.T. and Meagher, D.J. (2005). Delirium. Textbook of Psychosomatic Medicine. Levinson, J.L. Washington DC, The American Psychiatric Publishing: 92-130.

Vos, G. (2004). Pediatric interhospital intensive care transport in The Netherlands: current situation and future perspectives. Maastricht, Universiteit Maastricht. 


\title{
CHAPTER 7
}

A comparison of the phenomenology of pediatric, adult, and geriatric delirium

\author{
By: A. Leentjens, J. Schieveld, M. Leonhard, R. Lousberg, \\ F. Verhey and D. Meagher.
}

Accepted for publication by the Journal of Psychosomatic Research 
Abstract

Background: The phenomenology of delirium in childhood is understudied.

Objective: To compare the phenomenology of delirium in children, adults and geriatric patients.

Population and methods: 46 children (mean age 8.3, SD 5.6, range 0 to 17 years (inclusive)), admitted to the paediatric intensive care unit (PICU) of Maastricht University Hospital, with DSM IV delirium underwent assessment with the Delirium Rating Scale (DRS). The scores are compared with those of 49 adult (mean age 55.4 , SD 7.9 , range 18 to 65 years) and 70 geriatric patients (mean age 76.2, SD 6.1, range 66 to 91 years) with DSM-IV delirium, occurring in a palliative care Unit. Score profiles across groups, as well as differences in individual item scores across groups are analysed with MANOVA, applying a Bonferroni correction.

Results: Although the range of symptoms occurring in all three groups was similar, DRS score profiles differ significantly across the three groups (Wilks Lambda = $0.019, F=804.206, p<0.001)$. On item level, childhood delirium is characterized by a more acute onset, more severe perceptual disturbances, more frequent visual hallucinations, more severe delusions, more severe lability of mood, greater agitation, less severe cognitive deficits, less severe sleep-wake cycle disturbance, and less variability of symptoms over time. Adult and geriatric delirium do not differ in their presentations, except for the presence of more severe cognitive symptoms in geriatric delirium $(p=0.001)$.

Conclusion: Childhood delirium has a different course and symptom profile than adult and geriatric delirium. Adult and geriatric delirium differ only in the severity of cognitive symptoms. 
Introduction

Delirium is a complex neuropsychiatric syndrome that frequently complicates physical illness and negatively impacts upon prognosis. It is associated with longer hospital stay, poorer functional outcome and cognitive decline (Leentjens \& Van der Mast, 2005; Trzepacz \& Meagher, 2005) in addition to an elevated morbidity and mortality that is at least in part independent of underlying medical morbidity and premorbid cognitive status (Inouye, Rushing et al., 1998; McCusker, Cole et al., 2002; McCusker, Cole et al., 2003). Moreover, delirium is recognised as a source of considerable patient and family distress (Breitbart, Gibson et al., 2002; Morita, Hirai et al., 2004). Even though the importance of adequate detection and management of delirium in hospitals is increasingly recognized, studies of phenomenology, aetiology and treatment of delirium are still scarce. Delirium in children remains a particularly neglected area (Schieveld \& Leentjens, 2005) even though childhood delirium also appears associated with longer hospital stay and higher mortality (Turkel \& Tavare, 2003). While some studies have described the symptomatic presentation of delirium in children, to date the phenomenological profile in children and adults has not been directly compared. The objective of this study is to compare the symptom profile of delirium in children, adults and geriatric patients.

Population and methods

\section{Population}

In this study the symptomatic presentation of delirium in three different populations, paediatric, adult and geriatric, is compared. The data necessary for the analysis stem from two different data files from ongoing studies on delirium. Data on childhood 
delirium were collected in Maastricht University Hospital. The paediatric population consists of critically ill patients aged 1 to 17 (inclusive), admitted to the paediatric intensive care unit (PICU) of Maastricht University Hospital, that were referred to the child-psychiatrist because of suspect delirium. Data on adult and geriatric delirium were collected in Milford Care Centre. The adult and geriatric populations consist of patients admitted for a variety of medical indications related to their cancer. These patients were screened for delirium using the Confusion Assessment Method (Inouye, Van Dyck, et al., 1990), by the treating medical team and subsequently referred for psychiatric assessment. Patients meeting DSM-IV criteria for delirium were then assessed with the Delirium Rating Scale. The rationale of the study was explained to all patients but because patients had DSM-IV delirium at entry into the study it was presumed that most were not capable of giving informed written consent. Because of the non-invasive nature of the study ethics committee approval was given to augment patient assent with proxy consent from next of kin (where possible) or a responsible caregiver for all participants, in accordance with Helsinki Guidelines for Medical research involving human subjects. Adult patients are 18 to 65 (inclusive) years old, while the geriatric population was defined as being over 65 years of age.

Methods

\section{Measures}

Delirium diagnosis was based on DSM-IV criteria (American Psychiatric Association, 2000). These criteria were developed for adult populations and strictly followed for the adult and geriatric study populations. However, memory deficits, orientation, perceptual disturbances, and delusional thinking are difficult to assess in very young children. Because adapted criteria for delirium in children are lacking, diagnosis was 
based on the DSM criteria, but subject to a consensus procedure within a multidisciplinary paediatric treatment team, as described elsewhere (Schieveld \& Leroy, 2007).

The Delirium Rating Scale (DRS) is used to screen for and quantify delirious symptoms. The DRS consists of 10 items addressing different symptoms of delirium. It has a maximum total score of 32 , with higher scores indicating more severe delirium; a score above 10 is considered a diagnostic indicator of delirium (Trzepacz, Baker et al., 1988). Apart from the Paediatric Anaesthesia Emergence Delirium scale (PAED), the DRS is the only delirium rating scale that has been validated for use in children (Turkel, Braslow et al., 2003). The first DRS rating whilst delirious was used in all patients for analysis.

\section{Statistics}

Demographic characteristics of the different populations were described without further statistical comparisons.

Only patients with complete DRS ratings were included in the analysis, with the exception of missing values on items: 2 (perceptual disturbance), 3 (hallucination type), 4 (delusions) and 6 (cognition) in younger children. These four items could not be reliably scored in a larger number of younger children and, in order to allow MANOVA, were substituted by the average score on the remaining items DRS items. This procedure was done for items 2, 3, 4, and 6 in 12, 13, 17 and 15 cases respectively. DRS score profiles of children, adults and geriatric patients were compared by way of MANOVA. Subsequent ANOVA, with Bonferroni adjusted $p$ values for multiple testing, were performed to detect differences in individual DRS item scores. 
Results

The demographic characteristics are shown in table 1. The groups included 46 children, 49 adults and 70 geriatric patients with an average age of 8.4 (range 0 to 17), 55.4, and 76.2 years respectively. Details on diagnoses and medication use in the three populations are presented in tables $2 a$ and $b$ respectively.

Table 1. Demographic characteristics of the pediatric, adult and geriatric populations.

\begin{tabular}{|l|l|l|l|}
\hline population & Child $(<18)$ & Adult $(18-65)$ & Geriatric $(65<)$ \\
\hline $\mathrm{n}$ & 46 & 49 & 70 \\
\hline Age & $8.4($ SD 5.6$)$ & $55.4($ SD 7.9$)$ & $76.2($ SD 6.1) \\
\hline$\%$ male & 64 & 55 & 44 \\
\hline
\end{tabular}

Tables $2 \mathrm{a}$ and $\mathrm{b}$. Overview of medical diagnoses and medication use in the pediatric, adult, and geriatric populations. For adults and geriatric patients, table $2 a$ lists the number and percentage of the diagnoses that were clinically considered most important in the etiology of delirium; for children the main reason for admission to the PICU is listed. Table $2 \mathrm{~b}$ lists the number and percentage of patients using specific classes of medication. 
Table 2 a.

\begin{tabular}{|c|c|c|c|}
\hline diagnosis $(\mathrm{n}) /$ population & Child $(<18)$ & Adult $(18-65)$ & Geriatric $(65<)$ \\
\hline medication intoxication or withdrawal & & $12(24 \%)$ & $13(19 \%)$ \\
\hline systemic infection & & $7(14 \%)$ & $11(16 \%)$ \\
\hline organ failure & & $1(2 \%)$ & $3(4 \%)$ \\
\hline cerebrovascular accidents & & $1(2 \%)$ & $2(3 \%)$ \\
\hline metabolic/endocrine & & $10(20 \%)$ & $18(26 \%)$ \\
\hline brain metastases/CNS neoplasms & & $12(24 \%)$ & $7 \quad(10 \%)$ \\
\hline systemic effects of neoplasm & & $5(10 \%)$ & $13(19 \%)$ \\
\hline traumatic brain injury & & & $2(3 \%)$ \\
\hline neurological disorder & $18(39 \%)$ & & \\
\hline respiratory disorder & $12(26 \%)$ & & \\
\hline circulatory disorder & $8(17 \%)$ & & \\
\hline multiple trauma & $2(4 \%)$ & & \\
\hline other & $6(13 \%)$ & $1(2 \%)$ & $1(1 \%)$ \\
\hline total n $(100 \%)$ & 46 & 49 & 70 \\
\hline
\end{tabular}

Table $2 b$.

\begin{tabular}{|l|l|l|l|}
\hline medication class/ population & Child (<18) & Adult $(18-65)$ & Geriatric $(65<)$ \\
\hline benzodiazepine & & & \\
\hline opiate & $30(65 \%)$ & $36(74 \%)$ & $56(80 \%)$ \\
\hline antipsychotic & $23(50 \%)$ & $38(78 \%)$ & $49(70 \%)$ \\
\hline antidepressant & $3(7 \%)$ & $18(37 \%)$ & $35(50 \%)$ \\
\hline psychostimulant & - & $16(33 \%)$ & $22(31 \%)$ \\
\hline corticosteroid & - & $2(4 \%)$ & $4(6 \%)$ \\
\hline anesthetic (ventilation) & $7(15 \%)$ & $19(39 \%)$ & $35(50 \%)$ \\
\hline
\end{tabular}

The MANOVA comparison of overall score profiles between the three groups, yielded a Wilks Lambda $=0.019(F=804.206, p<0.001)$ indicating significant differences of score profiles between the three groups. Average scores (left three columns) and MANOVA $p$ values on item level between each of the three groups (middle column) and all groups two by two (right three columns) are displayed in table 3 . Children differ from adult and geriatric delirium on all DRS items. Their delirium is characterized by a more acute onset, more severe perceptual disturbances, more 
intense hallucinations, more severe delusions, greater agitation, more severe lability of mood, but less severe cognitive deficits, less severe sleep-wake cycle disturbance, and less variability of symptoms over time. The only significant difference between adult and geriatric delirium was the presence of more severe cognitive symptoms in geriatric delirium.

Table 3. Average scores on DRS items (standard deviation between brackets) and MANOVA $p$ values (after bonferroni correction) per DRS item in the pediatric, adult and geriatric populations.

\begin{tabular}{|l|l|l|l|l|l|l|}
\hline Item/population & Child (1) & Adult (2) & Old Age (3) & $(1-2)$ & $(1-3)$ & $(2-3)$ \\
\hline 1. temporal onset & $2.8(0.59)$ & $2.0(0.84)$ & $2.1(0.70)$ & $<0.001$ & $<0.001$ & 1.00 \\
\hline $\begin{array}{l}\text { 2. perceptual } \\
\text { disturbance }\end{array}$ & $1.7(1.05)$ & $1.0(1.15)$ & $0.9(1.05)$ & 0.008 & $<0.001$ & 1.00 \\
\hline 3. hallucination type & $1.7(0.98)$ & $0.4(0.78)$ & $0.2(0.61)$ & $<0.001$ & $<0.001$ & 0.877 \\
\hline 4. delusions & $1.5(1.05)$ & $0.3(0.79)$ & $0.2(0.73)$ & $<0.001$ & $<0.001$ & 1.00 \\
\hline 5. psychomotor & $2.1(0.88)$ & $1.5(0.67)$ & $1.6(0.80)$ & $<0.001$ & 0.002 & 1.00 \\
\hline 6. cognitive status & $1.8(1.15)$ & $2.4(0.84)$ & $3.0(0.82)$ & 0.004 & $<0.001$ & 0.001 \\
\hline 7. physical disorder & $2.0(0.15)$ & $1.8(0.42)$ & $1.9(0.39)$ & 0.017 & 0.215 & 0.645 \\
\hline 8. sleep-wake cycle & $1.5(1.01)$ & $1.9(0.60)$ & $1.8(0.65)$ & 0.020 & 0.048 & 1.00 \\
\hline 9. lability of mood & $1.7(0.79)$ & $0.7(0.74)$ & $1.0(0.76)$ & $<0.001$ & $<0.001$ & 1.00 \\
\hline 10. variability & $1.0(1.36)$ & $3.7(1.11)$ & $3.8(0.67)$ & $<0.001$ & $<0.001$ & 0.818 \\
\hline
\end{tabular}

Discussion

This study is the first to directly compare the symptomatic presentation of delirium in children with that in adult and geriatric patients. It revealed that delirium in severely ill children is characterized by a distinct course and symptom profile. Childhood delirium has a more acute onset, and a less fluctuating course, with less sleep/wake cycle disturbances. Some symptoms in childhood delirium are more severe than in adult or geriatric delirium, notably perceptual disturbances, hallucinations, delusions, agitation, and lability of mood, while cognitive deficits are less severe. Although the difference in severity score of the underlying physical disease between children and 
adult patients (but not geriatric patients) was significant, the difference in scores was not considered clinically relevant. However, the fact that the underlying diseases in the pediatric group on the one hand and the adult and geriatric groups on the other hand are quite different, makes interpretation of this finding difficult. Adult and geriatric delirium differed only in the severity of cognitive symptoms, with more severe cognitive symptoms occurring in geriatric patients.

In keeping with Turkel and colleagues' review, we found a similar range of symptoms occur in delirium regardless of age (Turkel, Trzepacz et al., 2006). This would provide support for the clinical practice of making a diagnosis of delirium in children that is also based on DSM criteria. However, while for older children this may be feasible, some of the criteria cannot be reliably scored in young children. This is why, for the children, we resorted to a consensus approach (Schieveld \& Leentjens, 2005). The DSM criteria may require adaptation to suit the developmental level of young children. Whether childhood delirium is characterized by additional specific symptoms, different from those occurring in adults, cannot be answered with the present design, since only symptoms that are part of the DRS were scored. The fact that quantitative, but not qualitative, differences are found between pediatric and adult populations, may indicate similar pathophysiological mechanisms in pediatric, adult and geriatric delirium.

Our findings contrast with Turkel and colleagues (Turkel, Trzepacz et al., 2006) in relation to the severity and frequency of individual symptoms. They report that in children fluctuation of symptoms and sleep-wake cycle disturbances were more often described, while in our study they appear to be less severe. One possible explanation of this finding may be the fact children at the PICU setting are also 
frequently sedated with opioids and benzodiazepines. Also, in our study delusions and hallucinations appear to be more severe in children, and not less severe or similar respectively. Interpretation of these differences are difficult, also because Turkel et al. report on the frequency with which symptoms are reported in literature, while our study made use of average severity scores, that in addition were substituted when missing.

Our study has several important limitations. First of all: the data of the three different study populations came from two different study-groups. This implies that there may be a systematic difference in scoring between the groups. Due to the nature of the analysis, inter-rater agreement between the members of the different study groups was not tested. Second, the study populations are both selected samples and recruited in different ways. The children are were critically ill PICU patients with a variety of diseases that were included in the study after being referred to the childpsychiatrist. This could have introduced a 'referral bias' since more severely agitated children may have been more readily referred. The adult and geriatric patients were all terminally ill patients admitted to a hospice. They all suffered from cancer and related medical illnesses, and received palliative treatment. Referral for these patients took place on the basis of routine screening for delirium. A third limitation is the fact that some of the DSM criteria cannot be reliably scored in very young children because of their level of verbal and intellectual development. In this case the diagnosis was based on DSM criteria as much as possible, and finalized in a consensus discussion between the clinicians involved. This may have introduced some bias in the diagnosis of delirium in children. However, the low cumulative incidence of delirium in our sample of children on the PICU of $4.6 \%$ (Schieveld, Leroy et al., 2007), suggests that this represents a conservative approach to diagnosis. The same problem appears when applying the DRS to children. In the youngest children 
items: 2 (perceptual disturbances), item 3 (hallucination type), 4 (delusions) and 6 (cognitive deficits) cannot be reliably scored most of the time. Moreover, some of the operationalised options are difficult to ascertain in children, for instance option 3 of item 2 (confusion about external reality) and option 3 of item 4 (transient poorly organized delusions in response to misperceived environmental cues). In order to allow ANOVA we decided to substitute missing values in these items. This may have introduced a confounding effect. Between group comparisons of these two items may be less reliable. Fourth, the pediatric group may not be homogenous, since it encompasses and age span in which important developmental and maturing processes take place. This is also reflected in the prevalence of delirium, that increases with increasing age (Schieveld, Leroy et al., 2007). Finally, medication use and other etiological factors were not considered in this study. A substantial number of the adult and geriatric patients were already using antipsychotics at the time their symptoms of delirium started (see table 2a). This may in part be responsible for the lower score on the DRS 'hallucinations' item in these groups compared to children, although children score higher on the 'delusions' item. In addition, sedative medications, such as benzodiazepines and opoids, may be a contributing etiological factor of delirium, in addition to influencing several symptoms of delirium, such as cognitive processes and sleep-wake cycle disturbances.

\section{Conclusion}

Studies of the phenomenology of childhood delirium are scarce. We report the first study that directly compares the phenomenology of delirium in children with that in adult and geriatric patients. Childhood delirium is characterized by a distinct course with a more acute onset, but less diurnal variability of symptoms and less sleep-wake 
cycle disturbances. Although the range of symptoms appears to be similar across age groups, delirium is characterized by differences in symptom intensity with more severe perceptual disturbances, more intense hallucinations, more severe delusions, more agitation, and more severe lability of mood, but less severe cognitive deficits in children. As this study is based on different databases that have followed different inclusion and assessment strategies in selected patient groups, the findings of this study should be confirmed in studies that have been more specifically designed to compare symptoms of delirium across the age span. In addition, further research into the phenomenology, etiology, treatment and prognosis of delirium in children is warranted. 


\section{References}

American Psychiatric Association (2000). Diagnostic and statistical manual of mental disorders. 4th edition text, revision (DSM-IV-TR). Washington DC, American Psychiatric Association.

Breitbart, W., Gibson, C. and Tremblay, A. (2002). "The delirium experience: delirium recall and delirium-related distress in hospitalized patients with cancer, their spouses/caregivers, and their nurses." Psychosomatics(43): 183-94.

Inouye, S.K., Rushing, J.T., Foreman, M.D., Palmer, R.M. and Pompei, P. (1998). "Does delirium contribute to poor hospital outcomes? A three-site epidemiologic study." J Gen Intern Med 13(4): 234-42.

Inouye, S.K., Van Dyck, C.H., Alessi, C.A., Balkin, S., Siegal, A.P. and Horwitz, R.I. (1990). "Clarifying confusion: the confusion assessment method. A new method for detection of delirium." Ann Intern Med 113(12): 941-8.

Leentjens, A.F.G. and Van der Mast, R.C. (2005). "Delirium in the elderly; an update." Current Opinion in Psychiatry 18: 325-330.

McCusker, J., Cole, M., Abrahamowicz, M., Primeau, F. and Belzile, E. (2002). "Delirium predicts 12month mortality." Arch Intern Med 162(4): 457-63.

McCusker, J., Cole, M.G., Dendukuri, N. and Belzile, E. (2003). "Does delirium increase hospital stay?" J Am Geriatr Soc 51(11): 1539-46.

Morita, T., Hirai, K., Sakaguchi, Y., Tsuneto, S. and Shima, Y. (2004). "Family-perceived distress from delirium-related symptoms of terminally ill cancer patients." Psychosomatics 45(2): 107-13.

Schieveld, J.N.M. and Leentjens, A.F.G. (2005). "Delirium in severely ill young children in the pediatric intensive care unit." Journal of the American Academy of Child and Adolescent Psychiatry 44: 392-394

Schieveld, J.N.M., Leroy, P.L.J.M., van Os, J.J., Nicolai, J., Vos, G.D. and Leentjens, A.F.G. (2007). "Pediatric delirium in critical illness: phenomenology, clinical correlates and treatment response in 40 cases at the pediatric intensive care unit." Intensive Care Medicine 33: 10331040.

Trzepacz, P.T., Baker, R.W. and Greenhouse, J. (1988). "A symptom rating scale for delirium." Psychiatry Res 23(1): 89-97. 
Trzepacz, P.T. and Meagher, D.J. (2005). Delirium. Textbook of Psychosomatic Medicine. Levinson, J.L. Washington DC, The American Psychiatric Publishing: 92-130.

Turkel, S.B., Braslow, K., Tavare, C.J. and Trzepacz, P.T. (2003). "The Delirium Rating Scale in children and adolescents." Psychosomatics 44: 126-129.

Turkel, S.B. and Tavare, C.J. (2003). "Delirium in children and adolescents." The Journal of Neuropsychiatry and Clinical Neurosciences 15: 431-435.

Turkel, S.B., Trzepacz, P.T. and Tavare, C.J. (2006). "Comparing symptoms of delirium in adults and children." Psychosomatics 47(4): 320-4. 



\section{CHAPTER 8}

General Discussion 


\subsection{Multidisciplinary teamwork}

Although they say it takes two to tango and three's a crowd, with four or five one can work easily and productively in a multidisciplinary group (if, of course, everyone can manage his or her own ego). Realizing the stakes - namely better individual patient care, better medical care in general, and a perspective on novel scientific data and ideas - led in our case to a keen eye for all our mutual interests and helped wonderfully to focus minds and hearts. And so in this context a fellowship, with mutual understanding and pleasurable cooperation, was soon developed. This thesis is one of its fruits.

\subsection{The title and subtitle}

Regarding the title 'Pediatric Delirium in Critical Illness'.

Critical illness is a container concept to describe the dangerous state of health of a patient who is trying to survive. This state is due to those disorders in which there is an acute threat of severe complications and/or dying. Most of the time this is due to a threatening respiratory, haemodynamic or neurological failure, and frequently a combination of these exists (see NHS Sussex Critical Care Network, NHS, 2007). Given the strong relations in the triangle delirium - critical illness - mechanical ventilation, we considered it logical to study PD primarily at the PICU. In the adult ICU world, this clinical fact has already been recognized; see e.g. Textbook of critical care (Fink, Abraham et al., 2005). Chapter 1 of the Textbook is titled 'Sudden deterioration in neurological status' and its opening line is 'Patients admitted to the intensive care unit (ICU) with critical illness or injury are at risk for neurological complications'. Chapter 2 is entitled 'Agitation and delirium'. 
Regarding the subtitle 'A clinical multidisciplinary study in child neuropsychiatry at the PICU'.

What is neuropsychiatry? It is the domain where neurology and psychiatry merge; at its boundaries, the neurologist deals with the neurological aspects of psychiatry, and the psychiatrist deals with the psychiatric aspects of neurology. After all, the human brain is not a single organ, but a set of different, closely intertwined organ systems that cooperate intensely (Gualtieri, 2002). As the human brain is large - in fact, huge - there is place and space for all of us: intensivists, anaesthesiologists, nurses, psychologists, psychotherapists, epileptologists, neuropathologists, neuroradiologists, neurosurgeons and general practitioners, and even then there is still enough room for neurologists and psychiatrists (as well as musicians, painters, poets, mathematicians and the rest). So Emily Dickinson, with her poem 'The brain is larger than the sky' (c. 1860) can rightly be named the godmother of the natural multidisciplinary neuropsychiatric teamwork (see our 'Preliminary Thoughts') (Dickinson, 1960).

\subsection{Study design and limitations}

The data collected were used to describe the clinical course and treatment outcome of childhood delirium at the PICU. The thesis mainly revolves around descriptive articles of clinical expression of childhood delirium and associated treatment outcomes, as well as retrospective quantitative analyses of prospectively collected case note data (see Kirkwood \& Sterne, 2003). It dealt solely with daily clinical care and with the endeavour to maximize the comfort and psychological well-being of critically ill children (and of their families); essentially it was a project to improve the 
quality of care. Prospectively sampled data such as the PIM and the PRISM scores were used for retrospective quantitative analysis in relation to the occurrence of PD. There were several limitations to the study: one is the fact that, most of the time, I was the only child neuropsychiatrist directly involved in this study. But I had the luck to work in two very critical but most helpful teams, both inside and outside the PICU. This sharpened my mind and kept me (I believe) on the right track most of the time. Other limitations are a lack of: 1) diagnostic criteria for PD, 2) validated rating scales especially for the use in critically ill children in a PICU context, 3) knowledge regarding predisposing and precipitating riskfactors for $\mathrm{PD}$. A last limitation is the fact that this was the first study of its kind regarding specifically PD in a PICU context, so we are certainly in need of confirmatory evidence produced by other groups (according to the principle 'One witness is no witness').

\subsection{Methods}

8.4.1 Guiding epidemiological basic facts and rules in solving the conceptual and methodological problem

\section{Epidemiological basic facts}

I) Although it is common knowledge that children react with delirium very easily, nobody knows the exact figure (Bleuler, 1955; American Psychiatric Association, 2000). Among adults and the elderly, the prevalences of delirium are $10-30 \%$ in a general hospital, up to $50 \%$ in an ICU setting and up to $80 \%$ in the terminally ill. And in general hospitals, approximately $10 \%$ of the patients referred to psychiatric consultation have delirium, and just about $10 \%$ of all general hospital patients with delirium receive a 
psychiatric consultation (Trzepacz \& Meagher, 2005). So it was logical and reasonable to assume that, also in analogy with the adults and the elderly, there must be also a very high probability of the occurrence of PD in critical illness in children at the PICU ('frequent things happen to occur frequently').

II) Delirium in adults and the elderly is a serious disorder in many different ways: it is basically an encephalopathy that can keep its deficits in the short and/or the long run (NINDS, 2007); that is associated with a poorer prognosis especially in combination with mechanical ventilation; and that can lead to self-harm by the patient by auto extubation, pulling out lines and/or by falling out of bed. The neuro-metabolic stress of being delirious in itself is bad for the recovery of the patient, and it can be psychologically very dramatic for the patient, the patient's family and the multidisciplinary team. This risk consideration in adults and the elderly again made it logical and obligatory for us to place delirium in children at the forefront of the differential diagnosis of behavioural and/or emotional problems at the PICU.

\section{Decision rules}

There were two guiding rules for our decision-making:

I) Occam's razor: 'The simplest explanation that covers all the different facts is most probably the best' (Schieveld \& Leentjens, 2005).

II) The exclusion principle: 'How often have I said to you [Watson] that when you have eliminated the impossible, whatever remains, however improbable, must be the truth?' (The Sign of Four, Conan Doyle, 2005). 


\subsubsection{Algorithm}

In accordance with these basic facts and decision rules, we adopted the following algorithm: at the PICU all the children who were referred to us with refractory behavioural and/or emotional problems/disorders that did not have a sound explanation, had been first ruled out for pain, discomfort and withdrawal. Next, and often simultaneously, they were ruled out for unequivocal other child psychiatric disorders, and only then we could safely diagnose PD on positive criteria as an explanation. But frequently (i.e. in 17 out of 40 cases), when the delirium criteria were not or were only partially or marginally fulfilled, we nevertheless had to suspect or assume its existence, safely based on the aforementioned facts and decision rules, as the most probable explanation and diagnosis. And this was discussed in our consensus meetings (Schieveld, Leroy et al., 2007).

We were reinforced in this approach by the frequently rapid and positive effects of our medication treatment in these cases; although this happened in an uncontrolled fashion. This mechanism is also known as the diagnosis ex juvantibus principle (finally making a diagnosis by way of the treatment response (Dorland, 1974)); this principle is also known in science and engineering, as well as in the philosophical school of knowledge theory known as pragmatism, as: 'Truth is all that works.'

This was the way we solved the conceptual and methodological problems.

8.5) The main findings and results 


\subsection{1) Common sense}

Common sense is a seriously underestimated tool in everyday clinical practice. Paraphrasing Samuel Shem's laws of 'The house of God' with law XIV, I state: 'There is no substitute for kindness, courtesy and common sense' (Shem, 1978). It is not taught, or discussed, very frequently during our studies at university (as is the case with most of the other basic values of medical practice, such as compassion, comfort, sense of humour, honesty, and how to apologize properly and why). There is no 'science of common sense', but there is in knowledge theory a philosophical school known as pragmatism. Nevertheless, a search for 'common sense' in PubMed resulted in 1443 hits. Most of these are anecdotal case reports, and the earliest dates from 1949, from the USA, on common sense in heart disease. A definition is hard to give, but 'cleverness', 'not overlooking the obvious' and 'the everyday practicality of the busy mother and housewife' are perhaps all synonyms. The Oxford dictionary, thesaurus and wordpower guide (Oxford, 2001) defines 'common sense' as 'Good sense and sound judgement in practical matters'. In The Oxford dictionary of medical quotations (McDonald, 2004), there are five entries on the subject of common sense. Two of the quotes are apt at this place to close this subsection (after all: this is a thesis, as well as a clinical study, written by an M.D.). 'Science is nothing but developed perception, interpreted intent, common sense rounded out and minutely articulated' (Georges Santayna, Spanish-born US philosopher and poet, 1863 1952). The second one is: 'From inability to let well alone; from too much zeal for the new and contempt for what is old; from putting knowledge before wisdom, science before art, and cleverness before common sense, from treating patients as cases, and from making the cure of the disease more grievous than the endurance of the 
same, good Lord, deliver us.' (Sir Robert Hutchinson, physician, the London Hospital, UK, and president of The Royal College of Physicians, 1871- 1960).

\subsubsection{The relation between catatonia and pediatric delirium}

There are many similarities, conceptually as well as clinically, between catatonia and delirium (Fink \& Taylor, 2003; Schieveld, 2006; Taylor \& Fink, 2003). In general medicine it is relatively rare (Masand, Christopher et al., 2005), but probably not in, for example, autism. Leo Kanner described, in his 1966 edition, that he had seen 6 cases of catalepsy (waxy flexibility) in children due to different infectious diseases, ages 16 months - 9 years; and he quoted Epstein who saw 7 rachitic children, with catalepsy, ages 10 months -3 years (Kanner, 1935). Stupor has somewhat different meanings in neurology and in psychiatry. In neurology it comprises behavioural nonresponsiveness, loss of speech (mutism), hypokinesia and a reduced level of consciousness, manifested by patients responding only to vigorous stimuli (Williams, 2002), so it clearly resembles catatonia/catatonic features with hypoactive delirium. And in psychiatry, most of the time it has the same clinical meaning but then without the disturbance of consciousness (ibid.). There are not many differences in the number of hits between a PubMed search from 2005 and one from today. Checking in June 2007 for the number of the latest publications resulted in: 'catatonia and delirium/and children' 131 and 18 hits; 'catatonia and critical illness/and delirium/or PICU' all 0 hits; 'stupor/and child/or delirium' gave 813 hits, the first from France (1951), respectively 121 hits (1956) and 48 (1964) hits. Finally, 'stupor and ICU/or critical illness/or PICU' resulted in 11, 2 and 0 hits, respectively. Lipowski, amongst other experts, regarded motor signs - hyperactive and/or hypoactive ones pathognomonic for delirium, and then we come full circle in our thinking about the 
relation between delirium and catatonia (Lipowski, 1980). After all, who can tell the difference between hyperactive delirium versus catatonic excitement, or between hypoactive delirium versus catatonic negativism, mutism and hypokinesia versus stupor? So hypoactive delirium and stupor are often synonyms and refer to the same clinical entity; and hypoactive motor signs, catatonic features and stupor are often used as synonyms as well.

\subsubsection{The preliminary cumulative incidence}

The preliminary cumulative incidence of PD at our PICU was $5 \%$; the age-specific incidence rates varied from $3 \%(0-3$ years, $n=513)$ to $19 \%(15-17$ years, $n=31)$. The figure of $5 \%$ was unexpectedly low, given the high incidence in critical illness in adults and the elderly combined with the strong tendency in children to develop delirium with, for example, fever or post-anaesthesia (Ouimet, Kavanagh et al., 2007). We therefore expected a much higher figure. On the other hand: the intensive psychosocial care, so common at Dutch PICUs, is perhaps a strong counterforce regarding the onset of $\mathrm{PD}$, and Larsen et al. reported in their paper regarding adverse events at the PICU also an incidence of 4\% (Larsen et al. 2007; Schieveld, Leroy et al., 2007). This is also suggested by a recent, and beautifully executed, study regarding family-centered preparation for elective 'minor' surgery in children, age 2-12 years, which improved their outcome. The incidence of post-anaesthesia delirium in the control group was $24 \%$, and in the treatment group $10 \%$ (Kain, Caldwell-Andrews et al., 2007). Most of my colleagues who work in child psychiatricconsultation liaison services in other university hospitals, however, considered our number as surprisingly high - but then they do not visit a PICU regularly. And as the detection rate of a particular, and perhaps rare disorder is also a positive function of 
the attainability of the specialized discipline, it is perhaps not so surprising. After all, our team visited the PICU at least once a day. And then we did not even screen all the children for PD at the PICU, so an under-recognition of especially the hypoactive and the subsyndromal forms is even more likely. Besides, there is another famous quote, which I shall slightly paraphrase: 'Confusion at the $(P) I C U$ is so common, that a child psychiatric consultation is only requested if the patient is also agitated' (see American Psychiatric Textbook on Consultation-Liaison Psychiatry; (Wise, Hilty et al., 2002). Or: in critical illness with threatening multiple organ failure the brain is very frequently encompassed, and then preferentially responds with delirium at least in adults and the elderly.

\subsubsection{The clinical presentations}

Along with the first, classic prototype with the two presentations (hyperactive and/or hypoactive; see the Introduction), there appeared to exist, to our surprise, two important other presentations of PD at the PICU. One is called the 'veiled', 'emerging', 'partial' or 'subsyndromal' type, just as others and we described in Chapter 5 (Cole et al., 2003; Schieveld, Leroy et al., 2007). For what have influenza, anorexia nervosa and delirium in common? That for every classic case with influenza there are many more cases with an atypical or subclinical/subthreshold presentation, and that for every typical case with anorexia nervosa there are many more atypical ones. This is one of the basic rules of clinical medicine and presumably holds for every disorder, and thus also for delirium. This subsyndromal type at an ICU was also described, at the same time in ICM, regarding adults and the elderly at an ICU setting by the Canadian group of Sebastian Ouimet, Yonna Skrobik and colleagues (Ouimet, Riker et al., 2007). They found an overall distribution of delirium of 
approximately $1 / 3$ no delirium, $1 / 3$ subsyndromal and $1 / 3$ delirium. So in an ICU setting they described a more or less 50:50 distribution between the classic and the partial type, just as we found in children. They concluded that delirium in an ICU setting is a spectrum disorder, and so did we. But through the years we got the impression that we had to extend this spectrum concept to a probable fourth presentation. After all, we found clinically, and later on also in the scarce literature, that there are accumulating indications that pediatric delirium, and also PD in a PICU context, can be subtle and accompanied or even dominated by other delicate neuropsychiatric signs and/or symptoms, such as reduction of awareness of the caregiver and/or surrounding, purposeless actions (cf. catatonia), restlessness, inconsolability, partial regressions and/or partial and temporarily loss of skills, subtle higher cortical dysfunctions and signs of autonomic dysregulations (Schieveld \& Leentjens, 2005; Schieveld, Leroy et al., 2007; Sikich \& Lerman, 2004; Stoddard \& Wilens, 1995; Wise, 1987). So it seems that in children, and especially in a PICU context, these neuropsychiatric signs and symptoms are sometimes all that is left of the two classical full blown pictures.

Thus, in retrospect the definition/concept of delirium as formulated in the Introduction as a 'special case of EP (encephalopathy)' or 'confusion due to EP' has to be revised and extended. I now define PD - see scheme 1 - as 'pediatric delirium at the PICU, a special case of an EP, is a spectrum disorder with two poles: pole 1 is the classic type, which can change into (or present itself primarily as) the subsyndromal/partial type and back again; and pole 2 is a gamut of neuropsychiatric signs and symptoms that can dominate the clinical presentation or accompany the presentations at pole 1' (American Psychiatric Association, 2000; Lishman, 1987; Ouimet, Kavanagh et al., 2007; Schieveld, Leroy et al., 2007; Wise, 1987). 


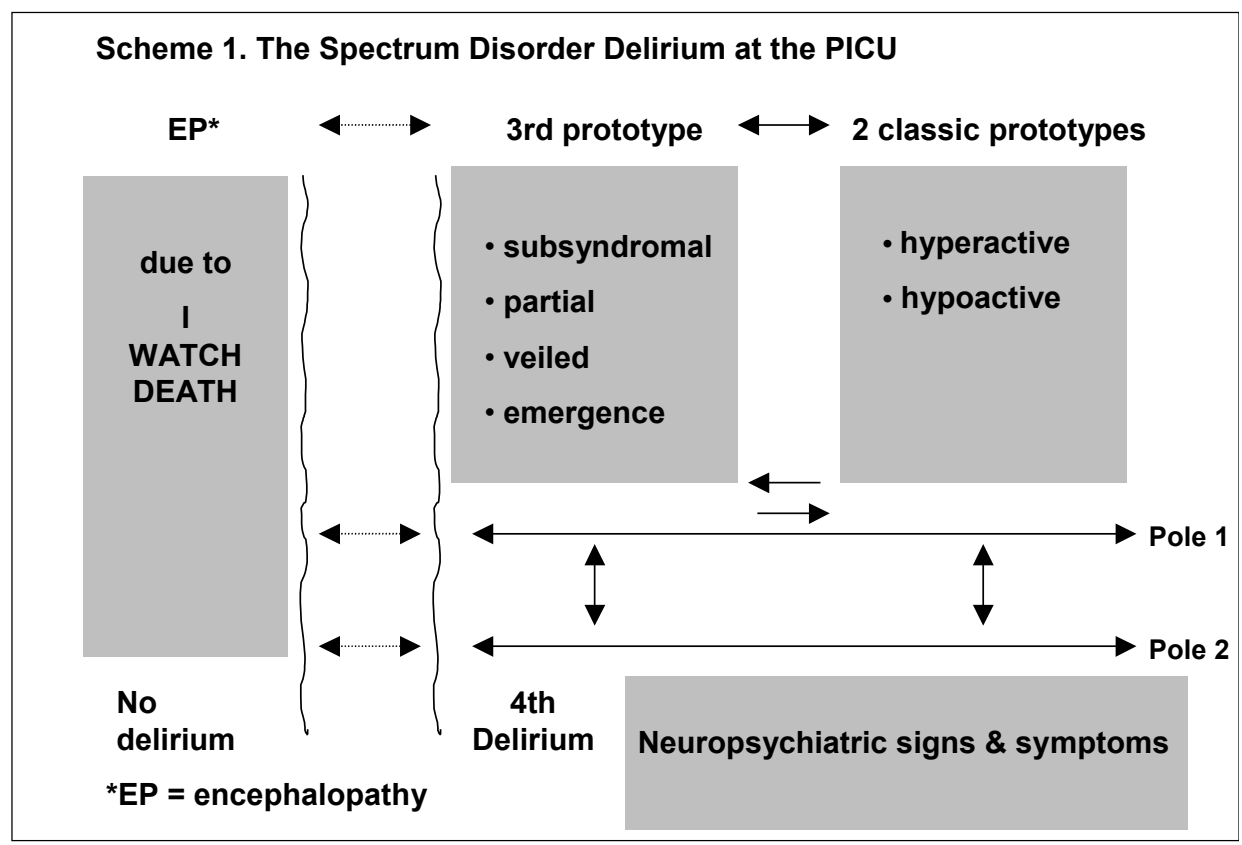

8.5.5 The haloperidol IV and risperidone PO treatment responses and the psychosocial care

Treatment with haloperidol IV in an open and uncontrolled fashion was effective, usually within 2 to 6 hours, and sometimes even after just one IV dosage. Sometimes we had to titrate the child with repeating IV dosages according to the response. As a rule of thumb we always started with a loading dosage of $0.25 \mathrm{mg}$ haloperidol slowly IV in 30 minutes; and in children $<3$ years and/or $<15 \mathrm{~kg}$ we started with $0.15 \mathrm{mg}$.

Given the relative frequency of EPS with haloperidol i.v. dosage in especially children younger than three years of age (which was probably the result of the immature blood-brain barrier and the immaturity of the infant brain), we composed by adaptation guided by our experiences of the last six years, this table: 
Table 1. Intravenous haloperidol dosage in pediatric patients

\begin{tabular}{cccc}
\hline Age (years) & Weight $(\mathrm{kg})$ & $\begin{array}{c}\text { Loading dosage } \\
(\mathrm{mg} / \mathrm{iv})\end{array}$ & $\begin{array}{c}\text { Haloperidol starting } \\
\text { dosage }(\mathrm{mg} / \mathrm{kg} / \mathrm{iv} 24 \\
\text { hours })\end{array}$ \\
\hline $0-1$ & $3.5-10$ & 0.05 & 0.01 \\
$1-3$ & $10-15$ & 0.15 & 0.025 \\
$3-18$ & $>15$ & 0.25 & 0.05 \\
\hline
\end{tabular}

(Shann, 2005; Ratcliff et al., 2004; Spencer \& Campell, 1994; Schieveld \& Leentjens, 2005). We then followed the development of the PD for totally 1.5 hours after the start of this medication. If there was no response or an insufficient one, we repeated the whole procedure in order to find the minimal effective maintenance dosage, per 24 hours, which we next divided in two or three gifts (personal communication Mrs. T.B.Y. Liem, pharmacologist UMC Utrecht/Wilhelmina Kinderziekenhuis). Two children developed extrapyramidal side effects, but they responded quickly with biperidene IV (50 microgram/kg/IV/each time in 15 minutes), which can be repeated immediately if there is no response; see (Shann, 2005). Over the years it has become our common opinion that this possibility of the IV use of haloperidol, with its mostly swift and beneficial effects, is of great value for the treatment of PD at the PICU (but nobody yet knows the natural course of untreated PD), especially in comparison with the much slower, but also very effective results with risperidone, which can be given only orally.

We also tried to care for the family and the multidisciplinary team. We wrote an information leaflet regarding the various aspects of PD and distributed it to the family of the child and to our colleagues at the PICU. In addition, in every case of PD our team intensified the daily visits at the PICU to twice or thrice a day, combined with 
extra patient visits during the weekend and/or by extra telephone contacts at night. After hospital discharge we always had, if possible, at least one out-patient contact with the child and family. If this could not be arranged there was at least one followup by telephone with the family and/or their local pediatrician or general physician. We have not tried to evaluate the satisfaction of our patients and their families, but they were almost always grateful to us and our leaflet was appreciated especially for its clarity. And regarding the appreciation of our care by our colleagues at the PICU: we are still welcome there.

\subsubsection{On the predictive values of the PIM and the PRISM II}

Just as weight or abdominal circumference scores are positively correlated with coronary heart disease, and thus these two variables can be considered risk factors/ predictors for myocardial infarction, we hypothesized about the predictive powers of the PIM and the PRISM II scores for the occurrence of PD. After all, in adults and the elderly there are strong positive correlations between delirium and critical illness (especially in combination with mechanical ventilation) and in turn between critical illness and death (which is precisely what the adjective 'critical' means). And so we found, not totally unexpectedly, a fair relation between PIM and PRISM II scores and the AUC (Area Under the Curve) of the corresponding ROC (Receiver Operator Characteristic) curve, with values of 0.70 and 0.73 , respectively. The ORs (Odds Ratios) at the optimum cut-off points were 9 and 19, which are very high values. We also found that nearly all cases of PD occurred at the upper $50 \%$ of the median PIM and PRISM II values. So if one is using only these scores, one can safely rule out PD in 1 of 2 cases at this PICU. But PD is a rare event, and this was reflected in the PPVs (Positive Predictive Values), which were around $7 \%$ - and up to $10 \%$ in 
combination with mechanical ventilation - and in the corresponding NPVs (Negative Predictive Values), which were all $99 \%$. But this is still work in progress, and once we have intensified our screening for PD for all of the PICU children on a daily basis, we expect to find even better scores. This is because the PIM and PRISM II are good mortality risk instruments, and there is a strong relation between critical illness, imminent death and delirium. And so we expect that the APACHE score (the adult equivalent of the PIM and PRISM scores) will be of equal value in predicting delirium in adults and the elderly.

8.5.7 The comparison of delirium symptoms across the age span using the Delirium Rating Scale

This comparison gave three findings:

1) Delirium symptomatology in critically ill children in a PICU setting is much more pronounced than in adults and the elderly in a hospice setting, with two exceptions: there is less diurnal variability of symptoms and there are fewer sleep-wake cycle disturbances. This is probably explained by the PICU context with opioid and benzodiazepine medication.

2) This more severity of symptoms is in accordance with the scarce findings in the literature (see Turkel, Trzepacz et al., 2006), but we have no explanation for this remarkable difference.

3) There are a lot of missing data especially in very young children when using the DRS. This is largely so regarding item 2: Perceptual disturbances (except option 3 - 'confusion about external reality' - which could be scored frequently); item 3: Hallucination type; item 4: Delusions (again option 3: 'transient, poorly organized, and misperception regarding e.g. environment 
and care givers etc.' could be scored frequently); and item 6: 'Cognitive status during formal testing'.

This, of course, did not come as a big surprise. Together, the composition of the very young age + the critical illness + the frequent combination of opioids, benzodiazepines and (possibly temporary) mechanical ventilation + the facts that the DRS is essentially 1) an adult psychiatric, partially cognitive-psychometric, examination tool and 2) not primarily developed for use in an ICU setting, made a sound explanation. So there is great need for a tailor-made instrument for diagnosing PD in critically ill children in a PICU setting. The PAED seems to be the logical answer to this need because of its five phenomenological items, namely contact, goal-directed actions, awareness of surrounding, restlessness and inconsolability. And we wonder whether this instrument could not be also of similar value in diagnosing delirium in adults and the elderly, whether or not mechanically ventilated, in an ICU setting.

\subsection{Answering the research questions}

8.6.1 Are there guiding basic facts and decision rules to solve the conceptual and methodological problem?

Yes there are. The guiding facts are: children react with delirium very easily, there is a very high prevalence in critically ill adults and the elderly, just $10 \%$ of the adult and elderly patients with delirium receive a psychiatric consultation, and delirium is a serious diagnosis in many different ways. The decision rules are: Occam's razor and 
the exclusion principle; the diagnosis ex juvantibus principle and 'Truth is all that works' are reinforcers.

8.6.2 What are the clinical presentations of PD in a PICU setting?

There are probably four presentations possible: hyperactive, hypoactive, subsyndromal and with a variety of neuropsychiatric signs and symptoms. These can all occur singularly, but they can also arise, and fluctuate, in every imaginable combination during the course of the disease.

\subsubsection{Is there a relation between PD and catatonia?}

Yes, and there are important conceptual and clinical similarities between the two. And delirium, encephalopathy, stupor, hyperactive and hypoactive motor signs, and catatonic features are frequently used as synonyms; however not always quite correctly.

8.6.4 What is the preliminary incidence of PD?

There is a cumulative incidence, which proved to vary according to the age group: with the $0-3$ years it is $3 \%$, and this figure increases to $19 \%$ in the $15-17$ years group.

\subsubsection{What are risk factors for PD?}

The severity of critical illness, expressed in PIM and PRISM II scores, and mechanical ventilation. Male gender is not a risk factor; although there is always a 
male preponderance among the PICU population and especially in the mortality figures $<1$ year, this is never statistically significant and without explanation.

8.6.6 What is the psychopharmacological treatment response?

This is good, in an open and uncontrolled design, with however occasionally extrapyramidal side effects (although strictly speaking we do not know anything about the natural course of PD). Extra psychosocial care including an information leaflet on PD has been greatly appreciated.

8.6.7 What are the similarities and differences regarding delirium evaluation with the DRS across the age span?

PD symptoms are much more pronounced than those in adults and the elderly, except for the diurnal variation of symptoms and the sleep-wake cycle disturbances. In the very young there are lots of missing data due to a partial mismatch between a number of DRS items on the one hand, and the psychological maturity of the child and the disease context (the PICU) on the other hand. 
References

American Psychiatric Association (2000). Diagnostic and statistical manual of mental disorders. 4th edition text, revision (DSM-IV-TR). Washington DC, American Psychiatric Association.

Bleuler, E. (1955). Lehrbuch der Psychiatrie. Berlin, Springer Verlag.

Cole M, McCusker J, Dendukuri N, Han L (2003). "The prognostic significance of subsyndromal delirium in elderly medical inpatients". J Am Geriatr Soc 51:754-760.

Conan Doyle, A.I. (2005). The complete works of Sherlock Holmes, Dell Publishing Group Inc.

Dickinson, E. (1960). The brain is wider than the sky. The Complete Poems of Emily Dickinson. Johnson, T.H. Boston, Little, Brown and Company.

Dorland, W.A.N. (1974). Dorland's Illustrated Medical Dictionary, W.B. Saunders Company.

Fink, M. and Taylor, M.A. (2003). Catatonia: A Clinician's Guide to Diagnosis and Treatment. Cambridge, Cambridge University Press.

Fink, M.P., Abraham, E., Vincent, J.L. and Kochanek, P.M. (2005). Textbook of Critical Care, Saunders Elsevier.

Gualtieri, C.T. (2002). Brain Injury and Mental Retardation: Psychopharmacology and Neuropsychiatry. Philadelphia, Lippincott Williams \& Wilkins.

Kain, Z.N., Caldwell-Andrews, A.A., Mayes, L.C., Weinberg, M.E., Wang, S.M., MacLaren, J.E. and Blount, R.L. (2007). "Family-centered preparation for surgery improves perioperative outcomes in children." Anesthesiology 106(1): 65-74.

Kanner, L. (1935). Child Psychiatry. Springfield, Chas. C. Thomas.

Kirkwood, B.R. and Sterne, J.A.C. (2003). Essential Medical Statistics, Blackwell Publishing Limited.

Larsen, G.Y., Donaldson, A.E., Parker, H.B., Grant, M.J.C. "Preventable harm occurring to critically ill children." Pediatric Critical Care Medicine 8(4):331-336.

Lipowski, Z.J. (1980). Delirium: Acute brain failure in man. Springfield (Illinois), Charles C. Thomas, Publisher.

Lishman, W.A. (1987). Symptoms and syndromes with regional affiliations. Organic Psychiatry. The psychological consequences of cerebral disorder. Oxford, Blackwell Scientific Publications: 21-77. 
Masand, P.S., Christopher, E.J., Clary, G.L., Mago, R., Levenson, J.L. and Patkar, A.A. (2005). Mania, Catatonia, and Psychosis. Textbook of Psychosomatic Medicine. Levenson, J.L. Washington, DC, American Psychiatric Publishing Inc: 235-250.

McDonald, P. (2004). The Oxford Dictionary of Medical Quotations. Oxford, Oxford University Press. NHS (2007). "http://www.sussexcritcare.nhs.uk/." NHS Sussex Critical Care Network.

NINDS (2007). "http://www.ninds.nih.gov/." The National Institute of Neurological Disorders and Stroke.

Ouimet, S., Kavanagh, B.P., Gottfried, S.B. and Skrobik, Y.K. (2007). "Incidence, risk factors and consequences of ICU delirium." Intensive Care Medicine 33(1): 66-73.

Ouimet, S., Riker, R.R., Bergeron, N., Cossette, M., Kavanagh, B.P. and Skrobik, Y.K. (2007). "Subsyndromal delirium in the ICU: evidence for a disease spectrum." Intensive Care Medicine 33: 1007-1013.

Oxford, U.P. (2001). Oxford Dictionary Thesaurus \& Wordpower Guide. Oxford, Oxford University Press.

Ratcliff, S.L., Meyer, W.J. ${ }^{\text {rd }}$, Cuervo, L.J., Villarreal, C., Thomas, C.R., Herndon, D.N. (2004). The use of haloperidol and associated complications in the agitated, acutely ill pediatric burn patient. J Burn Care Rehabil 25:472-78.

Schieveld, J.N.M. and Leentjens, A.F.G. (2005). "Delirium in severely ill young children in the pediatric intensive care unit." Journal of the American Academy of Child and Adolescent Psychiatry 44: 392-394

Schieveld, J.N.M. (2006). Case reports with a child psychiatric exploration of catatonia, autism, and delirium. Catatonia in Autism Spectrum Disorders. Dhossche, D.M., Wing, L., Ohta, M. and Neumarker, K., Elsevier Academic Press. 72: 195-206.

Schieveld, J.N.M., Leroy, P.L.J.M., van Os, J.J., Nicolai, J., Vos, G.D. and Leentjens, A.F.G. (2007). "Pediatric delirium in critical illness: phenomenology, clinical correlates and treatment response in 40 cases at the pediatric intensive care unit." Intensive Care Medicine 33: 10331040.

Shann, F. (2005). Drug Doses, Publishers Collective PTY Ltd.

Shem, S. (1978). The House of God, Dell Publishing.

Sikich, N. and Lerman, J. (2004). "Development and psychometric evaluation of the pediatric anesthesia emergence delirium scale." Anesthesiology(100): 1138-45. 
Spencer, E.K., Campell, M. (1994). Children with schizophrenia: diagnosis, phenomenology, and pharmacotherapy. Schizophr Bull 20(4):713-25.

Stoddard, F.J. and Wilens, T.E. (1995). Delirium. Psychiatric Aspects of General Hospital Pediatrics. Jellinek, M.S. and Herzog, D.B. Chicago, Yearbook Medical Publishers: 254-259.

Taylor, M.A. and Fink, M. (2003). "Catatonia in psychiatric classification: a home of its own." American Journal of Psychiatry 160(7): 1233-1244.

Trzepacz, P.T. and Meagher, D.J. (2005). Delirium. Textbook of Psychosomatic Medicine. Levinson, J.L. Washington DC, The American Psychiatric Publishing: 92-130.

Turkel, S.B., Trzepacz, P.T. and Tavare, C.J. (2006). "Comparing symptoms of delirium in adults and children." Psychosomatics 47(4): 320-4.

Williams, D.T. (2002). Neuropsychiatric Signs, Symptoms, and Syndromes. Child and Adolescent Psychiatry, a Comprehensive Textbook. Lewis, M. Philadelphia, Lippincott Williams \& Wilkins: 399-404.

Wise, M.G. (1987). Delirium. Textbook of Neuropsychiatry. Hales, R.E. and Yudofsky, S.C. Washington, The American Psychiatric Press: 89-106.

Wise, M.G., Hilty, D.M., Cerda, G.M. and Trzepacz, P.T. (2002). Delirium (confusional states). Textbook of Consultation-Liaison Psychiatry in the Medically III. Wise, M.G. and Rundell, J.R. Washington, American Psychiatric Publishing: 257-272. 
CHAPTER 9

\author{
Epilogue
}


'We shall not cease from exploration

And the end of all our exploring

Will be to arrive where we started

And know the place for the first time'

T. S. Eliot (1943)

And thus what more can be said about pediatric delirium?

'It's non-existent.' That is the first conclusion one makes when scanning for the section on delirium in 'Pediatric psychosomatic medicine: An annotated bibliography' by Maryland Pao, Elizabeth Ballard and colleagues, in Psychosomatics (Pao, Ballard et al., 2007). The main aim of this important paper (it even mentions catatonia) is to support adult PM (psychosomatic medicine, or 'consultation-liaison psychiatry') physicians and child psychiatrists who are called upon to perform a pediatric PM consultation, by providing a reading list of relevant papers. But then, at a second glance and with closer reading, delirium is mentioned under the headings 'Emergency issues' and 'Psychopharmacology'.

'It's confusing' might be another answer, reading 'Risperidone treatment of three seriously medically ill children with secondary mood disorders' a case report by Judith Bealke and Karen Meighen also in Psychosomatics (Bealke \& Meighen, 2005). Here, our two colleagues carefully describe three impressive cases in which they eventually, after long and thorough debates, ruled out delirium and ruled in secondary mood disorder. And then they successfully treated these children not with antidepressant medication (which one would expect), but with an antipsychotic drug! 
The DRS (using cut-off $>13$, and others use even $>10$ ) and the PAED (cut-off $>10$ ) scores of the three children, scored by me based on their case histories, were 12 and 14, 10 and 13, and 10 and 8, respectively. Bealke and Meighen state that 'In each case, the diagnosis of delirium was carefully considered, but ultimately ruled out because the criteria could not be fully met'. But the case histories, their clinical presentations, these DRS and PAED scores and the dramatic responses with antipsychotic drug treatment made these children, in my opinion, textbook cases of the classic diagnosis ex juvantibus principle. So I carefully conclude 1) that Bealke and Meighen overlooked the subsyndromal variety and 2) that there is a great need for consensus regarding diagnostic criteria for PD in all its varieties.

'It is oversimplified' can be another answer when one reads 'Subtypes of pediatric delirium: a treatment algorithm', which comprises case reports by Niranjan Karnik, Shashank Joshi and colleagues in Psychosomatics (Karnik, Joshi et al., 2007). Here, the authors hypothesize about the right neuroleptic treatment strategies for the two delirium types: haloperidol in the case of hyperactive delirium, and risperidone for the hypoactive variety. But in my opinion their treatment strategies do not hold because they maintain a too static view of delirium. After all, so often there is a form with a frequently changing presentation: from hyperactive to hypoactive, from clinical to subclinical, and from delirium to normal, and then back again. Besides, in clinical practice, regardless of the 'dynamics' of delirium, one usually needs only one drug to treat delirium successfully.

But on the other hand, all the authors (and the editors of Psychosomatics) are to be praised for focusing the attention on pediatric child psychiatry and especially on pediatric delirium. 


\subsection{Future main research questions}

I have described in this thesis, especially in the General discussion, what we now know about PD 'for the first time'. What is left is: 'We shall not cease from exploration.' What we now want to know about PD I have described and discussed for the most part at different places in this thesis. I shall now sum up the main questions regarding children, bearing in mind the words of Andrews and Azoulay from their 'Intensive Care Medicine' paper of 2004 regarding adults: 'The optimal management of patients with delirium and the effects of the pharmacological treatment on the outcome are still key concerns for today' (Andrews, Azoulay et al., 2005).

I) Regarding diagnosis

1) What are the diagnostic criteria for PD in a PICU context?

2) How can we achieve consensus about these criteria?

3) What are the main items for a bedside screening/diagnostic instrument?

4) Are there four prototypes, and are these different disorders?

5) What are their EEG findings?

II ) Regarding causes

1) What are predisposing and precipitating risk factors?

2) What is the pathophysiology?

3) How can we prevent PD? 
III ) Regarding course and treatment

1) What are their natural courses?

2) Are there two kinds of PD, namely a benign and a malignant PD? After all, pediatric delirium febrile of everyday life is self-limiting and does not need psychopharmacological intervention.

3) What are the short- and the long-term neuropsychological/neuropsychiatric outcomes of treated and untreated children with PD?

4) How can we treat PD optimally? And is a RCT (randomized controlled trial) both ethical and possible?

IV) Regarding our findings:

1) Can these findings in children be replicated - and even be generalised? Especially regarding the possible usefulness of the PAED - and Apache scores for diagnosing, respectively predicting delirium in adults and the elderly.

\subsection{Research outline}

How, in an ideal world, could one answer these questions? Regarding the questions about pathophysiology, there is on the one hand the matter of the level: should it be at the clinical, or brain structure or brain circuitry level? Or should it be at the cell, or neurometabolic or neurotransmitter level? On the other hand, there is the question: what kind of disorder is PD anyway? And what are the hallmarks, and which of the four types does one like to consider in this pathophysiological respect? 
At the moment, however, there are too many other matters that have to be resolved. The two most important ones are: what are the clinical essentials of PD, and which is the best screening/diagnostic tool? The best way to achieve this is a consensus cycle using questionnaires and meetings. The participants are experts working at the PICU: pediatric intensivists, child neurologists, PICU nurses, child anaesthesiologists, child neuropsychologists, child psychiatrists and a child psychiatrist-epidemiologist, and the meetings are chaired by an adult neuropsychiatrist who is an expert on delirium. By means of a pilot study and cluster analysis one can try to reach consensus on the diagnostic criteria and a diagnostic tool. There is at least consensus about one aspect: the disturbance of consciousness, although this is also questioned at the ICU setting. So trying to link EEG findings and neuropsychological findings regarding disturbances of consciousness in combination with the related clinical presentations of PD on the ward and at the PICU (including the PD diagnostic tool scores) could be very elucidating. This in combination with daily PIM and PRISM II score gathering of also all of the children should give, after trend and cluster analysis, very promising information regarding the prediction of $\mathrm{PD}$ and the possible pathophysiological underlying mechanisms, as well as for possible intervention strategies regarding the occurrence and prevention of PD. And then to perform follow-ups with these children by means of EEGs, neuropsychological testing, and child psychiatric examinations and questionnaires in an outpatient setting seems to be obligatory as well as very worthwhile for a period of at least two years. The most logical way seems to be to extend the known world of delirium downwards with age finally towards the age of zero, thus moving from the known to the unknown. The better the psychological ripeness, the better one can detect neuropsychiatric deficits due to delirium; thus at first , a minimum age of two years as a inclusion criterion is the best considering 
language, cognition, contact modalities, orientation and action. And as there seems to be a strong correlation between PD and the severity of the critical illness, the best place to study this is at the PICU.

In conclusion: we need a prospective multicentred field study at the PICU for at least three years based on the results of the expert consensus cycle regarding diagnostic criteria and a diagnostic tool, and we need to screen all children $\geq 2$ year, for PD daily (including data collecting of EEG recordings and PIM and PRISM II scores), with medication and psychosocial care as usual (so no RCT from the start) in combination with the outpatient follow-up and the sampling of all the multidisciplinary data, is a very promising approach. This will help greatly to settle major issues, especially those regarding the diagnostic criteria, the validity and reliability of the diagnostic tool, the prediction and prevention, the pathophysiology, the rationale and need for drug treatment, and the short- and long-term risks. We should then be in a better position to discuss and answer perhaps two of the most interesting and important issues of all: 1) is it ethical to study the natural course(s) of untreated $\mathrm{PD} /$ varieties of PD, and next, is it ethical to perform an RCT?

And only then: 2) can we consider to extend our research questions also to the children at the NICU (Neonatal Intensive Care Unit). After all: there is up until now no lower bound regarding the age of onset of delirium, so there is every reason to suspect the occurrence of neonatal delirium, or its neuropsychiatric equivalent, in babies as well. 


\subsection{Quality of care}

A last word on the improvement of clinical care at the PICU. It should now be clear that the organization and execution of the multidisciplinary work that underlies this thesis, automatically improved the quality of care at the PICU. That is another and very important reason to continue and to extend the 'Delirium on the PICU' quality project. A delirium protocol is one of the quality of care standards in Dutch hospitals, and having one for PD will now be essential and very special (Leentjens \& Diefenbacher, 2006; Leentjens \& Diefenbacher, 2007). So that is what we shall do next: we shall write, in collaboration with colleagues in and outside the PICU as well as with Dutch child psychiatrist colleagues working in consultation-liaison services, a first guideline and a first protocol on pediatric delirium at the PICU.

And so, dear reader I have arrived at the end of my exploring and so can end this thesis. In the spirit of Richard B. Sheridan (1751-1816), who wrote 'Come into my garden, I would like my roses to see you', I salute you with the words: 'Come to the PICU, I would like the children to see you!' 


\section{References}

Andrews, P., Azoulay, E., Antonelli, M., Brochard, L., Brun-Buisson, C., Dobb, G., Fagon, J.Y., Gerlach, H., Groeneveld, J., Mancebo, J., Metnitz, P., Nava, S., Pugin, J., Pinsky, M., Radermacher, P., Richard, C., Tasker, R. and Vallet, B. (2005). "Year in review in intensive care medicine, 2004. III. Outcome, ICU organisation, scoring, quality of life, ethics, psychological problems and communication in the ICU, immunity and hemodynamics during sepsis, pediatric and neonatal critical care, experimental studies." Intensive Care Medicine 31(3): 356-72.

Bealke, J.M. and Meighen, K.G. (2005). "Risperidone treatment of three seriously medically ill children with secondary mood disorders." Psychosomatics 46: 254-258.

Eliot, T.S. (1943). Little Gidding. Four Quartets.

Karnik, N.S., Joshi, S.V., Paterno, C. and Shaw, R. (2007). "Subtypes of pediatric delirium: a treatment algorithm." Psychosomatics 48(3): 253-7.

Leentjens, A.F.G. and Diefenbacher, A. (2006). "A survey of delirium guidelines in Europe." Journal of Psychosomatic Research 61: 123-128.

Leentjens, A.F.G. and Diefenbacher, A. (2007). "Das Delirium als Qualitatsindikator medizinischer Krankenhausversorgung." Psychosom Konsiliarpsychiatr 1: 177-178.

Pao, M., Ballard, E.D., Raza, H. and Rosenstein, D.L. (2007). "Pediatric psychosomatic medicine: an annotated bibliography." Psychosomatics 48(3): 195-204. 


\title{
CHAPTER 10
}

\author{
Summary
}

Samenvatting

Acknowledgements

Publications \& Posters

Curriculum Vitae 


\subsection{Summary}

This thesis has one focus: research on pediatric delirium (PD) in relation to two themes, namely 1) daily child psychiatric case work at the PICU (pediatric intensive care unit), considered in 2) the historical context of ideas and related concepts and facts.

Chapter 1 presents the definition of 'delirium', along with the problems and the risks with adults and the elderly. It gives a concise review of the essential ideas and publications, which is also founded on a PubMed search. Next, the state of affairs regarding $P D$ is given. Then the developments regarding the history of the Dutch delirium research are described, as are those regarding two other traditions.

The chapter closes with the thesis outline, which is a summation of the main research questions: does $P D$ really happen, and how can we conceptualize this in a critically ill child at the PICU? And how can we make the proper diagnosis? Are there basic epidemiological facts to guide us, and what are decision rules to help us in these matters? Are there relations with catatonia, and what are the preliminary findings of the cumulative incidence? What are its presentations at the PICU, which are the main clinical correlates and what is the treatment response in an open and uncontrolled design? Can PD be predicted by means of PIM and PRISM II scores, and by using these to construct ROC (Receiver Operator Characteristic) curves and to calculate the AUCs (Area Under the Curve), can the PPVs and NPVs (Positive, respectively, Negative Predictive Values) and the odds ratios be calculated? What are the DRS (Delirium Rating Scale) scores across the full age span in critical and/or terminal illness, and what are the differences between these scores in children, adults and the elderly?

These questions are examined in Chapters 2-7. Chapter 8 presents and discusses some general aspects of the study as well as the main research answers. Chapter 9 presents the future research questions and the quality of care improvement. Chapter 10 comprises the abstracts, the acknowledgements and the author's CV. 
Chapter 2 is an introduction to pediatric child psychiatry, with a case example from everyday practice at the PICU, and it shows in a $n=1$ observation the profitable use of a common sense approach.

Chapter 3 presents two small children, age $<4$ years, with two very different but illustrative presentations of PD at the PICU, and discusses several important aspects regarding diagnosis and treatment.

Chapter 4 has pediatric catatonia as its focus. It discusses the relations between autism and catatonia, and between catatonia and delirium. To do so, two impressive cases are presented, as are the results of a focused search in textbooks, the literature and PubMed; in addition, the pioneering and classifying publications of Karl Leonhard, Max Fink and Michael Alan Taylor are discussed.

Chapter 5 presents extensively our multidisciplinary experiences at the PICU with 40 cases of PD during a 4-year period, especially regarding the phenomenology, clinical correlates and the treatment response.

Chapter 6 presents a possible way of predicting PD by means of PIM (Pediatric Index of Mortality) and PRISM II (Pediatric Risk of Mortality) scores in constructing ROC (Receiver Operator Characteristic) curves and calculating the AUCs (Area Under the Curve) in relation to the occurrence of PD. Next, the PPVs and NPVs (Positive, respectively, Negative, Predictive Values) as well as the odds ratios for PD, at the maximum sum of sensitivity and specificity, are calculated, and the accompanying PIM and PRISM II scores are assessed.

Chapter 7 gives a comparison of delirium symptomatology, expressed in DRS (Delirium Rating Scale) scores, across the age span: children, adults and the elderly with critical or severe illness. Two databases were used: one on children with PD from the PICU in Maastricht, the Netherlands, and the other on adults and the elderly from a hospice in Limerick, Ireland.

Chapter 8 presents a consideration regarding general aspects of the study, such as multidisciplinary teamwork, the title and the subtitle, the design, ethics and 
limitations. It also presents and discusses extensively the research findings and results, and answers the research questions presented in the Introduction. With all its limitations - an open and uncontrolled design, and the involvement of just one child psychiatrist - we can nevertheless state that PD does happen at the PICU, and in four, sometimes fluctuating presentations, namely hyperactive, hypoactive, subsyndromal and with a gamut of other neuropsychiatric signs and symptoms. There is a conceptual and clinical relation between catatonia and delirium, in both the major motor presentations with too much or too little motor activity. The guiding basic facts from epidemiology are: children react with delirium easily; the more severe the critical illness in adults and elderly, the higher the rate of delirium; just $10 \%$ of all adult patients with delirium receive a psychiatric consultation; and delirium is a serious and dangerous disorder in many ways. This forced us, in analogy with adults and the elderly, to place PD at the forefront of the differential diagnosis as an explanation for incomprehensible emotional and/or behaviour problems at the PICU. Of course, this happened only after a thorough ruling out of pain, general discomfort due to, for example, inappropriate ventilation settings or anuria, and withdrawal. Major decision rules were Occam's razor and the exclusion principle; reinforcers were the ex juvantibus principle and 'Truth is all that works'. Risk factors are the degree of severity of the critical illness and the need for mechanical ventilation. The first, preliminary, and with age increasing cumulative incidence is: $3 \%$ in age class 0 2 years, up to $19 \%$ in the age class $16-18$ years. The response to medication with haloperidol IV or risperidone PO is good; and there were two cases of extra pyramidal side effects which responded swiftly with biperidene IV. The predictive values of the PIM and the PRISM II are fair, with AUCs of 0.70 and 0.73 ; and with PPVs and NPVs of $7-10 \%$ and of $99 \%$. The odds ratios at the best cut-off points are 9 and 19, which are high, and the accompanying PIM and PRISM scores are then 1.8 and 2.9. DRS scores in critically ill children at a PICU are much more pronounced than the DRS scores in adults and the elderly with a terminal illness in a hospice setting. There are relatively many missing scores due to a mismatch between the DRS on the one hand, and the limitations of very young critically ill children in a PICU context on the other hand.

Chapter 9 discusses the question: 'What more can be said about pediatric delirium?' and presents the future research questions and a research outline. It also presents 
an observation regarding the quality of care improvement. This is followed by the announcement of the creation of a first Dutch PD guideline and protocol. The chapter ends with an invitation.

Chapter 10 comprises the abstracts in English and in Dutch, acknowledgements, publications, poster presentations and the author's CV. 


\subsection{Samenvatting}

Dit proefschrift heeft een focus: wetenschappelijk onderzoek naar het pediatrisch delier, gerelateerd aan twee thema's: 1) het dagelijks kinderpsychiatrische werk op de PICU (Pediatrische Intensive Care Unit), en beschouwd in 2) de context van de ideeëngeschiedenis van het $(P) D$ (pediatrisch delier), en aanverwante concepten en feiten.

Hoofdstuk 1) de Introductie geeft de definiëring van het delier, en beschrijft de problemen en de risico's bij volwassenen en bejaarden. Het geeft een kort overzicht van de belangrijkste ideeën en publicaties, mede onderbouwd door een PubMed search. Daarna wordt een stand van zaken gegeven m.b.t. het delier bij kinderen en jeugdigen, ook op grond van de belangrijkste ideeën en publicaties, opnieuw ook ondersteund door een PubMed search. Vervolgens worden de ontwikkelingen in Nederland kort geschetst, als ook twee andere tradities.

Het sluit af met een blauwdruk schets van de opbouw van het proefschrift d.m.v. een opsomming van de belangrijkste onderzoeksvragen: komt het PD voor, en hoe dit te conceptualiseren bij kleine kinderen en te diagnosticeren in een PICU context, zijn er richtinggevende epidemiologische feiten en zijn er besliskundige regels die behulpzaam hierbij kunnen zijn? Zijn er relaties met catatonie; wat zijn de eerste en voorlopige cijfers omtrent de cumulative incidentie; hoe presenteert het PD zich op de PICU, en met welke klinische correlaties; hoe zijn de behandelresultaten in een eerste open en ongecontroleerde opzet? Kan het PD voorspeld worden aan de hand van een mogelijke relatie tussen mortaliteitsrisico-inschatting m.b.v. PIM en PRISM scores en de daarbij horende ROC curves, en hoe is de klinische presentatie, uitgedrukt in DRS scores, tussen kinderen, volwassenen en bejaarden ?

Deze vragen worden onderzocht in de hoofdstukken $2 \mathrm{t} / \mathrm{m} \mathrm{7}$; hoofdstuk 8 geeft in een algemene discussie de relevante antwoorden en een beschouwing hieromtrent; hoofdstuk 9 is de afsluitende epiloog die ook toekomstige vragen en de kwaliteit van zorg aan de orde stelt; en het afsluitend hoofdstuk 10) geeft de samenvatting in het Engels en het Nederlands, het c.v. en het dankwoord. 
Hoofdstuk 2) beschrijft ter introductie van de pediatrische kinderpsychiatrie een vraagstuk uit de dagelijkse praktijk van de PICU, en laat in een $n=1$ opstelling zien wat de toegevoegde waarde kan zijn van het gebruik van common sense, ofwel ons "boerenverstand".

Hoofdstuk 3) presenteert twee kleine kinderen < 4 jaar, met twee heel verschillende en illustratieve klinische verschijningsvormen van het PD op de PICU; en het bespreekt belangrijke diagnostische en behandelvraagstukken.

Hoofdstuk 4) heeft als focus de pediatrische catatonie. Het bespreekt de relaties tussen: autisme, catatonie en het delier. Dit gebeurt aan de hand van twee indrukwekkende casussen, gecombineerd met de bespreking van de resultaten van een literatuuronderzoek m.b.v. de belangrijkste tekstboeken en publicaties hieromtrent, alsmede een gericht PubMed onderzoek, en aldus wordt ook het baanbrekend en ordenend werk van Karl Leonhard, Max Fink en Michael Alan Taylor aan de orde gesteld.

Hoofdstuk 5) beschrifft uitvoerig onze multidisciplinaire ervaringen op de PICU gedurende een periode van 4 jaar omtrent 40 kinderen met een PD rond de phenomenologie, klinische correlaties, en behandelrespons, in een open en ongecontroleerde setting.

Hoofdstuk 6) beschrijft een mogelijke wijze van het voorspellen van het PD d.m.v. van het toepassen van de PIM (Pediatrische Index Mortaliteit) en de PRISM II (Pediatrische Risico Mortalitieit II) - scores ten behoeven van het construeren van ROC (Receiver Operator Characteristic) curves, en de daarbij behorende AUC (Area Under Curve) te berekenen, in relatie tot het optreden van PD. Deze informatie wordt tevens gebruikt om Postief - en Negatief Voorspellende Waarden (PPV en NPV) te bepalen, alsmede ook om de Odd's Ratio's voor PD - bij de beste som van sensitiviteit en specificiteit - te bepalen en om zo ook de daarbij behorende PIM en PRISM II scores vast te kunnen stellen.

Hoofdstuk 7) vergelijkt de DRS (Delirium Rating Scores) over de gehele leeftijdspanne van kinderen, volwassenen en bejaarden, die allen ernstig ziek zijn. 
Dit gebeurt aan de hand van twee databases: de ene betreft Nederlandse kinderen van onze PICU met een delier, en de andere is een groep van lerse volwassenen en bejaarden met een terminale aandoening in een hospice met een delier.

Hoofdstuk 8) is de Algemene discussie en staat stil bij relevante aspecten van het proefschrift zoals: multidisciplinair werken, de titel en subtitel, de onderzoeksopzet, het ethische aspect alsmede de beperkingen. Daarnaast bespreekt het uitvoerig alle onderzoeksbevindingen en -resultaten, en beantwoordt het expliciet alle onderzoeksvragen. Met alle beperkingen van dien, te weten een open en ongecontroleerde studie-opzet, en het feit dat er hoofdzakelijk slechts een kinderpsychiater bij het onderzoek betrokken was, kan er gesteld worden dat: het PD inderdaad voorkomt op de PICU, in 4 - vaak in elkaar overgaande - presentaties: hyperactief, hypo-actief, subsyndromaal en met een scala aan neuropsychiatrische andere symptomen die zelfs kunnen domineren. Op grond van het literatuuronderzoek, en ook eigen klinische ervaringen, kan er gesteld worden dat er zeker een positieve relatie is tussen catatonie en het delier; rond beide motore presentaties - met zowel te veel, als te weinig motoriek - is er veel overlap.

Richtinggevende epidemiologische basale feiten zijn: kinderen worden erg gemakkelijk delirant; het delier komt des te meer voor naarmate volwassenen en bejaarden ernstiger ziek zijn, en het gegeven dat maar 10\% van alle volwassen delirante patienten een psychiatrisch consult krijgt. In combinatie met het feit dat het delier in velerlei opzichten een ernstige aandoening is resulteerde er in dat wij - ook in analogie met bovenstaande bij volwassenen en bejaarden - het PD op de eerste plaats (moesten) zetten van de differentiaal diagnose van: emotionele- en gedragsproblemen bij ernstig zieke kinderen op de PICU. Dit overigens pas wel na expliciete uitsluiting ook van belangrijke andere klinische problemen zoals: pijn, algemeen dyscomfort t.g.v, bijv. beademing en onttrekking. Als belangrijke besliskundige regels gebruikten wij: Occam's razor en het uitsluitingsprincipe. Reinforcers zijn: 1) het diagnosis ex juvantibus principe en 2) "Waarheid is al datgene dat werkzaam is". Risicofactoren zijn: de mate van ernstig ziek zijn, alsmede een beademingsbehoefte. Er is een eerste voorlopige, en met de leeftijd stijgende cumulatieve incidentie van $3 \%$ in de laagste leeftijdsklasse van 0 - 2 jaar, oplopend naar $19 \%$ in de hoogste klasse: 16 - 18 jaar. De medicamenteuze behandelrespons op haloperidol i.v. of risperidon p.o. is goed; en in twee gevallen van extra- 
pyramidale bijwerkingen werkte biperideen i.v. snel therapeutisch. De voorspellende waarden van de PIM en PRISM II zijn redelijk, met respectievelijke AUC's van 0,70 en 0,73; en met PPV's van slechts 7 - 10 \%, maar met NPV's van rond de 99\%. De odds ratios bij de beste cut-off points van de ROC curve zijn respectievelijk 9 en 19, wat erg hoog is; en de daarbij behorende PIM en PRISM II scores bedragen: 1,8 en 2,9. De DRS scores bij kinderen zijn in het algemeen veel hoger en uitgesprokener dan bij volwassenen en bejaarden, behalve m.b.t. slaap-waak-ritmeverstoringen en dagdagelijkse variabiliteit van de symptomen. Er zijn relatief veel missing scores, dit komt door de gedeeltelijke "mismatch" tussen een deel van de DRS items enerzijds, en de "beperkingen" van jonge kinderen in een PICU setting anderzijds.

Hoofdstuk 9) is de Epiloog, en bespreekt dat wat het PD allemaal nog meer kan zijn, alsmede de toekomstige onderzoeksvragen, en een opzet tot een beantwoording daarvan. Het sluit af met o.a. een opmerking omtrent de kwaliteit van zorg die verbeterd is als een direct uitvloeisel van dit onderzoek, en het kondigt de opzet aan tot een landelijk gedragen PD richtlijn en een PD protocol, en het sluit af met een uitnodiging.

Hoofdstuk 10) betreft de samenvattingen in het Engels en Nederlands, het dankwoord, de vermelding van overige publicaties, posterpresentaties, en het c.v. 


\subsection{Acknowledgements}

There are many people to whom I acknowledge my gratefulness:

First of all you, dear Kirsten - secretary of the Child and Adolescent Psychiatry division, research assistant, editor and Jill of all trades. I thank you for your expertise, kindness, patience, endurance and good spirit.

I also thank Andy Lameijn, Pieter Ahrends, Willem Prins, Michael Inbar, Lena Maartje, Ton Elferink, Mirjam, Stephan and Sally, Selma and Richard, Esmee and Lisa, Emmy and Leo, Caspar and Hans, Jan van Hemert, Jaap Patijn, Mia Raus, Jan de Vries, Hans vd Ploeg, Aad van Londen, Hans Schipper, Eric Hoenkamp, Theo Doreleijers and Rosemarie Willems: who took care of my multidisciplinary training. I salute Hans Crabbendam and Paul Schefman, who taught me some essentials of management and the law, respectively; and Paul van Wielink and Eric Wittewrongel, who first came with the idea of writing about this clinical problem and encouraged me.

I thank of course: Noel Notermans and so the nurses of the PICU and the medical students and residents; Anita Van den Neucker, Edward Dompeling and all my other colleagues at the department of pediatrics; Joost Nicolai and the other collegues of child neurology; Trudy Lahaye for her kind support and encouragement; Andries Korebrits, my dear room-mate, for the discussions and support and your care in the final phase of my thesis work; and you Richel Lousberg and Helen Vossen, who helped me with the essentials of the statistics.

Thank you my co-supervisors for your actual help en encouraging support, and you Albert Leentjens, for your expertise on adult delirium and keen eye for detail, and you Gijs Vos for the organization at the PICU and your remarks and ideas.

Thank you 'Young lady, parents and Orca' for the kind permission. Thank you dear Magpie for so much and so many, also on behalf of Madame F. Thank you Piet Leroy for our long and astute debates and your support and hospitality. I am of course also grateful to my dear other colleagues/PICU intensivists: Dick van Waardenberg, 
Monique Engel and Carolien van Goor, Arno Brouwers; and Mischa Sommer, pediatric anaesthesiologist. I also thank Ineke, Philomène, Aggi and Els, and you, Brigitte, our department sub-director, for your support.

Dear Jim: it was a pleasure and a very stimulating experience to be able to work with you, which I consider a great favour as well as a gift. Thank you for your kindness, responsiveness and closeness, for your support and wisdom, and for your intellectual courage when it was needed - you were a good example to me. 


\subsection{Publications \& Posters}

Schieveld JNM. Pediatrics, child neurology and child psychiatry: a 'menage à trois' in spite of the Dutch Act on youth care?! Acta Neuropsychiatrica 2001; 13(4):85-87

Schieveld JNM, Leentjens AFG. Delirium in severely ill young children in the pediatric intensive care unit (PICU). Journal of the American Academy of Child and Adolescent Psychiatry 2005; 44(4):392-394

Schieveld JNM, Leroy, PLJM, Leentjens AFG. Klinische lessen: Delier bij kritisch zieke jonge kinderen op een pediatrische intensive care afdeling. Nederlands Tijdschrift voor Geneeskunde 2006; 150 (28):1545-1548

Schieveld JNM. Case reports with a child psychiatric exploration of catatonia, autism and delirium. In: Catatonia in autism spectrum disorders. Dhossche DM, Wing L, Ohta M, Neumärker KL (Eds). International Review of Neurobiology 2006; 72:195206

Vos GD, van Os JJ, Leroy PLJM, Schieveld JNM. Peds or meds: how to tackle misery in a pediatric intensive care unit. Intensive Care Medicine 2007: 33:1492-1493

Schieveld JNM, Leroy PLJM, van Os JJ, Nicolai J, Vos GD, Leentjens AFG. Pediatric delirium in critical illness: phenomenology, clinical correlates and treatment response in 40 cases in the pediatric intensive care unit. Intensive Care Medicine 2007; 33:1033-1040

Devalkeneer L, Schieveld JNM, Bekers O. Het belang van cythochroom P450 in de dagelijkse praktijk. Tijdschrift voor Artsen voor Verstandelijk Gehandicapten 2007;25(4):87-92

Leroy PLJM, Schieveld JNM, Leentjens AFG. Delirium in the Pediatric Intensive Care Unit'. Abstract. Accepted for publication in Pediatric Critical Care Medicine, 2007 
Schieveld JNM, Lousberg R, Berghmans E, Leroy PLJM, Vos GD, Nicolai J, Leentjens AFG, van Os JJ. Predicting pediatric delirium using routine illness severity measures in a pediatric intensive care unit. Submitted.

Leentjens AFG, Schieveld JNM, Leonard M, Lousberg R, Verhey FRJ, Meagher DJ. A Comparison of the phenomenology of pediatric, adult and geriatric delirium. Submitted.

Posters:

Schieveld JNM. Delirium and pre-delirious state at the PICU (Pediatric Intensive Care Unit) and the pediatric ward. A preliminary report. Poster presented at ESCAP, Paris (F), 2003

Leroy PLJM, Schieveld JNM, Leentjens AFG. Delirium in the Pediatric Intensive Care Unit'. $5^{\text {th }}$ World Congress on Pediatric Critical Care, Geneva (Switzerland) 2007. 


\subsection{Curriculum Vitae}

Jan Schieveld was born in Amsterdam on 27 February 1952 to a Dutch Hungarian mother and a Dutch Indonesian father. He is the oldest of four children - two beloved sisters and one dear brother. The household was Roman Catholic, in a relaxed but serious way. There were always cats, kittens and dogs around ('Animals are our link with nature, and nature is our link with God'). There was music as well, especially opera and operetta ('Mozart moves, and Vivaldi enchants'). Jan's mother taught him to read and to think logically, while his father instilled in him that 'Gratefulness is the memory of the heart'. Both parents taught all four children, among other competences, how to cook 'real' chow mein and fried rice (yes, it was that type of family!).

After high school (Petrus Canisus College, Alkmaar, and Bonaventura College, Leiden), Jan Schieveld studied medicine at the Vrije Universiteit Amsterdam (Free University of Amsterdam). From 1978 to 1982 he was trained in psychiatry, psychotherapy and neurology. He worked from 1982 until 1989 at the RIAGG Midden-Holland (central Netherlands regional institute for mental welfare) in Gouda; during his last 5 years at the institute, he was head of the youth out-patient clinic. From 1989 till 2001 he worked as child and adolescent psychiatrist/management director and head of Wickraderheem child psychiatric hospital (once a division of Welterhof, now part of the Mondriaan Zorg Groep), in Heerlen.

Since 2001, Jan Schieveld has been a staff member of the department of Psychiatry, Psychology and Neuropsychology of the azM (University Hospital Maastricht), which is headed by Professor J. J. van Os. Jan Schieveld directs the Child and Adolescent Psychiatry division and is a consultant in the Child Psychiatric Consultation-Liaison Service at the pediatric ward and the PICU.

Jan Schieveld is also a staff member of the child psychiatric service of the Koraalgroep, in Sittard. This is a large organization operating in the southern Dutch provinces of Limburg and Brabant that cares for people with a handicap, especially a mental retardation. The guiding principle of the Koraalgroep is the 'full service' concept. In addition, Jan is a consultant at the Franciscusoord child rehabilitation 
clinic in Valkenburg, and a board member of the Dutch platform of Psychiatry and Mental Retardation, and of two schools for children with psychiatric and/or severe behavioural problems: De Buitenhof (Heerlen) and St. Jozef (Cadier en Keer).

Jan's hobbies include walking with a groenendaelster/belgian shepherd (or at least with a dog), the arts, reading, cooking, church architecture, and the philosophy of mathematics and the history of its ideas. 